\title{
Ten Years of Knowledge of Nano-Carrier Based Drug Delivery Systems in Ophthalmology: Current Evidence, Challenges, and Future Prospective
}

\author{
Jie Zhang ${ }^{l, *}$ \\ Jinghua Jiao $\mathbb{D D}^{2, *}$ \\ Meng $\mathrm{Niu}^{3, *}$ \\ Xiaotong $\mathrm{Gao}^{4}$ \\ Guisen Zhang $\mathbb{D D}^{5}$ \\ Honghua $\mathrm{Yu}^{6, *}$ \\ Xiaohong Yang ${ }^{6}$ \\ Lei Liu $\mathbb{D D}^{6,7}$
}

'Department of Ophthalmology, Weifang Eye Hospital, Weifang, 26104I, People's

Republic of China; ${ }^{2}$ Department of

Anesthesiology, Central Hospital,

Shenyang Medical College, Shenyang,

I I0024, People's Republic of China;

${ }^{3}$ Department of Radiology, First Hospital

of China Medical University, Shenyang,

I I000I, People's Republic of China;

${ }^{4}$ Department of Endocrinology and

Metabolism and the Institute of

Endocrinology, The First Hospital of

China Medical University, Shenyang,

I I000I, People's Republic of China;

${ }^{5}$ Department of Retina, Inner Mongolia

Chaoju Eye Hospital, Hohhot, 010050,

People's Republic of China; ${ }^{6}$ Guangdong

Eye Institute, Department of

Ophthalmology, Guangdong Provincial

People's Hospital, Guangdong Academy

of Medical Sciences; School of Medicine,

South China University of Technology,

Guangzhou, 510120, People's Republic of

China; ${ }^{7}$ Department of Ophthalmology,

The First Affiliated Hospital of China

Medical University, Shenyang, I I000I,

People's Republic of China

*These authors contributed equally to this work

Correspondence: Xiaohong Yang; Lei Liu Email syyangxh@scut.edu.cn;

liuleijiao@163.com

\begin{abstract}
The complex drug delivery barrier in the eye reduces the bioavailability of many drugs, resulting in poor therapeutic effects. It is necessary to investigate new drugs through appropriate delivery routes and vehicles. Nanotechnology has utilized various nano-carriers to develop potential ocular drug delivery techniques that interact with the ocular mucosa, prolong the retention time of drugs in the eye, and increase permeability. Additionally, nanocarriers such as liposomes, nanoparticles, nano-suspensions, nano-micelles, and nanoemulsions have grown in popularity as an effective theranostic application to combat different microbial superbugs. In this review, we summarize the nano-carrier based drug delivery system developments over the last decade, particularly review the biology, methodology, approaches, and clinical applications of nano-carrier based drug delivery system in the field of ocular therapeutics. Furthermore, this review addresses upcoming challenges, and provides an outlook on potential future trends of nano-carrier-based drug delivery approaches in ophthalmology, and hopes to eventually provide successful applications for treating ocular diseases.
\end{abstract}

Keywords: nano-carrier, nanomedicine, ocular disease, drug delivery system

\section{Key Summary Points}

- This review offers a comprehensive overview of nano-medicine-based treatments for ocular disorders in the last decade.

- Nanotechnology-based drug delivery systems will probably be used by ophthalmologists in the near future, allowing benefits such as reduced side effects, and less frequent dosing, among others.

- Active targeting ligands related to nano-medicine in ocular therapeutics have yet to be addressed to test their effects and safety.

- Further nanomedicine clinical trials for ocular disorders are needed until this promising pharmacological innovation becomes available in the ophthalmologist's daily therapeutic practice.

\section{Introduction}

The eye is one of the most sensitive organs and consists of several barriers and defense mechanisms to protect it from the environment. For example, it is challenging to deliver drugs to different compartments of the eye and treat ocular disorders due to this specific anatomy, such as the blood-aqueous barrier (BAB) and blood 
retinal barrier (BRB). Additionally, the bioavailability of drugs after ocular administration may be less than $5 \%$, which is often insufficient. ${ }^{1}$ At present, commonly used drug dosage forms to treat eye diseases include eye drops, eye ointments, and eye gels. Due to the numerous ocular barriers, including the tear film barrier, the corneal barrier, the conjunctival barrier, the scleral barrier, as well as the $\mathrm{BAB}$ and BRB, challenges, such as delivery of drugs to less accessible parts of the eye, are often encountered. ${ }^{2-4}$ Therefore, innovating ocular particulate drug delivery systems (DDSs) with sustained release effects or increasing permeability have become a recent research hotspot. These particulate DDSs mainly include liposomes, emulsions, micelles, dendrimers, and microspheres. ${ }^{5-8}$ The conventional administration route for an ocular DDS mainly includes the ocular surface and the intraocular (such as intravitreal and suprachoroidal space) and periorbital tissues. Due to the different barrier effects of each part of the eye, the factors affecting the administration of each route are not the same. The design of a novel ocular DDS has become a central issue to achieve efficient delivery of drugs to different parts of the eye. In the past, nanomedicine was mainly concentrated in the treatment of ocular surface diseases and glaucoma. However, in the last 10 years, nanomedicine has rapidly developed in ophthalmology to include fundus lesions and ocular tumors. Loading the drug into an ocular nano-level DDS enhances its solubility, stability, and permeability, while extending residence time, thereby enhancing drug efficacy. ${ }^{9}$

To provide an overview of recent advancements in ocular nanomedicine, we herein review the current evidence of various nano-micro matrices based on several conventional materials (eg, liposomes, nanoparticles, nano-suspensions, nano-micelles, and nano-emulsions) for ophthalmological applications reported over the last decade (2011-2020). Notably, recent advances in nanocarrier DDSs as well as their effects in the treatment of various ophthalmic diseases are comprehensively introduced. Finally, current challenges and future directions and perspectives about nano-carrier-based DDS applications for ocular therapeutics are further discussed.

\section{Structure of the Eyeball for Drug Delivery}

The diameter of the adult eyeball is about $24 \mathrm{~mm}$, which is composed of the ocular wall and the contents of the eyeball. ${ }^{10}$ The anterior segment of the eyeball mainly consists of the cornea, conjunctiva, iris, ciliary body, sclera, aqueous humor, and the lens, while the posterior segment mainly includes the vitreous body, retina, choroid, and sclera. ${ }^{11}$ The eyeball has a unique anatomical structure called the blood-eye barrier, which makes it difficult to achieve an effective drug concentration. ${ }^{12,13}$ Due to the lipophilic surface layer of the cornea and the hydrophilic nature of the inner layer, ointments do not have characteristics of being both fat-soluble and water-soluble, which makes it difficult to achieve an effective intraocular concentration after applying topical medications. ${ }^{14}$ The effective intraocular drug concentration is the key to the treatment of many ocular disorders. Therefore, changing the administration route and dosage form of ophthalmic drugs is an important measure to increase the intraocular drug concentration.

\section{Traditional Delivery of Ocular Drugs}

The traditional administration methods for treating eye diseases include local administration or systemic administration (Figure 1). Local administration includes periocular (subconjunctival, subtenon, posterior juxtascleral, retrobulbar, and peribulbar) and intravitreal injections. However, these drug delivery routes are limited. Local administration on the ocular surface (cornea, conjunctiva, sclera, and anterior uvea) is usually adopted in the clinic to treat ocular diseases. Generally, eye drops are quickly discharged from the surface of the eye. In addition, due to technological advancements and drug development, such as antiangiogenic drug (bevacizumab, ranibizumab, aflibercept, and conbercept) therapy and glucocorticoids, intravitreal injections are used for retinal and vitreous diseases. ${ }^{15,16}$ This local administration route also has many challenges, such as poor patient compliance and potential adverse effects (eg, endophthalmitis, cataracts, or retinal detachment). Only $1 \%$ to $2 \%$ of systemically administered drugs reach the target tissue due to the effects of the $\mathrm{BAB}$ and the BRB. ${ }^{17}$ In addition, large doses and frequent systemic administration can cause adverse effects. ${ }^{18}$ Recent studies have shown that nano-carriers are useful to deliver hydrophilic or lipophilic drugs to the eye, prolong the halflife of drugs in the vitreous, and improve the bioavailability of many drugs, including proteins and peptides. ${ }^{19,20}$ Interestingly, applications of polymeric nano-micelles have been tested for intraocular and surface ocular disease treatment. ${ }^{21}$ Furthermore, nanotechnology protects the drug from degradation both in the in vivo circulation and under storage conditions. Consequently, a new ophthalmic DDS with sustained release, strong penetration, and long duration in the eye is needed. 


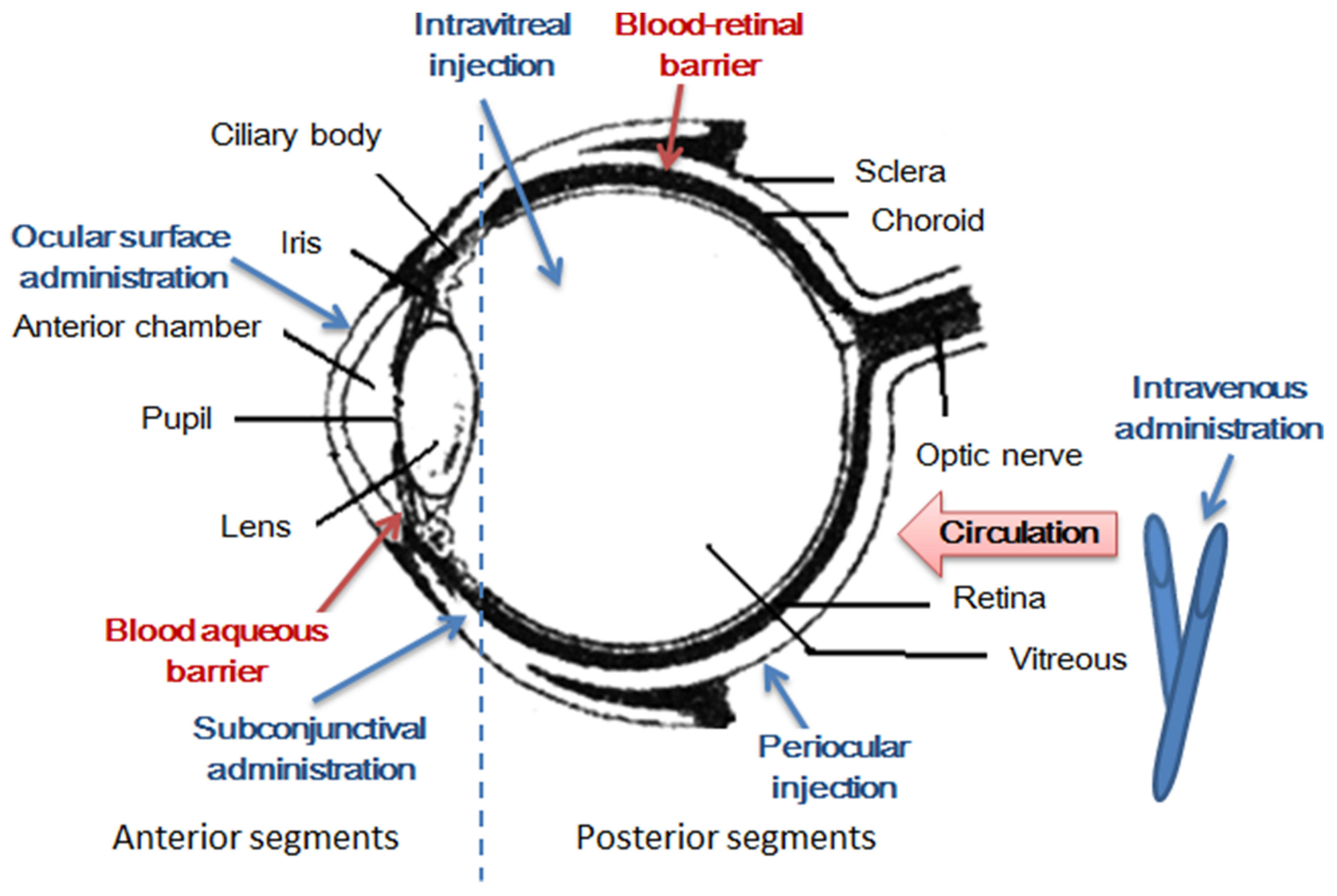

Figure I Structural particularities of the eye. The eye can be divided into two parts of the anterior segment and the posterior segment. There are many barriers to drug delivery to the retina. Drugs cannot be easily delivered to the retina by topical administration, such as eye drops, because of the presence of tear drainage and peribulbar and choroidal blood flow. In contrast, systemically administered drugs rarely enter the retina because of the presence of the blood - aqueous barrier and the inner and outer blood-retinal barriers.

\section{Ocular Nano-Drug Delivery System Advantages of Nano-Drugs and DDS}

A DDS with nanoscale spatial resolution plays a key role in making ocular tissue an attractive pharmacological target for therapies against disorders. Three different advantages of utilizing DDS include: (1) Promoting absorption: promote the passage of the drug through tissues acting as a barrier; (2) Controlled release: local administration effectively controls timed- and sustained release; (3) Targeted drugs: use drugs that are effective and act specifically on the target tissues. ${ }^{22,23}$ The development of DDS nanotechnology has made it possible to overcome eye-related obstacles.

Many promising vehicles are available for ocular DDS, such as nanoemulsions, liposomes, nanomicelles, nanosuspensions, and polymeric and lipid nanoparticles. ${ }^{24}$ Nanocarriers for eye DDSs have the following advantages: (1) A nano-material carrier can enter the capillaries through the blood circulation, and penetrate the endothelial cell gap, enter the lesion, and be absorbed by pinocytosis to improve bioavailability of the material. (2) Nano-carrier particles are small with a high specific surface area, which can embed hydrophobic substances, improve solubility, and reduce the side effects of conventional solvents. (3) A nano-material carrier can be modified by the targeting group to realize targeted drug delivery, which can reduce the dosage and side effects, such as folic acid-modified nanoparticles and magnetic nanoparticles. ${ }^{25}$ (4) Nanocarriers prolong the elimination half-life (t1/2beta) of a substance, increase effective blood concentration time, increase efficiency, reduce frequency of use, and reduce toxic and side effects. (5) Nanocarriers pass through the barriers of the body that limit the effects of substances, such as the blood-brain barrier, the blood-eye barrier (BAB and $\mathrm{BRB}$ ) and the cell biomembrane barrier, so substances reach the lesion. (6) Nanocarriers improve the interactions between drugs and the cornea and conjunctival epithelium, which improve the efficiency of delivery and bioavailability of drugs. ${ }^{24,26-28}$ 


\section{Common Nano-Carriers for Ocular Drug Delivery}

The nano-carrier DDS has become a hotspot in the field of ophthalmic preparation research. Ophthalmic nano-carrier DDSs mainly include liposomes, nanoparticles, nanosuspensions, nano-micelles, and nano-emulsions. Based on the special molecular structure and biological characteristics, the ophthalmic preparations of DDSs have advantages of sustained and controlled drug release as well as targeting and are advantageous for carrying ophthalmic sustained release systems.

\section{Liposomes}

A liposome is a double-layered membrane structure formed spontaneously during the water phase by phospholipid molecules under hydrophobic forces. ${ }^{29,30}$ The amphiphilic characteristics make it possible to load fat-soluble drugs between the double-layered membranes and to wrap water-soluble drugs in the center. Liposomes are highly biocompatible and degradable, reduce drug toxicity, and realize sustained drug release. In addition, liposomes interact with cells, including adsorption on the cell surface, fusion with cell membranes, exchange of phospholipid components with cell membranes, and endocytosis. ${ }^{30-33}$ Based on these characteristics, the potential of liposomes as drug delivery vehicles has been under development for the past 10 years.

Liposome is an ideal DDS in the field of ophthalmology because their structure is like a cell membrane that encapsulates hydrophilic and hydrophobic drugs. The efficiency of liposomes in the eye is related to their biocompatibility, size, charge, stability, residence time, the encapsulation rate, and distribution of the drug. ${ }^{22,34,35}$

In 1981, Smolin et al first reported the use of liposomes as ophthalmic drug carriers. They demonstrated that liposomes coated with iodides are more effective than ordinary eye drops for treating rabbit herpes simplex virus keratitis. ${ }^{36} \mathrm{In}$ 1988, Simmons et al injected $5 \mathrm{mg}$ of fluorouracil (5-FU) liposomes under the conjunctiva of rabbits to prevent scarring of the filtering mouth fibers after filtration in cases of glaucoma. It is believed that this improves the success rate of surgery and more secure. ${ }^{35}$ Studies have revealed that the clearance rates of liposomes in eyes with aphakia and those that underwent vitrectomy are faster, which is believed to be related to the increase in intraocular convection and molecular movement after vitrectomy. Experiments have also confirmed that the clearance rate of liposomes is inversely proportional to the size of the liposome. ${ }^{37}$ Larger liposomes have been speculated to be more stable Barza et al designed a set of experiments to study the effect of liposome size and lipid composition on pharmacokinetics. ${ }^{38}$ Arroyo et al reported that a conventional liposome formulation has the same effects on reducing intraocular pressure (IOP) compared to eye drops, and the effective time was significantly longer using a concentration 10-fold lower. ${ }^{39}$ In addition, local delivery of liposomes improves the bioavailability of drugs to posterior eye tissues (such as the retina). ${ }^{40}$

Zhang et al investigated the efficacy of an intravitreal injection of liposomes encapsulating infliximab in rats with experimental autoimmune uveoretinitis (EAU) and reported that liposomes prolong the persistence of the drug in the vitreous body and demonstrated a satisfactory safety and significant therapeutic potential in EAU. ${ }^{41}$ Additionally, Tan et al showed that the permeability and bioavailability of chitosan-modified liposomes were 2 and 3.9 times higher than those of unmodified liposomes containing a timolol maleate solution alone (1.71 times). Moreover, chitosan-modified liposomes continuously release drug in the eye tissues for 4 hours and unmodified liposomes release drug for 2 hours, which has a better effect on reducing IOP. ${ }^{42}$ The use of biodegradable particles for therapeutic antibody delivery provides a promising approach for treating ocular diseases.

\section{Nanoparticles}

Nanoparticles are formed by self-assembly of natural degradable phospholipids in the water phase and have bi-continuous micro-structural characteristics. ${ }^{43}$ Cubic liquid crystal nanoparticles have advantages for lipid soluble and amphiphilic drug loading compared with liposomes due to the size of the bilayer region. Therefore, good bioadhesion is another outstanding advantage of cubic liquid crystal nanoparticles. ${ }^{44}$ Furthermore, the common phospholipid used in calcium carbonate liquid crystal nanoparticles is glycerol monooleate.

Nanoparticles have attracted the most attention as a delivery system to locally treat ocular diseases. The distribution of nanoparticles in the eye mainly depends on their size and surface properties. Nanoparticles of 200 to $2000 \mathrm{~nm}$ remain in the eye tissue for at least 2 months. ${ }^{45}$ Nanoparticles adhere to the mucosa and remain in the anterior corneal tissue for a long time without rapid removal. Drugs can be encapsulated, conjugated, or adsorbed in nanoparticles. Biodegradable polymers, such as alginate, chitosan, gelatin, polycaprolactone, polylactic acid or poly lactic co-glycolic acid (PLGA), are the most widely used polymers for preparing nanoparticles. ${ }^{46,47}$ Varshochianand et $\mathrm{al}^{48}$ used albumin PLGA nanoparticles 
containing bevacizumab to treat ocular angiogenesis. The nanoparticles were prepared using the double emulsion method and injected into the rabbit vitreous body in a single dose. The results showed that the concentration of bevacizumab was more than $500 \mathrm{~g} / \mathrm{L}$ and was extended for about 8 weeks. Mahaling et al ${ }^{49}$ prepared a core-shell nanoparticle system to deliver triamcinolone acetonide non-invasively to the retina using a slowly degrading polycaprolactone core. They reported that the drugloaded nanoparticles significantly improved both structural and functional activities of the retina. Furthermore, expression of retinal inflammatory biomarkers, such as nuclear factor- $\kappa \mathrm{B}$, intercellular adhesion molecule-1 (ICAM-1), and tumor necrosis factor- $\alpha$ (TNF- $\alpha$ ) were reduced by the intervention. Wang et $\mathrm{al}^{50}$ developed biodegradable nanoparticles loaded with dexamethasone sodium phosphate (DSP) using zinc ion bridging (DSP-Zn-NP) with dense coatings of poly (ethylene glycol) (PEG). As results, the nanoparticles were safe after subconjunctival administration in rats and provided continuous DSP administration. A single subconjunctival administration inhibited corneal angiogenesis in rats within 2 weeks. These results suggest that subconjunctival administration of DSP-Zn-NP could be an effective strategy for preventing and treating corneal neovascularization (CNV).

\section{Nanosuspensions}

Unlike traditional matrix-framework nanosystems, nanosuspensions do not require carrier materials. A nanosuspension is a versatile formulation combining conventional and innovative features. It comprises $100 \%$ pure drug nanoparticles with sizes in the nano-scale range, generally stabilized by surfactants or polymers. After the drug is prepared in a nanosuspension, reducing the particle size increases the contact area and residence time of the drug with the cornea, and increasing the concentration of the drug in the infected tissue and the solubility of a poorly soluble drug improve bioavailability. ${ }^{45}$ Luschmann et al prepared a cyclosporine (CsA) nanosuspension and micellar formulations and evaluated their tolerance and drug release in corneal tissue using the rabbit eye model. ${ }^{51}$ The results showed that the drug concentrations in the corneal tissues of the rabbits in the nanosuspension and micelle groups were much higher than that in the commercially available Restasis ${ }^{\circledR}$ group. After topical administration of a hydrocortisone nanosuspension prepared by Ali et al, the hydrocortisone nanosuspension had a larger area under the curve (AUC) and a retention time of 9-hours in the local eye tissue, while the drug solution alone only maintained a 5-hour retention time. ${ }^{52}$ Similarly, other studies have suggested that nanosuspensions successfully deliver other drugs, such as pranoprofen, ${ }^{53}$ triamcinolone acetonide, ${ }^{54}$ and moxifloxacin, ${ }^{55}$ to eye tissues.

\section{Nanomicelles}

Nanomicelles are nanostructures formed spontaneously in an aqueous environment by block copolymers with amphiphilic properties. ${ }^{56}$ The lipophilic portion is composed of the micelle core that encapsulates the hydrophobic drug, while the hydrophilic part is composed of the outer surface of the micelle to increase drug solubility.

Nanomicelle carriers formed by self-assembly of block polymers containing hydrophilic and hydrophobic segments have attracted increasing attention as non-invasive ophthalmic DDSs. The amphiphilic nature of nanomicelles makes it easy for them to penetrate lipophilic corneal epithelial and endothelial cells, and they can also penetrate a hydrophilic matrix, which overcomes the solubility problems of poorly soluble drugs, promotes drug penetration, and improves bioavailability. In addition, nanomicelles are small in size and are easily taken up by corneal cells. ${ }^{57}$ Polymeric micelles have been demonstrated to improve the bioavailability of drugs in anterior eye tissues, help spread the drug in the sclera, and produce a sustained drug delivery effect of ophthalmic applications. ${ }^{58} \mathrm{Wu}$ et al reported that an intravitreal injection of labeled methoxy polyethylene glycol-block-polycaprolactone (mPEG-PCL) micelles loaded with rapamycin exists in retinal pigment epithelial cells for at least 14 days, which significantly prolongs the retention time of the drug in the retina. ${ }^{59}$ The micelle system had a better therapeutic effect on autoimmune uveitis in rats compared with the rapamycin suspension system alone. Cholkar et al prepared cyclosporine-loaded nanomicelles and studied the tissue distribution of CsA in rabbit eyes. ${ }^{60}$ The CsA concentration in the anterior eye tissue was highest after local instillation, but a higher level of CsA (53.7 ng/g) was detected in the retina, suggesting that nano-micelles have the potential to deliver drugs to eye tissues.

\section{Microemulsions/Nanoemulsions}

Other nanotechnology-based carriers, particularly nanoemulsion (NEs) and microemulsions (MEs) have various applications in drug delivery research. ${ }^{61}$ Furthermore, they are potential drug solubilizers that enhance penetration through their high surfactant/co-surfactant contents. ${ }^{62}$ NEs are highly stable, with low toxicity and irritation, 
large drug loading capacity, and greatly improved drug bioavailability. NEs are some of the most researched and applied nano-carriers DDSs in the field of ocular local drug delivery. After local administration to the eye, NEs are mainly absorbed through the cornea. ${ }^{63,64}$ Furthermore, the emulsion is composed of an oil phase, a water phase, an emulsifier, and a co-emulsion. The emulsion prolongs contact time between the drug and corneal epithelial cells, promotes absorption of the drug by the cornea, sclera or conjunctiva, and improves adhesion of the emulsion. ${ }^{65}$ Although NEs have many physical, chemical, and physiological advantages, their absorption and distribution are affected by the structure of the corneal layers.

Kalam et al confirmed that optimized MEs possess good stability, show greater adherence to the corneal surface, and diffuse gatifloxacin into the anterior chamber of the eye, resulting in a two-fold increase in gatifloxacin concentration than the conventional dosage form. ${ }^{66}$ Subsequently, Kesavan et $\mathrm{al}^{67}$ evaluated the mucoadhesive chitosan-coated cationic microemulsions (CH-MEs) to deliver dexamethasone to treat uveitis in vitro and in vivo. The inhibitory rate of CH-MEs on inflammatory cells was $93.4 \%$, and the protein content was reduced to $6.46 \mathrm{~g} / \mathrm{l}$, which was better than dexamethasone alone (the inhibitory rate of inflammatory cells was $62.14 \%$, and protein content was $16.15 \mathrm{~g} / \mathrm{l}$ ), indicating that a chitosancoated dexamethasone emulsion has good mucosal adhesion and slow-release characteristics. In addition, this emulsion interacts with the lipid layer of the tear film, and is retained in the conjunctival sac for a longer time, where it acts as a drug reservoir.

\section{In situ Gelling Drug Delivery Systems and Others}

In situ gelling drug delivery systems have gained enormous attention in the area of ophthalmology over the last decade. In situ gelling drug delivery systems are in a sol-state before administration, and capable of forming gels in response to different endogenous stimuli. ${ }^{68}$ Such systems can be administered through different routes, to achieve ocular drug delivery and can also be successfully used as vehicles for drug-loaded nano- and micro-particles to treat ocular diseases. ${ }^{69}$ Other nano-preparations, such as liposomes and nanoparticles have been combined to prepare composite systems to further extend the retention time of drugs on the ocular surface and improve their bioavailability. ${ }^{70}$ Quality control of the nanocomposite gel system is comprehensive. It is necessary to consider the quality of the entire system, including stability of the gel and the gelling performance of the in-situ gel at the macro level. Notably, the nano-gel composite system uses many auxiliary materials, and safety should be the focus. The eye irritation test for dorzolamide ME gel composite formulations shows that the it is non-irritating utilizing the Draize technique, but that study did not compare MEs and the gel matrix. ${ }^{71}$ It is recommended to set up a comparison between a single formulation and the corresponding matrix for a safety evaluation of a composite system, which provides a reference for designing new composite formulations.

Göttel et al developed a new solid in-situ gelling system for topical ocular therapeutics (Figure 2).$^{72}$ Electrospinning an amylopectin-gellan gum solution produces nanofibers with high porosity and a narrow size distribution. Nanocomputed tomography (CT) imaging produces a noninvasive and detailed 3D visualization of the internal structure of nanofibers. ${ }^{73}$ Rheological experiments showed that gelation behavior continued to occur after spinning. Researchers improved the application of fiber optic lenses in the eye using a 3D printed matrix to produce bending. This system can be easily processed and applied. A new 3D printing model has been developed to determine the residence time in in vitro pig eyes. ${ }^{74}$ As results, rapid dissolution and uniform distribution were observed on the porcine cornea with extended eye residence time. In the future, this new solid in-situ gelation system might be an attractive alternative to existing ophthalmic DDSs.

\section{Nano-Drug Preparations and Therapeutic Effects for Different Eye Diseases}

Many studies have focused on evaluating the preliminary therapeutic effects of drug loaded nanoformulations in ocular therapeutics in vitro and in vivo. Few drug loaded nanoformulations have been used in clinical research, possibly because it remains challenging to reach the internal structure of the eye through local infusion, and there are still some problems in nano preparation, such as poor stability, difficulties with sterilization, low drug loading, and high costs. Due to the strong irritation of excipients and incomplete drug release, the research progress on nano-level eye drops is still relatively slow. In the following sections, we describe the application of nano drug delivery systems in different types of ocular disorders.

\section{Conjunctivitis}

The most common ocular surface disease is conjunctivitis, which is a common cause of eye redness and is common in 

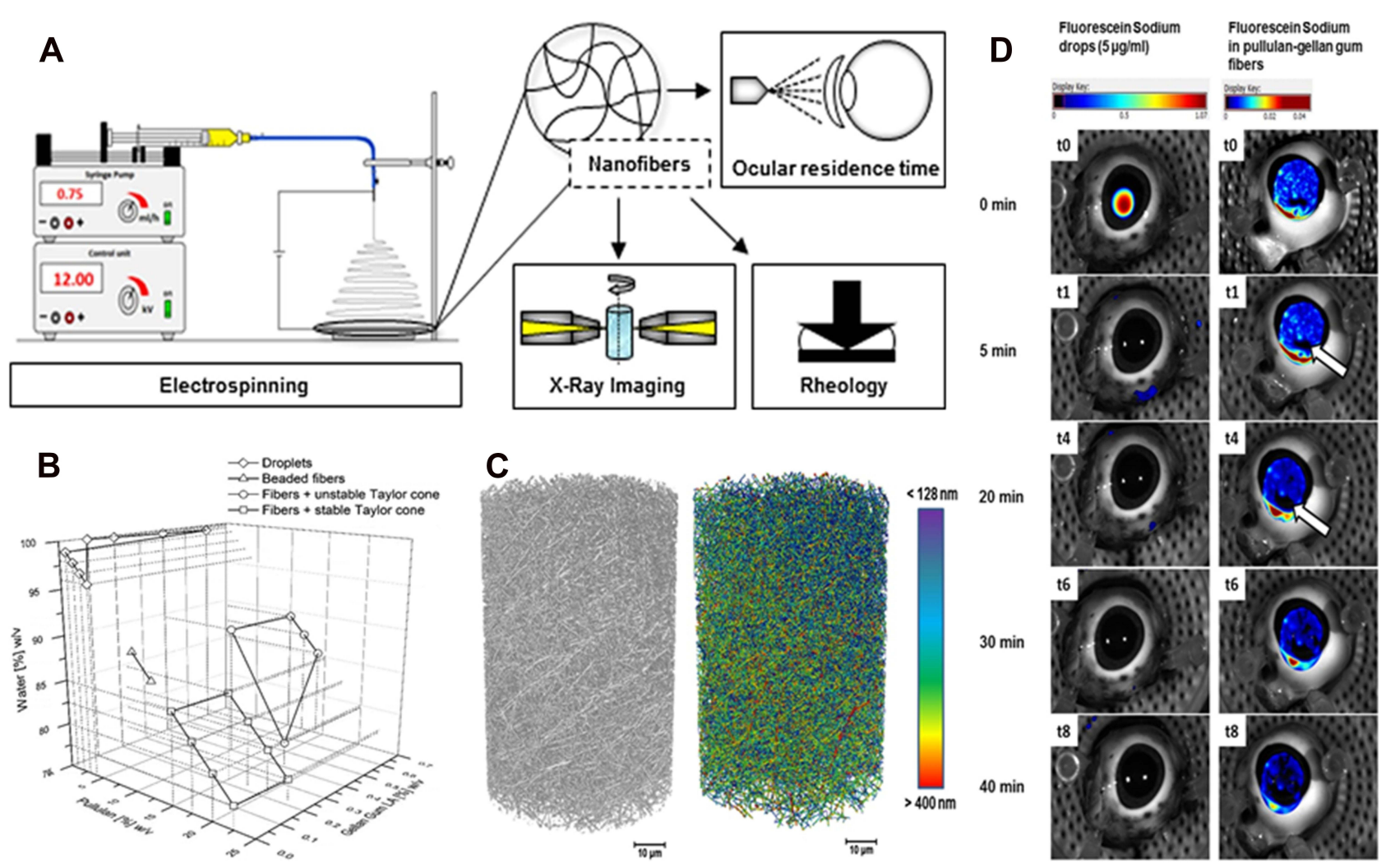

Figure 2 Electrospun nanofibers - A promising solid in-situ gel. (A) The diagram of study on electrospun nanofibers; (B) 3D diagram of the spinning solution composition and the product characteristics; (C) 3D X-ray images of the electrospun nanofibers: (black) grayscale and (color) fiber size distribution image with scale bar; (D) overlay of regular (photo) and fluorescence images of porcine eyes treated with fluorescein sodium eye drops $(5 \mu \mathrm{g} / \mathrm{mL})$ (left), and with pullulan-gellan gum nanofiber lens ( $0.0001 \%$ fluorescein sodium) (right) after different spray applications. Reprinted from Eur J Pharm Biopharm, I46, Göttel B. Electrospun nanofibers - A promising solid in-situ gelling alternative for ocular drug delivery, 125-132, Copyright 2020, with permission from Elsevier. ${ }^{72}$

emergency rooms, as well as emergency care and primary clinics. It can affect people of any age and demographic or socioeconomic status. According to pathogenic examination, the disease is divided into bacterial, viral, fungal, parasitic, allergic, and chlamydial conjunctivitis. ${ }^{75}$ The main symptoms of conjunctivitis include red itchy eyes, palpebral edema, excessive tearing, along with a yellowish mucous discharge. It is usually self-limiting and rarely causes loss of vision, but it often requires treatment to relieve symptoms and shorten the disease course. ${ }^{76}$ The treatment recommendations for conjunctivitis include pharmacological therapy targeting causes, such as antibiotics, ${ }^{77}$ antivirals $^{78}$ and antifungals ${ }^{79}$ and antiallergy medications. ${ }^{80}$ The common route of administration for ocular diseases is local administration on the ocular surface, of which, eye drops, ointments, and gels are the main dosage forms. However, because the conjunctival sac holds less fluid and affects eye blink behavior as well as orbicularis oculi muscle activity, the drug only stays on the ocular surface for a short time, which ultimately leads to a short time of the effective therapeutic concentration on the ocular surface. ${ }^{81}$ Interestingly, nanotechnology opens a new avenue for treating ocular diseases, particularly ocular surface disorders. Nano-carrier DDSs have the potential to reduce drug degradation, increase permeability and bioavailability, and prolong retention time by tailoring the release profile, thereby achieving sustained drug release and targeted therapeutic concentrations, which have been shown in in-vitro or animal studies. ${ }^{24}$

The main advantage of adding anti-infective/antiinflammatory drugs to a nano-carrier is to extend the residence time of the drug and improve bioavailability of the drug in the eye. Many studies have been performed on anti-allergy drugs loaded with nano-carrier DDSs for allergic conjunctivitis treatments (Table 1). Allergic conjunctivitis has immune-pathophysiology, in which, topical nonsteroidal anti-inflammatory drugs (NSAIDs) and immune modulators are conventional treatment. ${ }^{24}$ For example, the NSAID flurbiprofen has low penetration across the cornea 
and produces ocular irritation. Deformable chitosan-coated flurbiprofen-loaded liposomes were proposed and these flexible liposomes easily move across the pores which are too small for conventional liposomes to pass, as their bilayers are highly curved. ${ }^{82}$ Another NSAID, dexibuprofen, loaded onto biodegradable polymeric PLGA nanoparticles constitutes a suitable alternative to topical eye administration. These nanoparticles improve ocular bioavailability and simultaneously reduce drug-induced side effects. $^{83}$ Tacrolimus is a common immune modulator that has been loaded onto PLGA nanoparticle and proglycosomes to provide continuous sustained drug release without side effects (Figure 3). ${ }^{84,85}$

\section{Keratitis}

Keratitis is characterized by corneal edema, infiltration of inflammatory cells, and ciliary congestion and has symptoms, such as eye red, decreased vision, photophobia, difficulty opening the eyelids upon awakening, and excessive tearing. ${ }^{86}$ Keratitis is classified as infectious or non-infectious based on the etiological agent. The infectious type is subdivided into bacterial, protozoal (Acanthamoeba), pythium, fungal, viral, and onchocercal keratitis. Topical chloramphenicol is one of most commonly used drugs against all bacterial isolates, but it has some disadvantages, such as low solubility and short residence time in the conjunctival sac.

Table I Nanocarriers to Deliver Anti-Conjunctivitis Agents

\begin{tabular}{|c|c|c|c|c|c|}
\hline Study & Drug & $\begin{array}{l}\text { Vehiclel } \\
\text { Carriers }\end{array}$ & $\begin{array}{l}\text { Production } \\
\text { Method(s) }\end{array}$ & Results & Conclusion \\
\hline $\begin{array}{l}\text { E. Sanchez-Lopez, } \\
\text { et al }{ }^{159} 2020\end{array}$ & Dexibuprofen & $\begin{array}{l}\text { PLGA }^{*} \\
\text { nanoparticles }\end{array}$ & $\begin{array}{l}\text { Solvent } \\
\text { displacement } \\
\text { method }\end{array}$ & $\begin{array}{l}\text { Polyethylene glycol (PEG) } \\
\text { increased the interaction between } \\
\text { Dexibuprofen-NPs and } \\
\text { customized corneal membrane. }\end{array}$ & $\begin{array}{l}\text { These formulations containing } \\
\text { DXI PLGA I5\% PEG prepared } \\
\text { using Lutrol as a surfactant were } \\
\text { able to release DXI more } \\
\text { effectively for the treatment of } \\
\text { ocular inflammation. }\end{array}$ \\
\hline $\begin{array}{l}\text { X. Gai, et al }{ }^{160} \\
2018\end{array}$ & Ibuprofen & Liposomal & $\begin{array}{l}\text { Ethanol } \\
\text { injection } \\
\text { method }\end{array}$ & $\begin{array}{l}\text { Ibuprofen cationic liposomes } \\
\text { could significantly prolong the } \\
\text { T max to } 100 \text { min and the AUC to } \\
\text { I.53-folds, which indicated that } \\
\text { the ibuprofen cationic liposomes } \\
\text { could improve the precorneal } \\
\text { retention time and bioavailability } \\
\text { of ibuprofen. }\end{array}$ & $\begin{array}{l}\text { The ibuprofen cationic liposomes } \\
\text { probably are a promising } \\
\text { application in ocular drug delivery } \\
\text { system. }\end{array}$ \\
\hline Y. Xu, et al ${ }^{84} 2017$ & Tacrolimus & $\begin{array}{l}\text { PLGA } \\
\text { nanoparticles }\end{array}$ & $\begin{array}{l}\text { Emulsification- } \\
\text { diffusion } \\
\text { method }\end{array}$ & $\begin{array}{l}\text { PLGA-NPs improved corneal, } \\
\text { conjunctival and aqueous humor } \\
\text { bioavailability of Tacrolimus. }\end{array}$ & $\begin{array}{l}\text { The PLGA-NPs significantly } \\
\text { enhanced ocular bioavailability of } \\
\text { TAC than that of aqueous } \\
\text { suspension. }\end{array}$ \\
\hline $\begin{array}{l}\text { V. Garg, et al } \\
2017\end{array}$ & Tacrolimus & Proglycosomes & $\begin{array}{l}\text { Film hydration } \\
\text { method }\end{array}$ & $\begin{array}{l}\text { Incorporation of proglycosomes } \\
\text { enhanced the drug encapsulation, } \\
\text { decreased the vesicle aggregation } \\
\text { and increased the liposomal } \\
\text { elasticity, thereby enhancing the } \\
\text { transocular permeation. }\end{array}$ & $\begin{array}{l}\text { The developed proglycosomes } \\
\text { are prospective carriers for } \\
\text { enhanced ocular delivery of } \\
\text { tacrolimus. }\end{array}$ \\
\hline $\begin{array}{l}\text { H. Chen, et al } \\
2016\end{array}$ & Flurbiprofen & $\begin{array}{l}\text { Chitosan- } \\
\text { coated } \\
\text { liposomal }\end{array}$ & $\begin{array}{l}\text { Modified } \\
\text { ethanol } \\
\text { injection } \\
\text { method }\end{array}$ & $\begin{array}{l}\text { Flurbiprofen-loaded deformable } \\
\text { liposomes could prolong pre- } \\
\text { corneal retention and improve } \\
\text { transcorneal penetration. Edge } \\
\text { activator, Solutol HS-I5, could } \\
\text { potentiate its flexibility and } \\
\text { penetrability. }\end{array}$ & $\begin{array}{l}\text { Chitosan-coated deformable } \\
\text { liposomes appear to be a novel } \\
\text { ophthalmic drug delivery system } \\
\text { with the potential to overcome } \\
\text { the limitations of conventional } \\
\text { eye drops. }\end{array}$ \\
\hline
\end{tabular}

Abbreviation: *PLGA, poly (lactic-co-glycolic acid). 


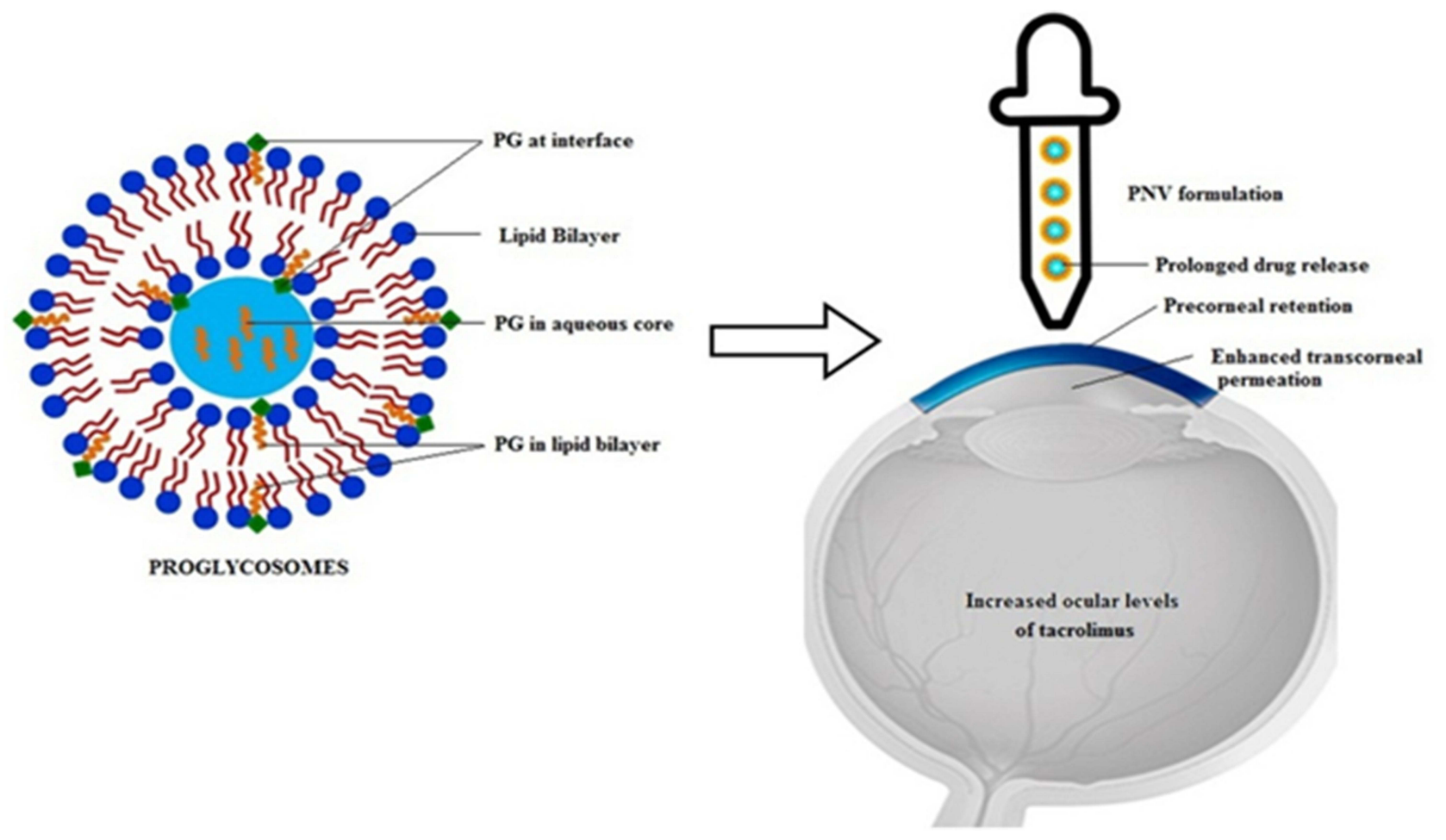

Figure 3 Tacrolimus is a common immune modulator that has been loaded onto Poly(lactic-co-glycolic acid) nanoparticle. Hypothetical representation of the location of propylene glycol in the vesicles and its effects as a novel drug delivery system for tacrolimus. Reprinted from Colloids Surf B Biointerfaces, I57, Garg V, Suri R, Jain GK, Kohli K. Proglycosomes: a novel nano-vesicle for ocular delivery of tacrolimus, 40-47, Copyright 2017, with permission from Elsevier. ${ }^{85}$

Abbreviation: PNVs, Proglycosomes nano-vesicles.

In order to solve these problems, $\mathrm{Xu}$ et al prepared chloramphenicol-containing cyclodextrin eye drops containing chloramphenicol to treat acute bacterial keratitis. Furthermore, the drug concentration in the aqueous humor using CHL/SBE- $\beta-C D$ eye drops was higher than that of commercial chloramphenicol eye drops, and the average ocular surface stay time was 1.9 times longer. ${ }^{84}$ Zorzi et al developed PEGylated polymeric vesicles encapsulating small interfering RNA (siRNA) sequences to treat keratitis caused by Acanthamoeba. The combined therapy of siRNAloaded polymeric vesicles with chlorhexidine led to a $60 \%$ reduction in corneal damage caused by Acanthamoeba in a 2 month-old Wistar rat model. ${ }^{87}$ Further studies should be performed to confirm the effectiveness of this treatment.

\section{Dry Eye Disease}

Dry eye disease (DED) is one of the most common ocular surface disorders characterized by a deficiency of tear production or excessive tear evaporation. The common symptoms of DED include a dry, foreign body sensation, burning, itching, photophobia, congestion, pain, blurred vision, fatigue, and a sticky silk secretion. Treatments for DED aim to improve these clinical symptoms using artificial tears and lubricants to moisten the ocular surface. ${ }^{88}$ In the last decade, nano-carrier systems have shown great promise to revolutionize drug delivery to treat DED, offering many advantages such as site-specific and sustained delivery of therapeutic agents. A number of studies have shown that nanotechnology drugs have a good therapeutic effect on the dry eye rabbit model (Table 2). For example, cyclosporine A, a poorly soluble immunosuppressant cyclic peptide required in some cases of xerophthalmia (severe drying and thickening of the conjunctiva), ${ }^{89}$ has been the subject of previous studies involving micelles. ${ }^{90}$ Kang et al used polyoxyl 35 hydrogenated castor oil micelles to demonstrate improved functionality and morphology of the conjunctival epithelium in a New Zealand albino rabbit dry eye model. ${ }^{91}$ In 2019, the NSAID amfenac loaded with poly(catechin) capped-gold nanoparticles had a synergistic anti-inflammatory effect in a DED rabbit model. ${ }^{92}$ Nagai et al loaded nanoparticles with rebamipide using the breakdown method and reported that this drug increases the mucin levels in the lacrimal fluid and prolongs tear film breakup time. ${ }^{93}$ These results will be 
Table 2 Nanocarriers to Deliver Anti-Dry Eye Agents

\begin{tabular}{|c|c|c|c|c|c|c|}
\hline Study & $\begin{array}{l}\text { Experimental } \\
\text { Models }\end{array}$ & Drug & $\begin{array}{l}\text { Vehicle/ } \\
\text { Carriers }\end{array}$ & $\begin{array}{l}\text { Production } \\
\text { Method(s) }\end{array}$ & Results & Conclusion \\
\hline $\begin{array}{l}\text { N. Nagai, } \\
\text { et } \text { al }^{93} 2020\end{array}$ & $\begin{array}{l}\mathrm{N} \text {-acetylcysteine- } \\
\text { treated rabbit } \\
\text { model }\end{array}$ & Rebamipide & Nanoparticles & $\begin{array}{l}\text { Breakdown } \\
\text { method }\end{array}$ & $\begin{array}{l}\text { The rebamipide solid } \\
\text { nanoparticle-based } \\
\text { ophthalmic formulation } \\
\text { increased mucin levels in the } \\
\text { lacrimal fluid and healed tear } \\
\text { film breakup levels in vivo. }\end{array}$ & $\begin{array}{l}\text { This novel sustained-release } \\
\text { drug delivery route and } \\
\text { creation of a nano- } \\
\text { formulation can be used to } \\
\text { design further studies aimed } \\
\text { at therapy for dry eye. }\end{array}$ \\
\hline $\begin{array}{l}\text { F. Yu, et al }{ }^{161} \\
2019\end{array}$ & $\begin{array}{l}\text { Dry eye murine } \\
\text { model }\end{array}$ & $\begin{array}{l}\text { Glycol } \\
\text { chitosan } \\
\text { cerium oxide }\end{array}$ & Nanoparticles & Unspecified & $\begin{array}{l}\text { Glycol chitosan cerium } \\
\text { oxide nanoparticles not only } \\
\text { ameliorate symptoms but } \\
\text { also reverse pathological } \\
\text { changes at the cellular and } \\
\text { molecular levels in dry eye. }\end{array}$ & $\begin{array}{l}\text { Glycol chitosan cerium } \\
\text { oxide nanoparticles are an } \\
\text { effective treatment for dry } \\
\text { eye and may represent } \\
\text { a potential new class of drug } \\
\text { for dry eye disease. }\end{array}$ \\
\hline $\begin{array}{l}\text { Y. J. Li, et al }{ }^{92} \\
2019\end{array}$ & Rabbits model & Amfenac & $\begin{array}{l}\text { Poly(catechin) } \\
\text { capped-gold } \\
\text { nanoparticles }\end{array}$ & Unspecified & $\begin{array}{l}\text { Poly (catechin) capped-gold } \\
\text { nanoparticles (Au@Poly-CH } \\
\text { NPs) not only act as an anti- } \\
\text { oxidant to suppress ROS- } \\
\text { mediated processes, but also } \\
\text { serve as a drug carrier of AF } \\
\text { for a synergistic effect on } \\
\text { anti-inflammation. }\end{array}$ & $\begin{array}{l}\text { Au@Poly-CH NPs loaded } \\
\text { with NSAIDs is a promising } \\
\text { multifunctional } \\
\text { nanocomposite for treating } \\
\text { various inflammation- and } \\
\text { oxidative stress-related } \\
\text { diseases. }\end{array}$ \\
\hline $\begin{array}{l}\text { H. Y. Huang, } \\
\text { et al }{ }^{162} 2018\end{array}$ & $\begin{array}{l}\text { New Zealand } \\
\text { White rabbits }\end{array}$ & $\begin{array}{l}\text { Hyaluronic } \\
\text { acid }\end{array}$ & Nanoparticles & $\begin{array}{l}\text { Self-assembly } \\
\text { method }\end{array}$ & $\begin{array}{l}\text { Large amounts of gelatin- } \\
\text { epigallocatechin gallate } \\
\text { nanoparticles (GEH-NPs) } \\
\text { accumulated in the } \\
\text { cytoplasm of human corneal } \\
\text { epithelium cells and the } \\
\text { ocular surfaces of rats and } \\
\text { rabbits, indicating the } \\
\text { advantage of GEH NPs for } \\
\text { ocular delivery of } \\
\text { medication. }\end{array}$ & $\begin{array}{l}\text { GEH NPs are potentially } \\
\text { valuable as a new } \\
\text { therapeutic agent delivered } \\
\text { in eye drops for treating dry } \\
\text { eye syndrome. }\end{array}$ \\
\hline $\begin{array}{l}\text { H. Kang, } \\
\text { et al }\left.\right|^{91} 2016\end{array}$ & $\begin{array}{l}\text { New Zealand } \\
\text { albino rabbits }\end{array}$ & $\begin{array}{l}\text { Cyclosporine } \\
\text { A }\end{array}$ & $\begin{array}{l}\text { Micelle } \\
\text { solutions }\end{array}$ & $\begin{array}{l}\text { Simple } \\
\text { method }\end{array}$ & $\begin{array}{l}\text { The number of goblet cells in } \\
\text { rabbit conjunctivas after the } \\
\text { administration of } \\
\text { cyclosporine A-micelle } \\
\text { solutions was significantly } \\
\text { higher than that with Restasis. }\end{array}$ & $\begin{array}{l}\text { The potential use of a novel } \\
\text { MS for the ophthalmic } \\
\text { delivery of CSA in treating } \\
\text { dry eyes. }\end{array}$ \\
\hline $\begin{array}{l}\text { C. Di } \\
\text { Tommaso, } \\
\text { et } \text { al }^{163} 201 \mathrm{l}\end{array}$ & $\begin{array}{l}\text { Female albino } \\
\text { New Zealand } \\
\text { rabbits }\end{array}$ & $\begin{array}{l}\text { Cyclosporin } \\
\text { A }\end{array}$ & $\begin{array}{l}\text { polymeric } \\
\text { micelles }\end{array}$ & $\begin{array}{l}\text { Co-solvent } \\
\text { method }\end{array}$ & $\begin{array}{l}\text { After incubation with } \\
\text { methoxy poly (ethylene } \\
\text { glycol)-hexylsubstituted } \\
\text { poly(lactides) (MPEG- } \\
\text { hexPLA) micelle } \\
\text { formulations, the activation } \\
\text { of caspase-dependent and - } \\
\text { independent apoptosis as } \\
\text { well as autophagy was } \\
\text { evaluated using } \\
\text { immunohistochemistry for } \\
\text { localizing antibodies }\end{array}$ & $\begin{array}{l}\text { MPEG-hexPLA micelles are } \\
\text { promising drug carriers for } \\
\text { ocular diseases involving the } \\
\text { activation of cytokines }\end{array}$ \\
\hline
\end{tabular}


attractive to both academic and pharmaceutical industry researchers working in DED therapeutics.

\section{Glaucoma}

Glaucoma is the second major cause of blindness worldwide, with a $1 \%$ global incidence rate, and a $2 \%$ rate in subjects over 45 years old. ${ }^{94}$ IOP increases intermittently or continuously in patients with glaucoma, and the dynamic balance in the aqueous circulation is disrupted, causing optic nerve atrophy and visual field defects. The other pathological manifestations of glaucoma are retinal ganglion cell (RGC) apoptosis and chronic progressive degeneration of axons. ${ }^{95,96}$ Two major problems are encountered in the clinic when treating glaucoma, such as low drug bioavailability and poor patient compliance. In last 10 years, studies of drug-loaded nano-technology formulations to treat of glaucoma have shown positive outcomes (Table 3).

Latanoprost has been injected into the subconjunctival space once to evaluate the safety and efficacy of a latanoprost nanoliposome carrier in human eyes $(n=6)$ diagnosed with either ocular hypertension or primary open-angle glaucoma. No significant irritation was detected after subconjunctival injection of the liposomal latanoprost. A significant reduction in IOP was detected from baseline $(27.55 \pm 3.25 \mathrm{mmHg})$ to $1 \mathrm{~h}$ later $(14.52 \pm$ $3.31 \mathrm{mmHg}$ ). More than a $20 \%$ IOP reduction was observed after 3-months, which provided evidence for clinical use of liposomal latanoprost in glaucoma therapeutics. $^{97}$

Furthermore, Rodriguez-Aller et al revealed that latanoprost-propylamino- $\beta$ cyclodextrin has significant solubility and stability compared with a commercial latanoprost formulation in vitro. Additionally, there is less ocular irritation with a latanoprost-propylamino- $\beta-C D$ formulation $(9.5 \%)$ than that with a commercially marketed formulation of latanoprost $(15.5 \%)$ in vivo. ${ }^{98}$

Interestingly, acetazolamide has been loaded onto water-soluble mucoadhesive carbosilane dendrimers to evaluate the cytotoxicity and cell viability of dendrimers in normotensive rabbit eyes. The results revealed that G3 (from the third generation of carbosilane cationic dendrimers) cationic carbosilane dendrimers $(5 \mu \mathrm{M})$ produced a rapid ( 1 hour post-instillation) and sustained (up to 7-hour) hypotensive effect, reaching a peak $22.6 \%$ reduction in IOP. ${ }^{99}$

Visual field loss in patients with glaucoma is caused by death of RGCs. Normal physiological ageing is responsible for an estimated rate of $0.4 \%$ RGC loss per year, ${ }^{100}$ but this percentage increases to $4 \%$ in cases of glaucoma. ${ }^{101}$ Considering the complex and multifactorial nature of glaucoma, multiple targets are thought to contribute to the loss of RGCs. The NMDA antagonist memantine loaded in PLGA nanoparticles using the double emulsion solvent evaporation technique significantly reduced loss of RGCs in Morrison's ocular hypertension rat model. ${ }^{102}$

\section{Posterior Capsular Opacification}

Postoperative capsular opacification, particularly posterior capsular opacification (PCO), is one of most common complications of cataract surgery. Residual lens epithelial cells (LECs) on the lens capsule lead to proliferation, migration, and trans-differentiation. ${ }^{103}$ Various management strategies to control PCO have been tested, including updates on intraocular lens materials and pharmacological treatments. Nano-carrier-loaded targeted drugs or the material method is effective to mechanically prevent the formation of PCO. However, only a few studies have evaluated the use of nanomaterials to prevent PCO. The antimetabolite drug fluorouracil (5-FU) inhibits cell proliferation directly by disturbing the cells' nucleic acids and proteins. 5-FU is also applied to cure eyes with these characteristics. ${ }^{104}$ To evaluate the effects of 5-FU modified intra ocular lens (IOL) to prevent PCO, Huang et al injected 5-FU carried by chitosan nanoparticles into the lens capsule after removing the lens cortex of New Zealand white rabbits during cataract surgery, compared with injecting 5-FU alone. Their findings suggested that 5-FU partially curbs the proliferation of LECs, and the $50 \%$ inhibitory concentration (IC50) of 5-FU carried by chitosan nanoparticles was only one-fifth that of direct administration, which significantly lowered damage to the cornea, iris, and ciliary body. ${ }^{105}$ In addition, another study found that other cytotoxic drugs, such as daunorubicin and mitomycin $\mathrm{C}$, also inhibit proliferation of LECs, but a suitable method to reduce the toxicity to intraocular tissues is needed. In the future, experiments combining pharmacological treatment of the underlying biological processes and the use of nanomedicine could help prevent PCO. ${ }^{106}$

\section{Diabetic Cataract}

Cataract is a major cause of vision disorders in the population with diabetes mellitus (DM), ${ }^{107}$ and they form much faster in patients with DM than in normal subjects. ${ }^{108}$ Oxidative stress 


\begin{tabular}{|c|c|c|c|c|c|}
\hline 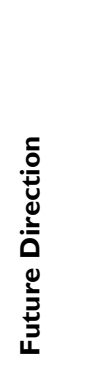 & 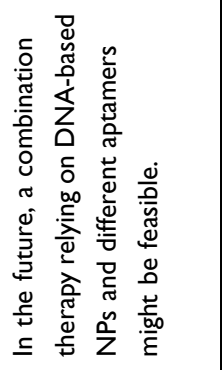 & 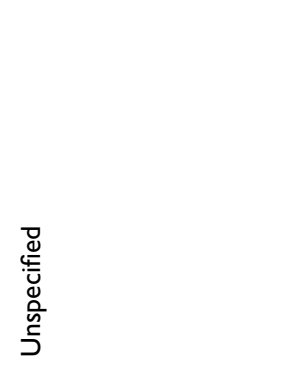 & 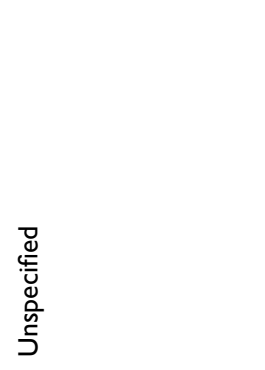 & 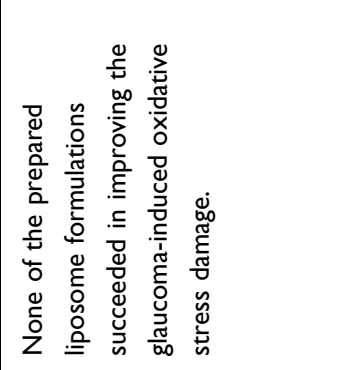 & 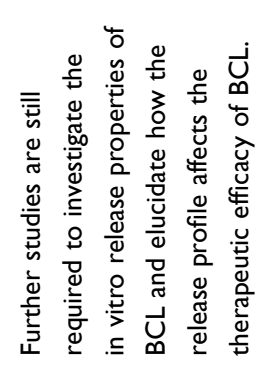 \\
\hline 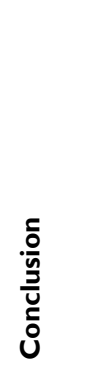 & 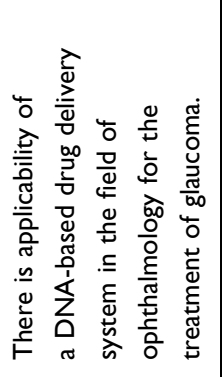 & 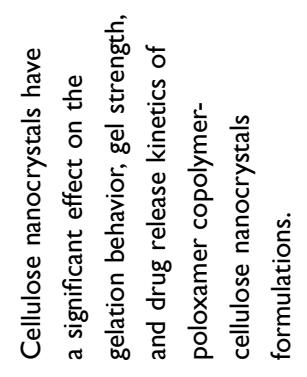 & 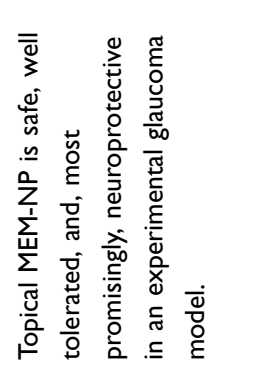 & 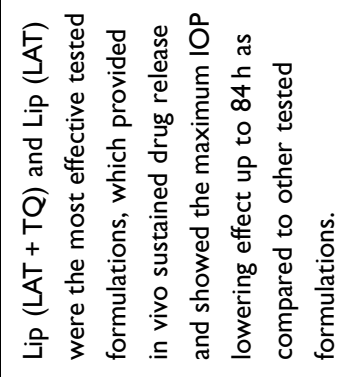 & 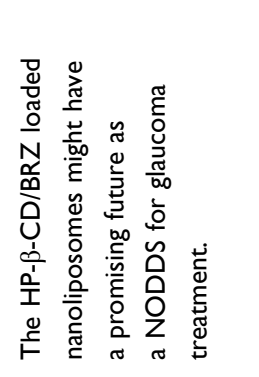 \\
\hline $\begin{array}{l}\frac{y}{5} \\
\frac{\ddot{y}}{x}\end{array}$ & 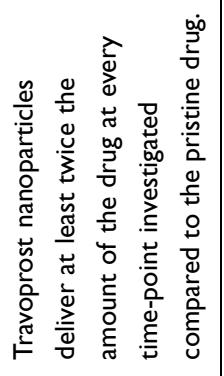 & 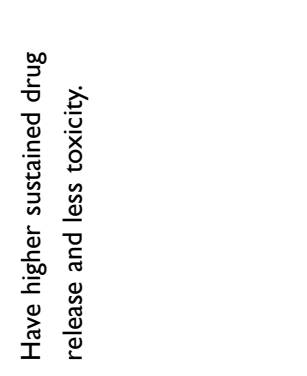 & 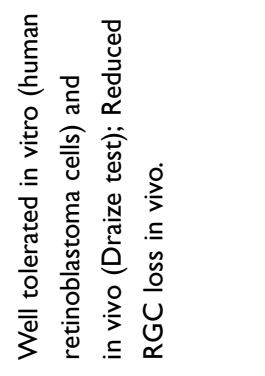 & 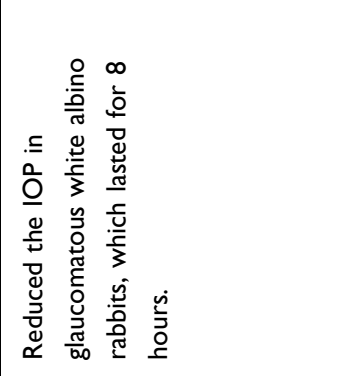 & 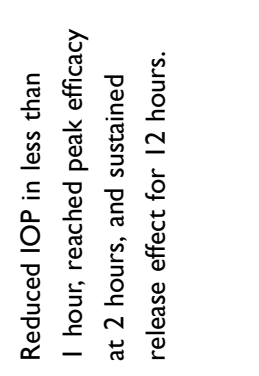 \\
\hline 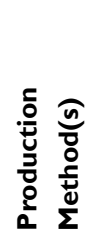 & 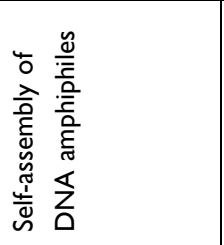 & 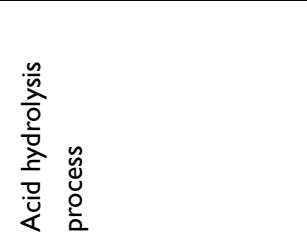 & 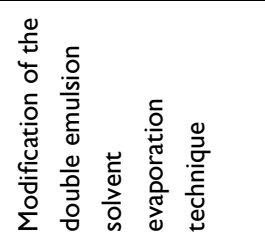 & 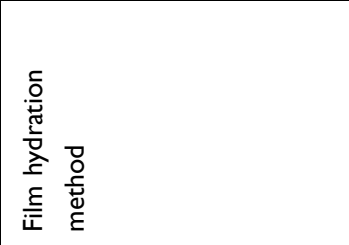 & 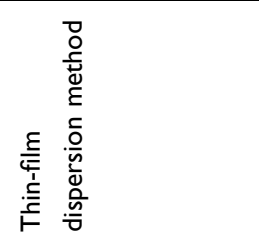 \\
\hline 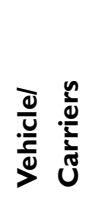 & 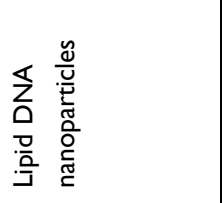 & 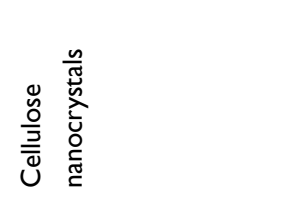 & 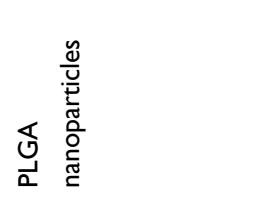 & 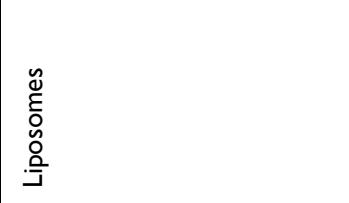 & 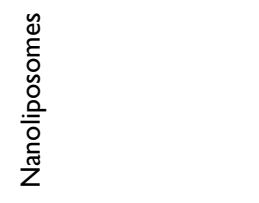 \\
\hline$\stackrel{D}{0}^{\infty 00}$ & 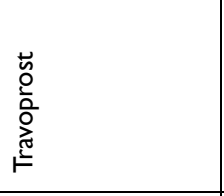 & 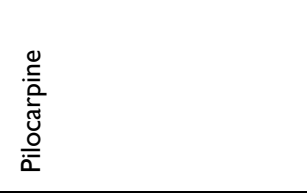 & 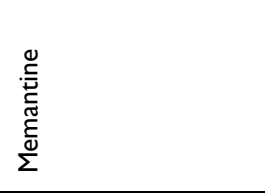 & 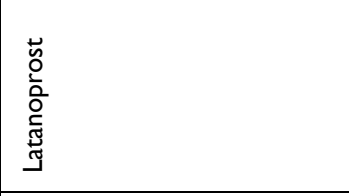 & 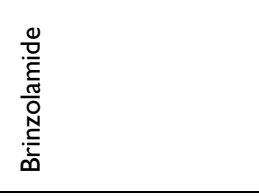 \\
\hline 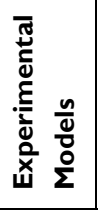 & 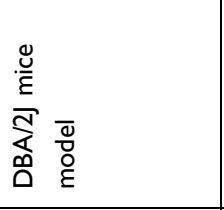 & 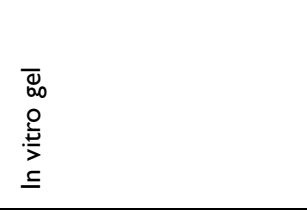 & 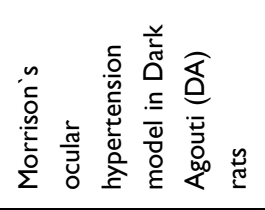 & 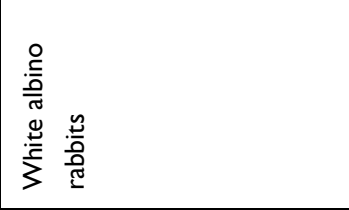 & 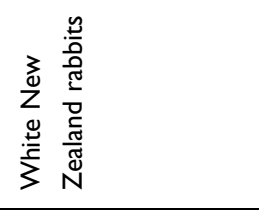 \\
\hline 竞 & 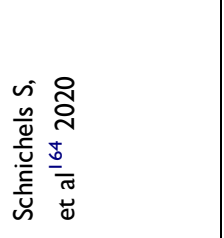 & 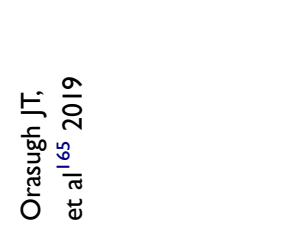 & 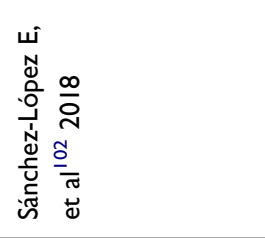 & 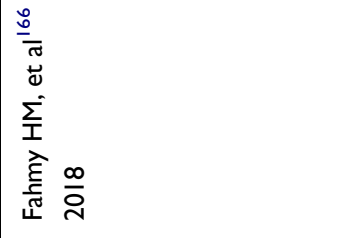 & 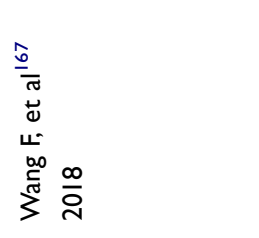 \\
\hline
\end{tabular}




\begin{tabular}{|c|c|c|c|c|c|}
\hline 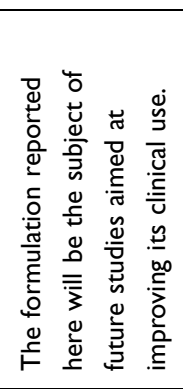 & 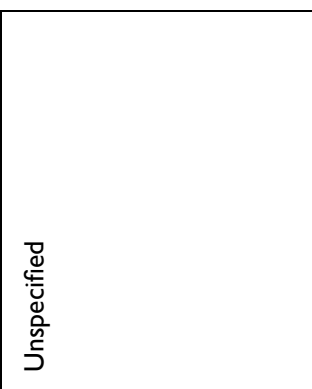 & 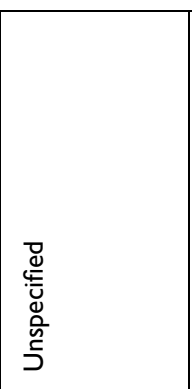 & 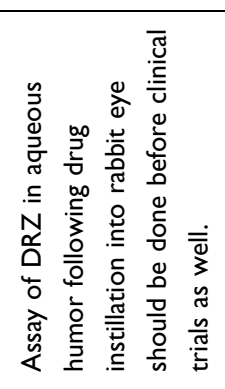 & 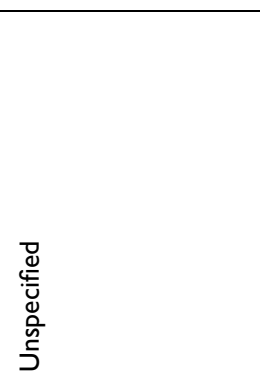 & 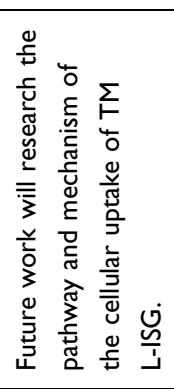 \\
\hline 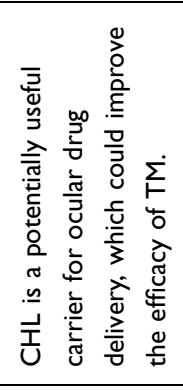 & 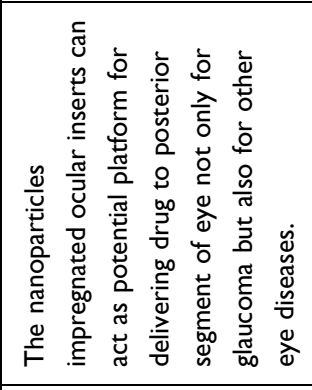 & 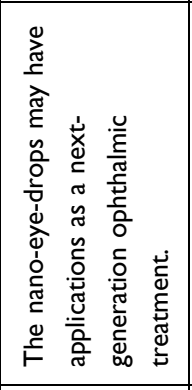 & 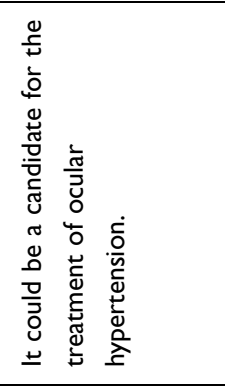 & 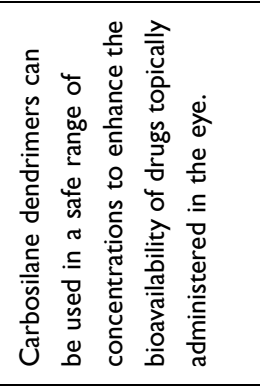 & 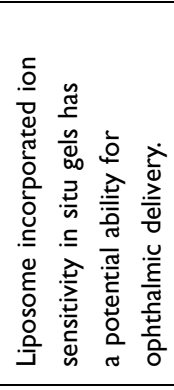 \\
\hline 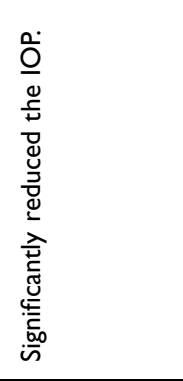 & 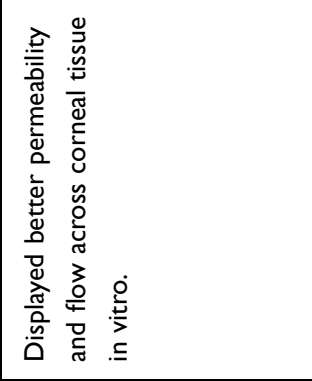 & 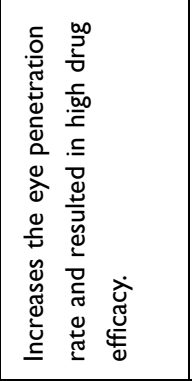 & 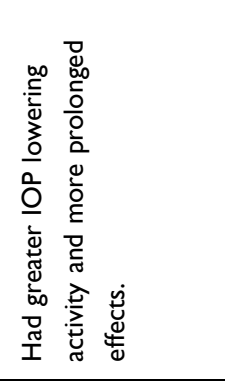 & 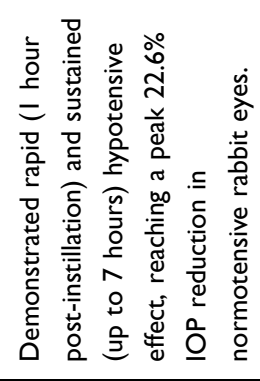 & 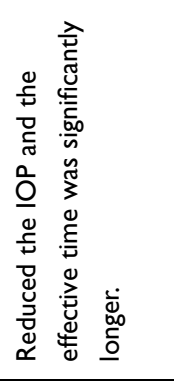 \\
\hline 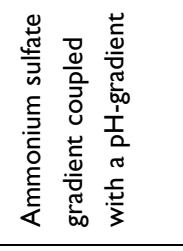 & 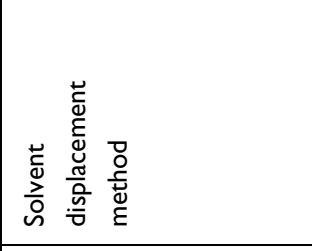 & 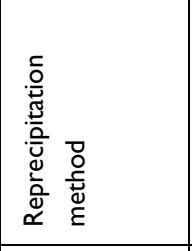 & 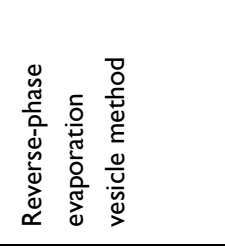 & 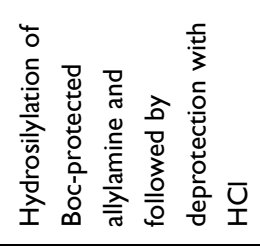 & 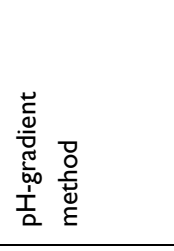 \\
\hline 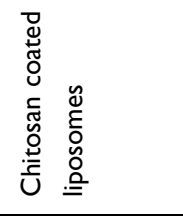 & 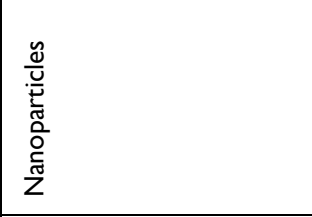 & 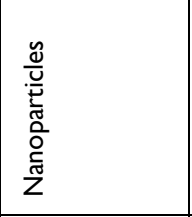 & 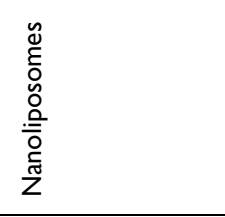 & 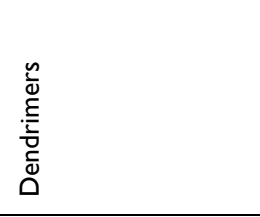 & 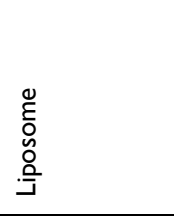 \\
\hline 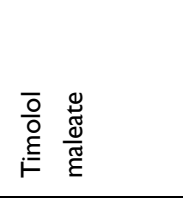 & 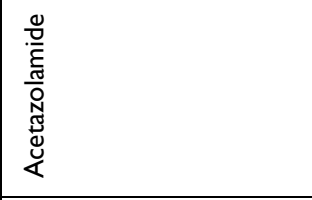 & 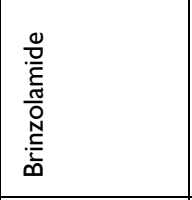 & 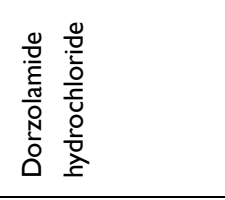 & 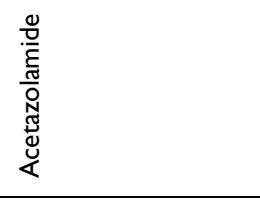 & 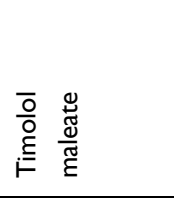 \\
\hline 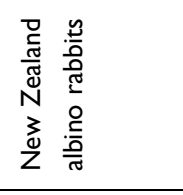 & 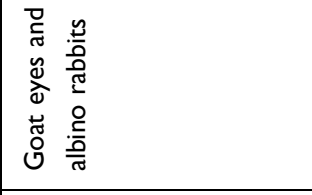 & 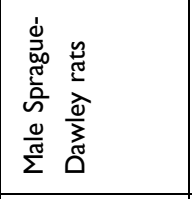 & 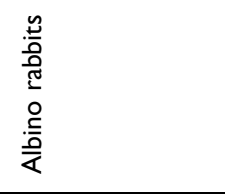 & 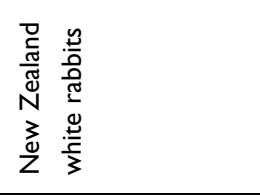 & 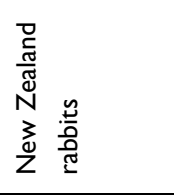 \\
\hline 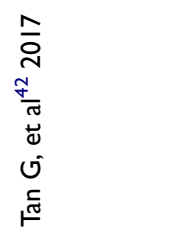 & 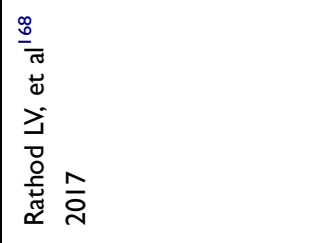 & 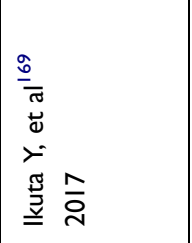 & 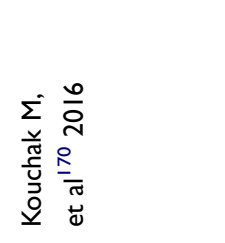 & 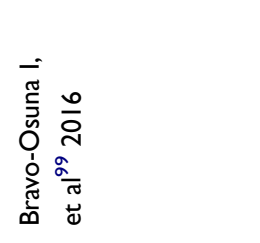 & 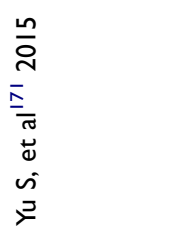 \\
\hline
\end{tabular}




\begin{tabular}{|c|c|c|c|c|}
\hline 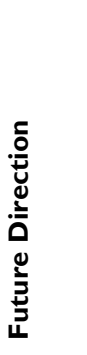 & 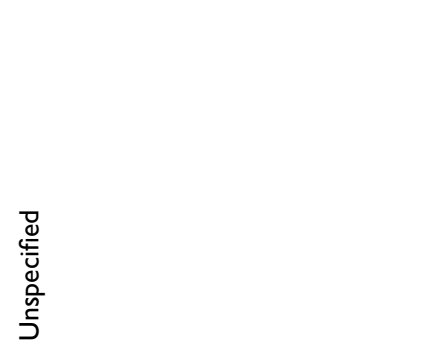 & 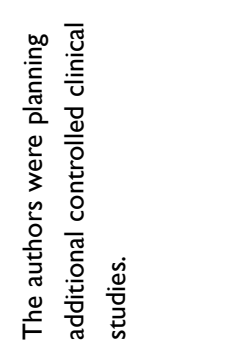 & 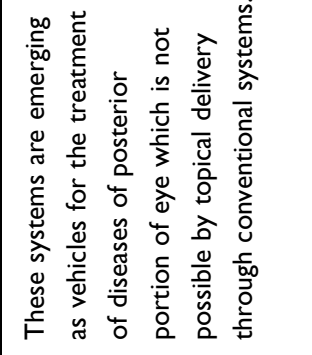 & 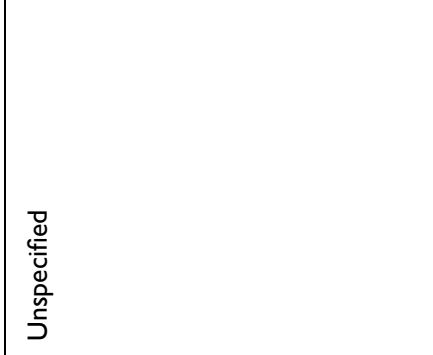 \\
\hline 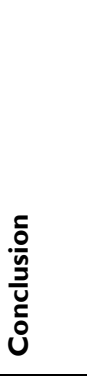 & 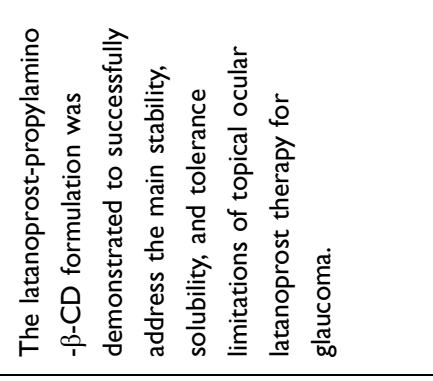 & 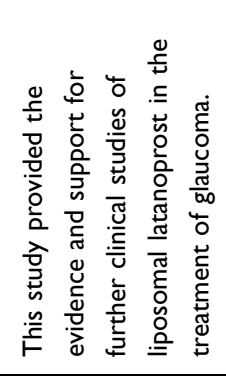 & 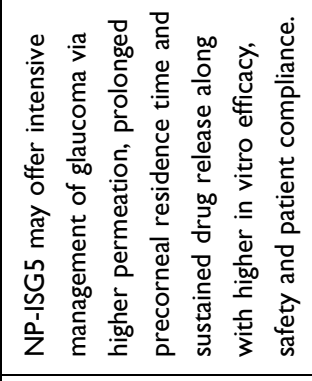 & 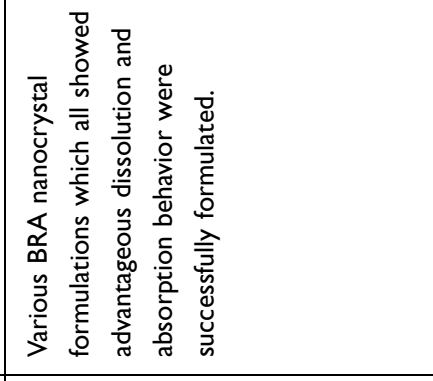 \\
\hline 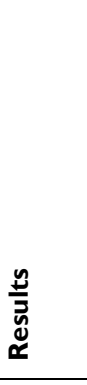 & 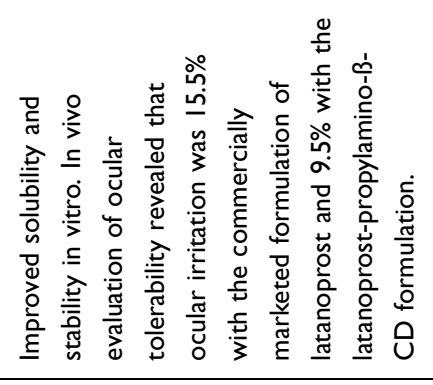 & 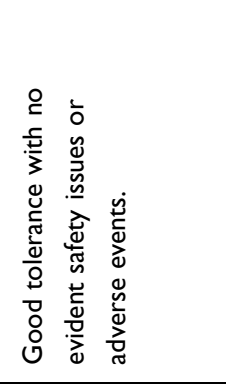 & 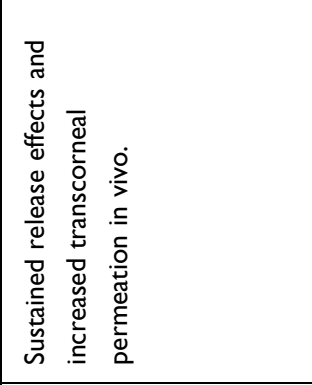 & 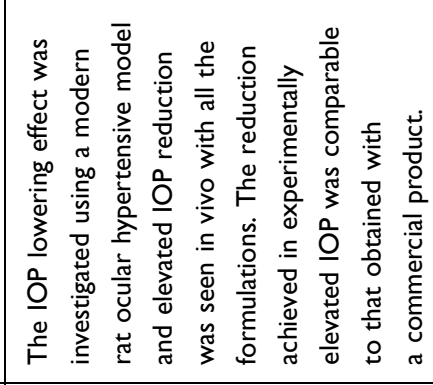 \\
\hline 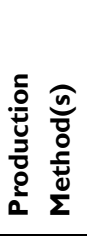 & 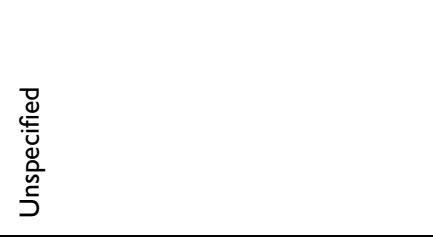 & 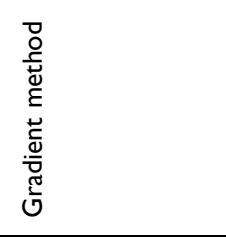 & 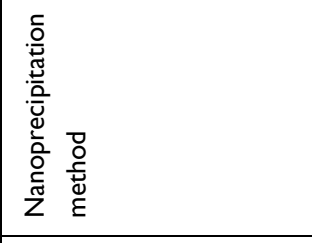 & 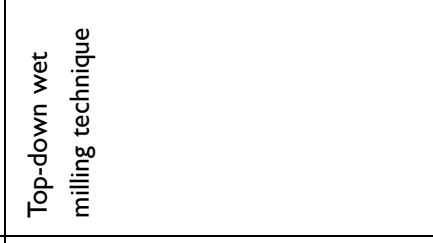 \\
\hline 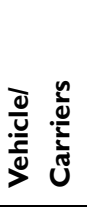 & 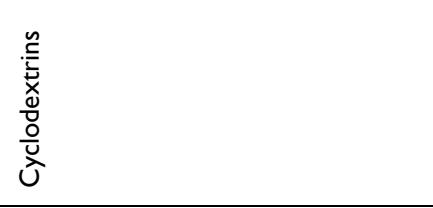 & 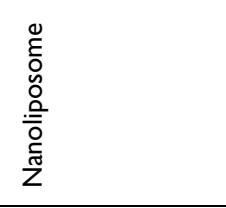 & 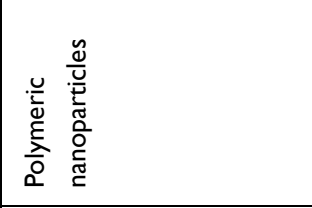 & 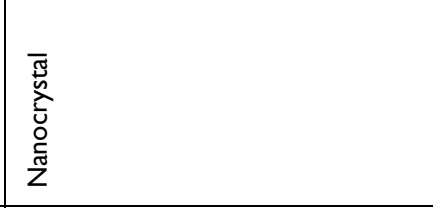 \\
\hline 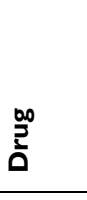 & 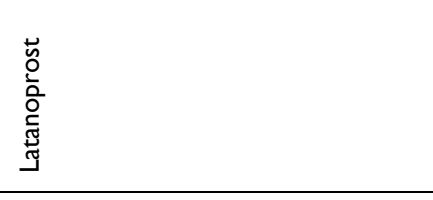 & 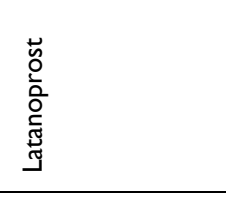 & 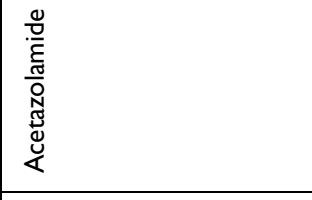 & 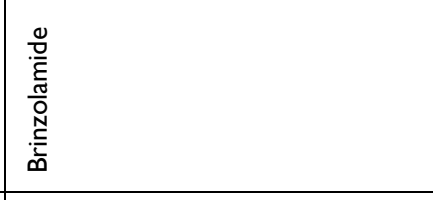 \\
\hline 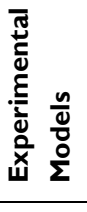 & 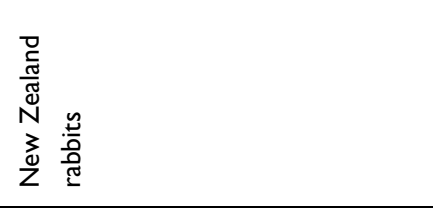 & 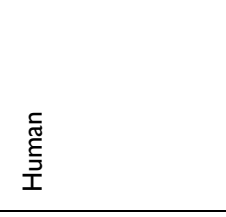 & 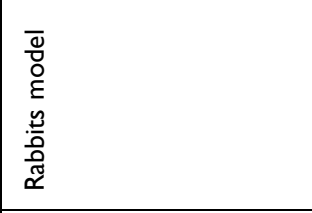 & 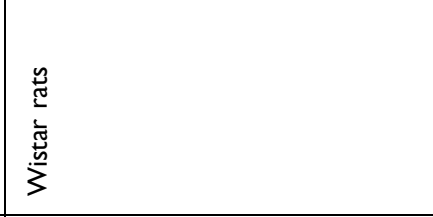 \\
\hline 密 & 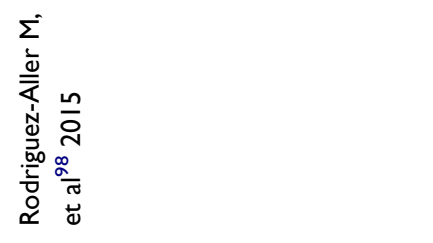 & 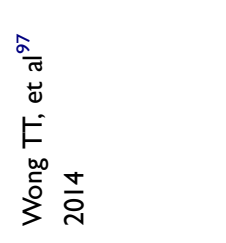 & 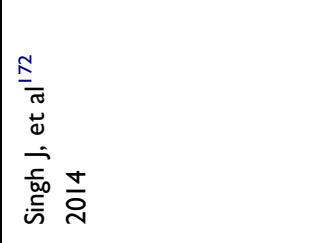 & 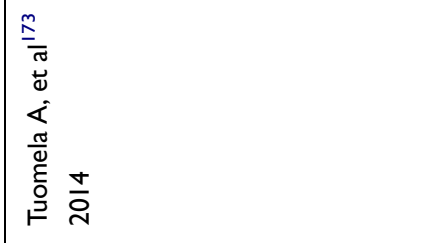 \\
\hline
\end{tabular}




\begin{tabular}{|c|c|c|c|}
\hline 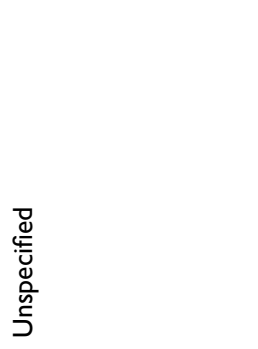 & 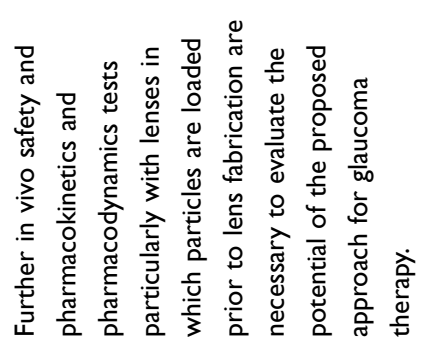 & 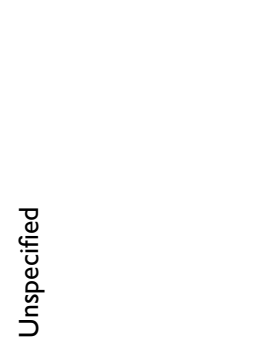 & 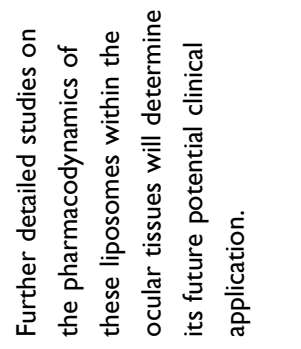 \\
\hline 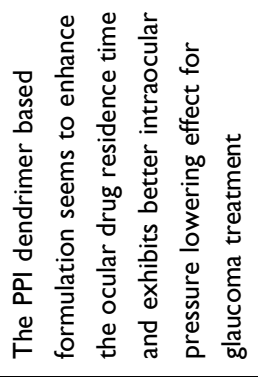 & 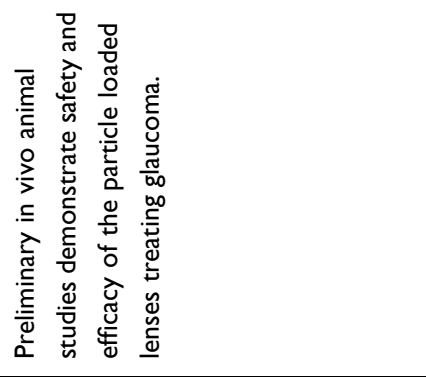 & 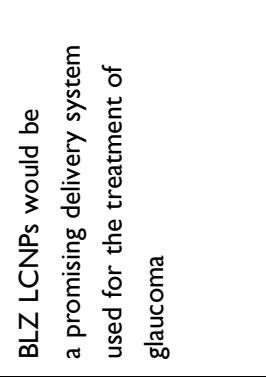 & 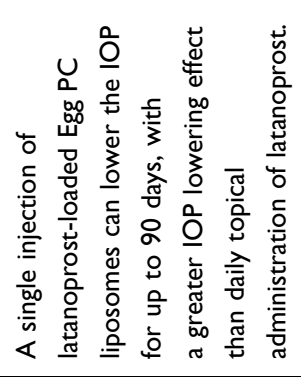 \\
\hline 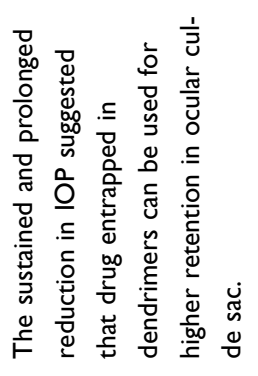 & 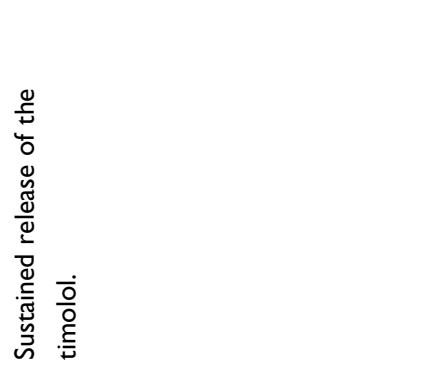 & 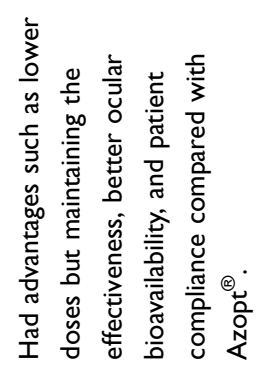 & 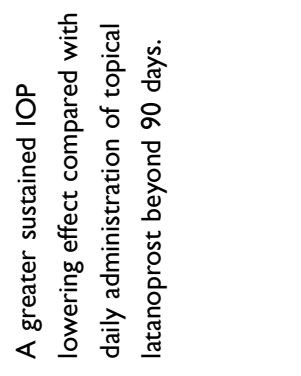 \\
\hline 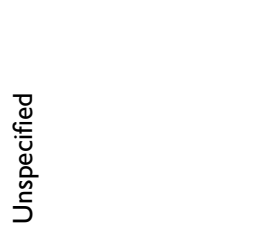 & 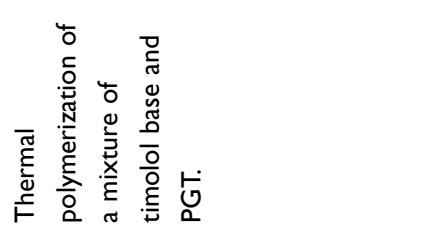 & 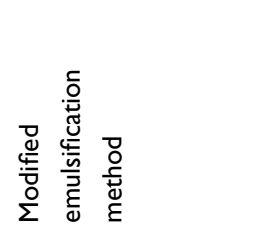 & 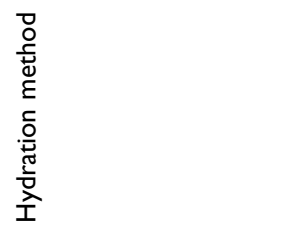 \\
\hline 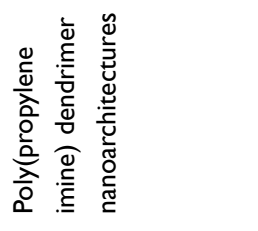 & 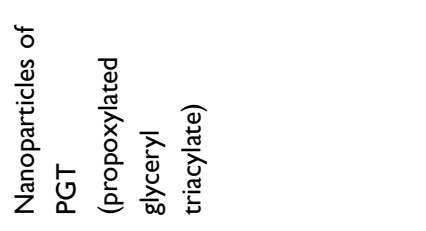 & 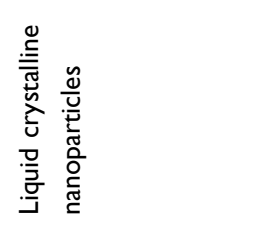 & 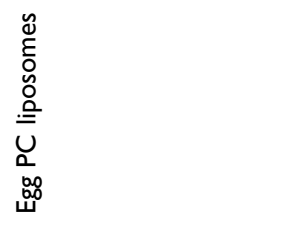 \\
\hline 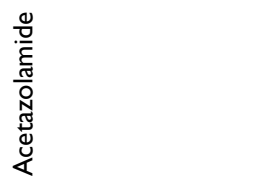 & $\begin{array}{l}\frac{\overline{0}}{0} \\
\stackrel{\underline{\xi}}{F}\end{array}$ & 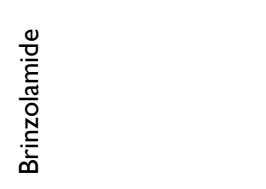 & 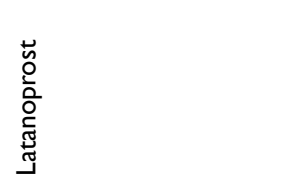 \\
\hline 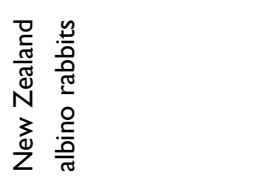 & $\begin{array}{l}a_{0} \\
0 \\
0 \\
\frac{0}{a 0} \\
\mathbb{0} \\
\infty\end{array}$ & 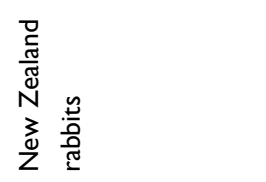 & 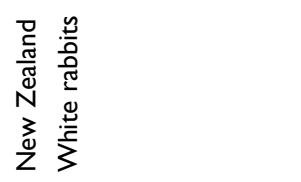 \\
\hline 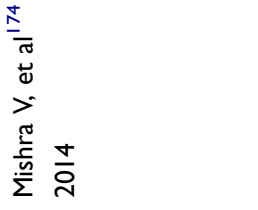 & 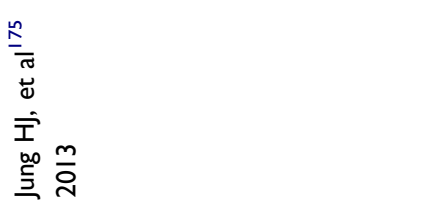 & 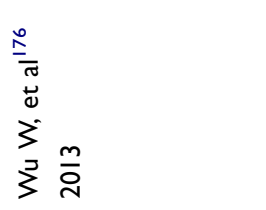 & 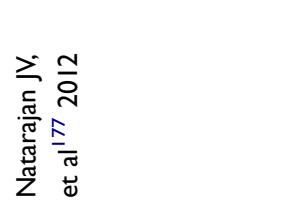 \\
\hline
\end{tabular}


affects the pathogenesis of cataract induced by hyperglycemia. ${ }^{109}$ Over the past 10 years, efforts have been made to develop nano-based formulations involving antioxidative stress control to treat diabetic cataract.

Cerium, an earth element in the lanthanide series, has oxidation states of $\mathrm{Ce}^{3+}$ and $\mathrm{Ce}^{4+}$, which scavenge free radicals. Yang et al prepared cerium (III) chloride $\left(\mathrm{CeCl}_{3}\right)$ loaded mesoporous silica $\left(\mathrm{CeCl}_{3} @ \mathrm{mSiO}_{2}\right)$ nanoparticles and revealed their application for treating diabetesassociated cataract in vitro and in vivo using the streptozotocin (STZ)-induced male Wistar diabetic rat cataract model (Figure 4). ${ }^{110}$ Furthermore, Zhou et al synthesized cerium oxide nanoparticles $\left(\mathrm{CeO}_{2}-\mathrm{NPs}\right)$ coated with PEG-PLGA (PCNPs) using the emulsification method, and reported that it protects LECs from oxidative stress damage by scavenging reactive oxygen species (ROS) and attenuating alpha-crystalline glycation in the STZinduced diabetic rat model. ${ }^{111}$

These findings have opened avenues for developing potential therapeutic strategies to treat diabetic cataract.

\section{A}

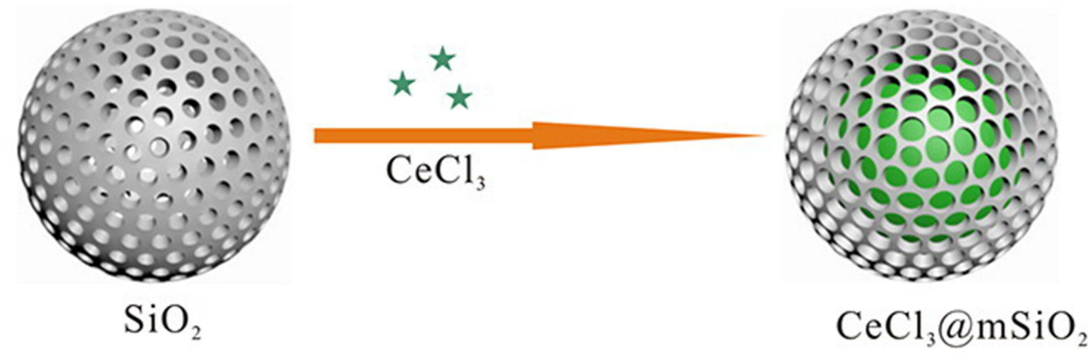

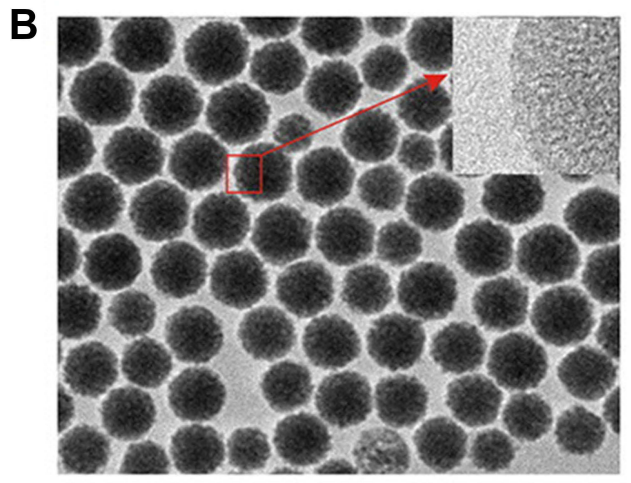

D

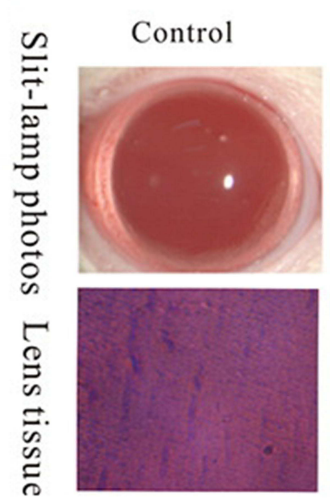

C $\quad \sqrt[4]{-\theta \cdot \text { Control }}$

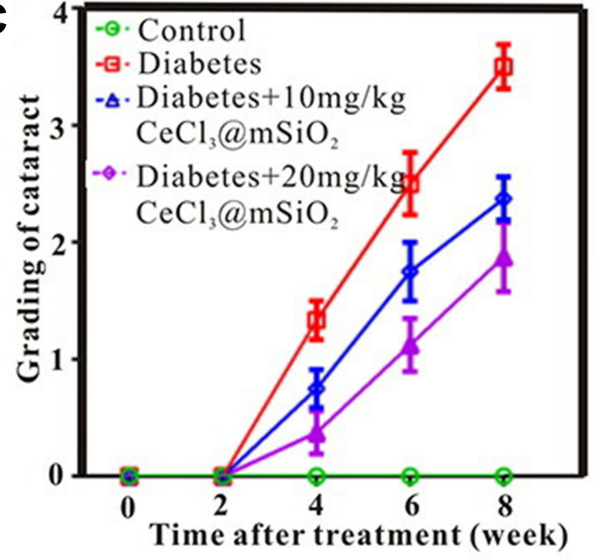

Diabetes $+10 \mathrm{mg} / \mathrm{kg}$ Diabetes $+20 \mathrm{mg} / \mathrm{kg}$ $\mathrm{CeCl}_{3} @ \mathrm{mSiO}_{2}$

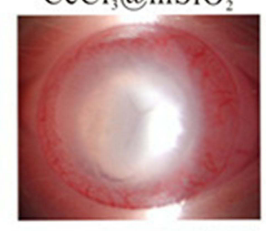
$\mathrm{CeCl}_{3} @ \mathrm{mSiO}_{2}$
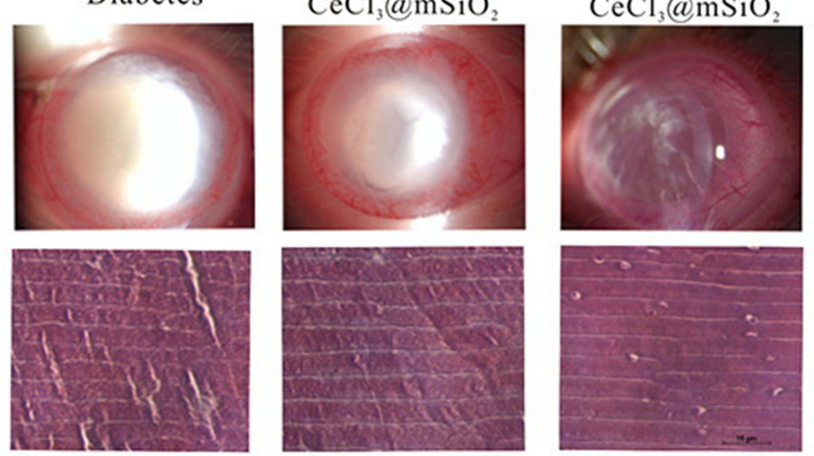

Figure 4 Cerium (III) chloride $\left(\mathrm{CeCl}_{3}\right)$-loaded mesoporous silica $\left(\mathrm{CeCl}_{3} @ \mathrm{mSiO}_{2}\right)$ nanoparticles. $\mathrm{A}$ type of cerium (III) chloride $(\mathrm{CeCl})$-loaded mesoporous silica $\left(\mathrm{CeCl} \mathrm{C}_{3}\right.$ $@ \mathrm{mSiO}_{2}$ ) nanoparticles designed and to prevent the formation of diabetic cataract in vitro and in vivo using a well-established rat model of streptozotocin-induced diabetes. (A) Schematic diagram of $\mathrm{CeCl}_{3} @ \mathrm{mSiO}_{2}$ nanoparticle preparation; (B) The morphology of the $\mathrm{mSiO}_{2}$ nanoparticles under transmission electron microscopy (spherical, uniform and monodisperse morphology with an average diameter of $85 \mathrm{~nm}$ ); (C) A line graph, showing the time course of changes in the cataract degrees in different groups of animals; (D) various degrees of cataract and representative images of H\&E-stained sections of the lens tissue in experimentally induced diabetic animals 8 weeks after treatment with vehicle or 10 and $20 \mathrm{mg} / \mathrm{kg} \mathrm{CeCl}{ }_{3} @ \mathrm{mSiO}_{2}$ nanoparticles, respectively. Reprinted from Nanomed, I3, Yang J, Gong X, Fang L, et al. Potential of $\mathrm{CeCl} 3 @ \mathrm{mSiO} 2$ nanoparticles in alleviating diabetic cataract development and progression, 147-II55, Copyright 2017, with permission from Elsevier. ${ }^{110}$ 
Notably, administering these nanoparticles is invasive, as $\mathrm{CeCl}_{3} @ \mathrm{mSiO}_{2}$ nanoparticle is an intraperitoneal injection, ${ }^{110}$ and PCNP is a subconjunctival injection. ${ }^{111}$ Therefore, studies are necessary to optimize potential noninvasive nanotechnology-based DDS to prevent diabetic cataract.

\section{Diabetic Retinopathy}

Diabetic retinopathy (DR) is one of most common microvascular complications of DM, and is the main cause of blindness in the working-age population. The pathological mechanisms of DR include hyperglycemia and lipid disorder. ${ }^{112}$ Quercetin has been isolated from leaves and grains, and is reported to have anti-diabetic activities. Thus, quercetin has been traditionally used to treat DM and its complications. ${ }^{113}$ However, poor bioavailability and multiple biological interactions are the major challenges of phytomedicines. ${ }^{114}$ Wang et al reported that intravitreal injection of quercetin coated with a freezedried nano-formulation had significant therapeutic effects against DR, and reduced lipid peroxidation in a zebrafish model, one of the disadvantages of nano-formulations is that they do not achieve target cell specificity. ${ }^{115}$ Therefore, Wang et al used cell-specific promoters to deliver specific retinal cell types, such as retinal pigment epithelium, rod cells, cone cells, and ganglion cells, using liposome-protamine-DNA complex (LPD)mediated gene delivery loaded in lipid-based nanoparticles by a two-step packaging technology employing a multilayering method. ${ }^{116}$ These findings indicate that peptide-modified LPD nanoparticles can be delivered for ocular gene therapy of retinal diseases including DR.

\section{Age-Related Macular Degeneration}

Age-related macular degeneration (AMD) is a major cause of blindness in the developed world and choroidal neovascularization (CNV) and geographic atrophy are serious and potentially devastating complications of the disease. ${ }^{117}$ Many studies have shown that nano-carrier DDSs have potential to treat AMD (Table 4). However, these studies are still in the preliminary stage. Therefore, further studies are needed to develop novel formulations. Unlike anterior segment drugs, posterior segment drugs must overcome several ocular barriers before reaching the target site. For example, anti-VEGF drugs are given through an intravitreal injection, and even though the delivery is of small therapeutic molecules, there is still poor permeability. Nano-carrier DDSs improve the permeability of therapeutic agents across biological membranes and benefit therapeutics of $\mathrm{CNV}$ of the eye using both invasive and non-invasive techniques. ${ }^{118}$ Nanomedicine targets delivery and binds with the CNV site, and prolongs the release time of the therapeutic agent.

Kringle 5 (K5) is a natural anti-angiogenic peptide and a proteolytic fragment of plasminogen with a length of 80 amino acids. However, its anti-angiogenic effect is shortlived due to the short half-life of the K5 peptide in the vitreous and retina. $\mathrm{K} 5$ nanoparticles containing the $\mathrm{K} 5$ plasmid mediate continuous expression of $\mathrm{K} 5$ in the retina for up to 4 weeks. Jin et al used K5-carrying PLGA nanoparticles (K5-NP) to observe their effect on laser-induced CNV in rats. The results showed that K5-NP mediated the continuous expression of $\mathrm{K} 5$ in the retina (primarily in the inner retina) for up to 2 weeks. Interestingly, there was also high expression of $\mathrm{K} 5$ in the outer retina at the laser photocoagulation site. Intravitreal injection of K5-NP reduced the area of CNV, reduced the permeability of retinal blood vessels and the high expression of VEGF, and downregulated the expression of inflammatory factors, such as TNF- $\alpha$ and ICAM-1, and even weakened $\beta$-catenin aggregation. These results suggest that K5 has anti-inflammatory activity, and that K5-NPs have a sustained inhibitory effect on CNV. ${ }^{119}$

Very few studies have been conducted on treating AMD with nanotechnology in the past 5 years, and this should inspire more attention from researchers in the future.

\section{Retinopathy of Prematurity}

Retinopathy of prematurity (ROP) is a type of proliferative retinopathy that occurs in premature infants and lowweight infants. Premature birth can cause the retina to be exposed to a high partial pressure oxygen environment. The relative hypoxia generated in the body promotes the release of VEGF, which induces retinal angiogenesis, vitreous hemorrhage, and traction retinal detachment, leading to preventable causes of childhood blindness. ${ }^{120}$ A nanocarrier DDS has been developed for ROP in the last decade. In the study by Kim et al, gold was loaded onto nanoparticles and exhibited anti-VEGF-induced angiogenesis through blocked autophosphorylation of VEGF receptor-2 to inhibit extracellular signal-regulated kinase (ERK) $1 / 2$ activation in a ROP mouse model. ${ }^{121}$

\section{Retinoblastoma}

Retinoblastoma $(\mathrm{Rb})$ is one of the most common malignancies of children. Current therapeutic strategies for 


\begin{tabular}{|c|c|c|c|c|}
\hline 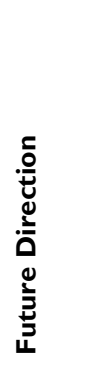 & 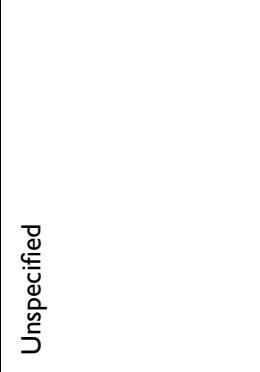 & 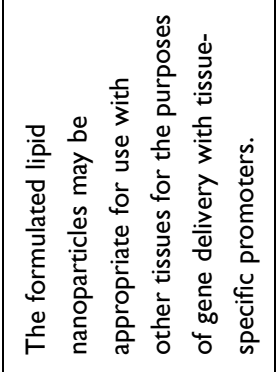 & 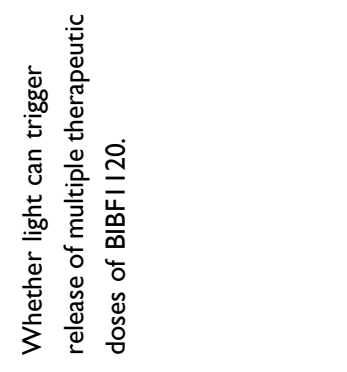 & 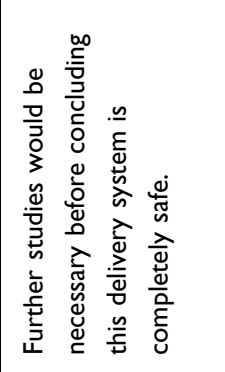 \\
\hline 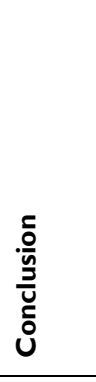 & 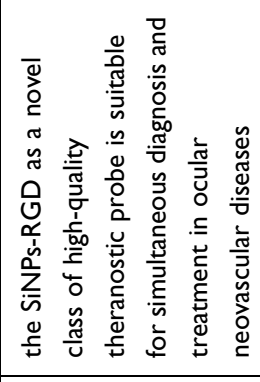 & 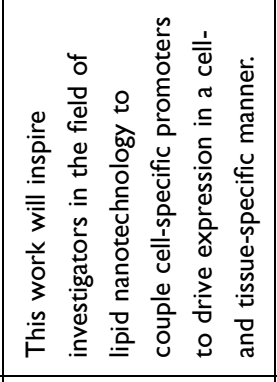 & 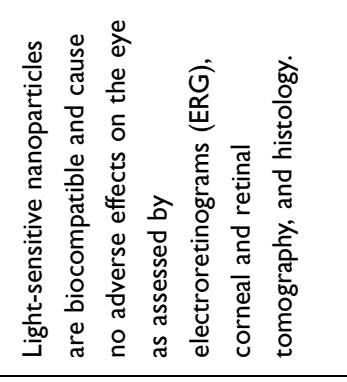 & 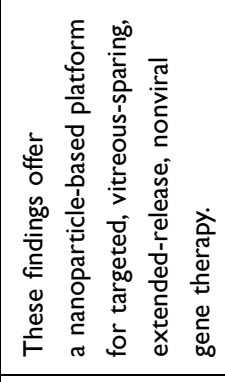 \\
\hline $\begin{array}{l}\frac{\underline{y}}{\bar{z}} \\
\stackrel{\Delta}{x}\end{array}$ & 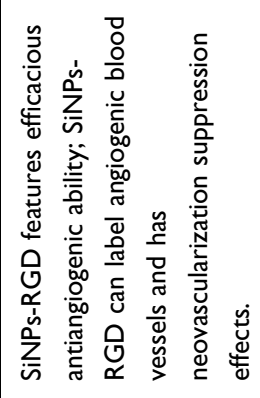 & 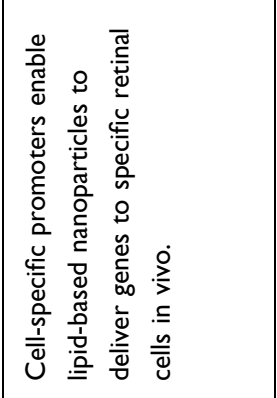 & 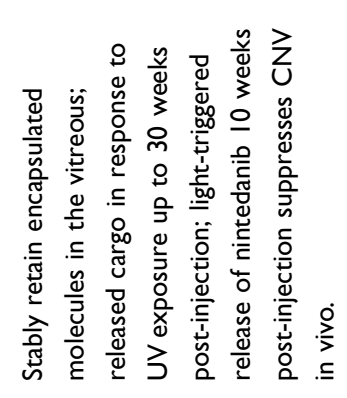 & 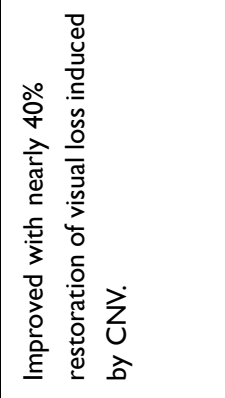 \\
\hline 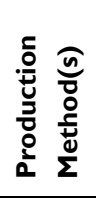 & 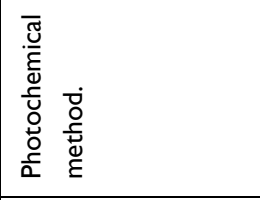 & 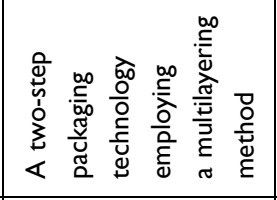 & 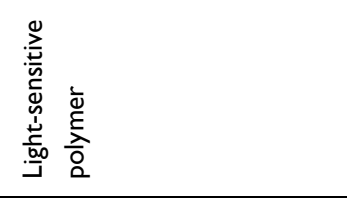 & 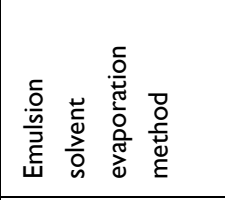 \\
\hline 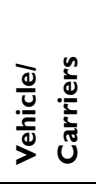 & 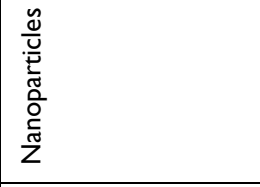 & 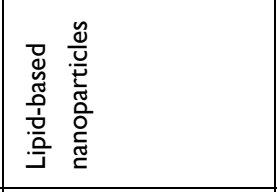 & 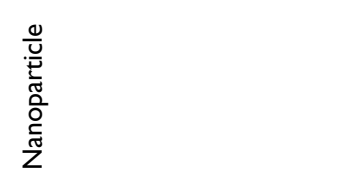 & 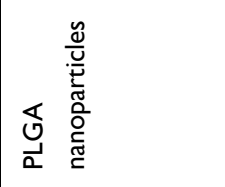 \\
\hline ב⿱艹⿹勹巳 & $\begin{array}{l}\frac{\bar{\delta}}{\underline{\underline{\bar{\nu}}}} \\
\end{array}$ & 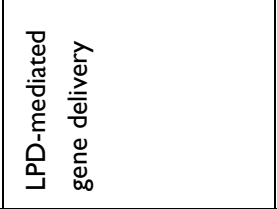 & 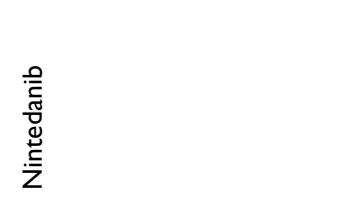 & 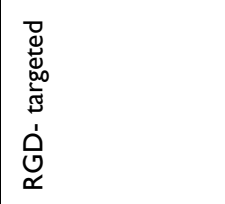 \\
\hline 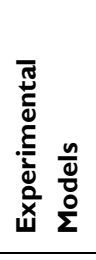 & 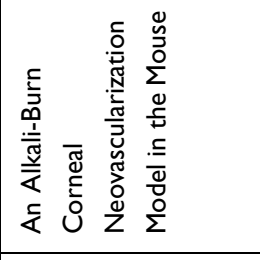 & 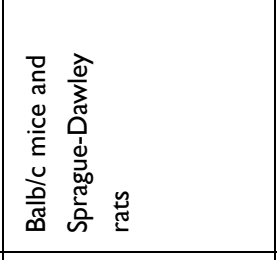 & 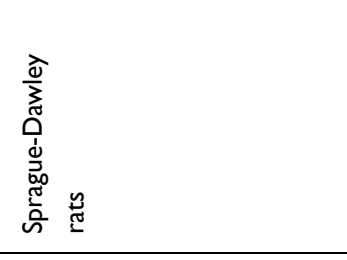 & 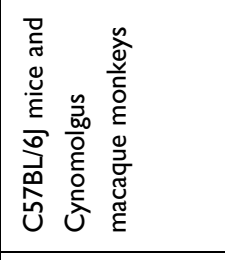 \\
\hline 总 & 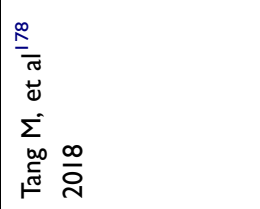 & 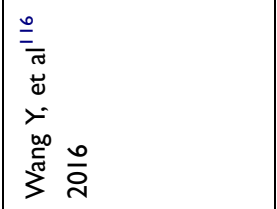 & 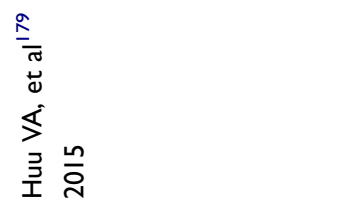 & 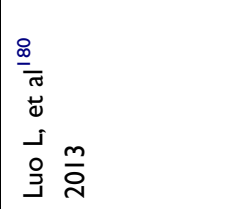 \\
\hline
\end{tabular}




\begin{tabular}{|c|c|c|c|}
\hline 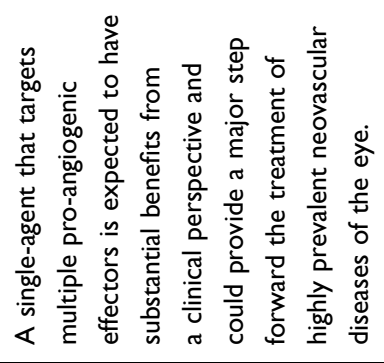 & 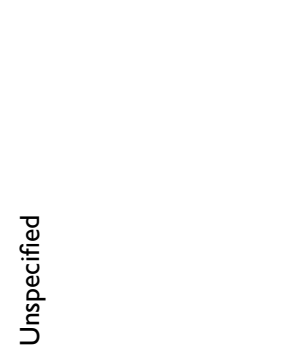 & 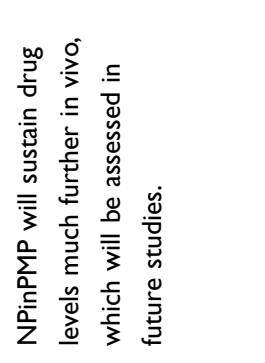 & 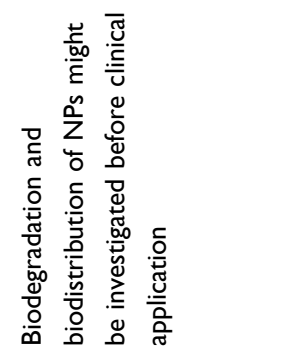 \\
\hline 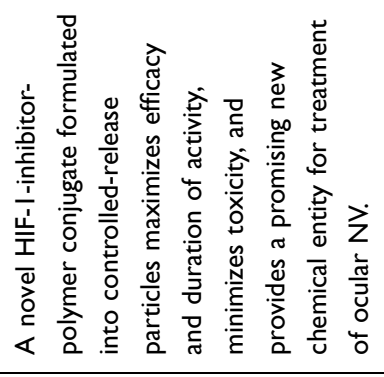 & 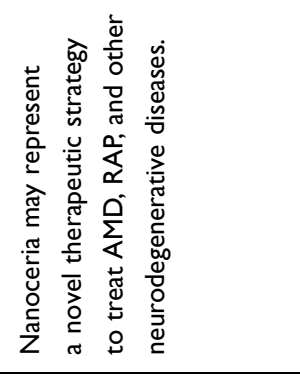 & 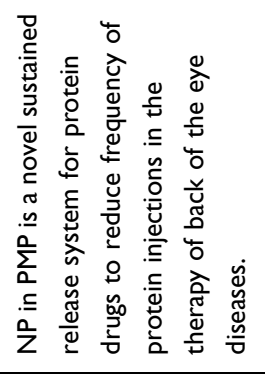 & 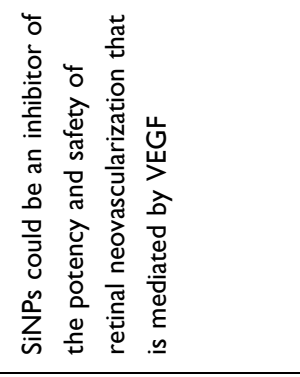 \\
\hline 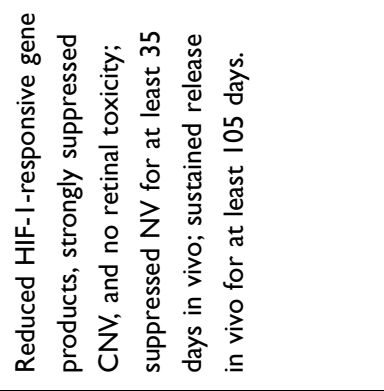 & 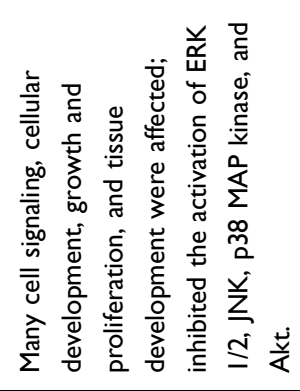 & 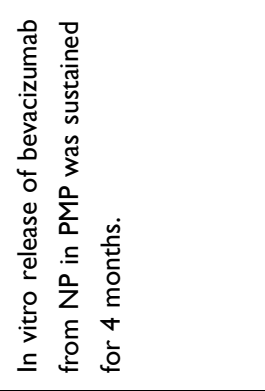 & 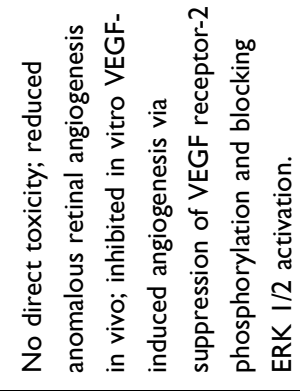 \\
\hline 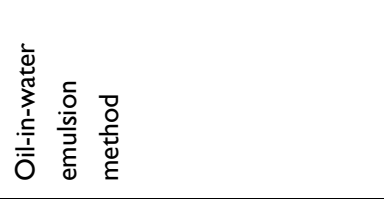 & 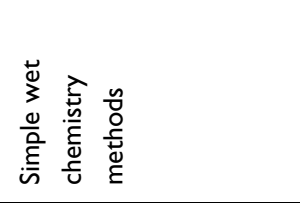 & 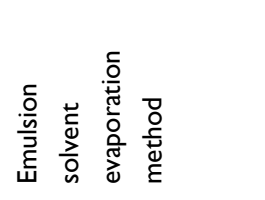 & 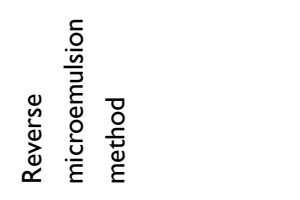 \\
\hline 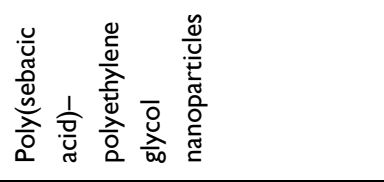 & 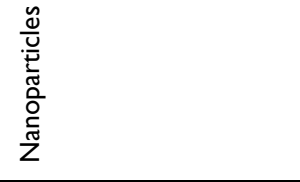 & 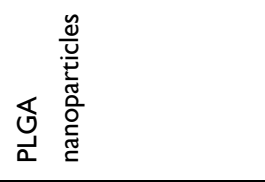 & 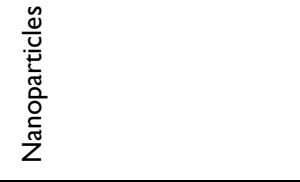 \\
\hline 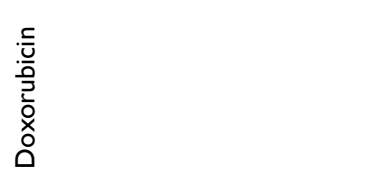 & 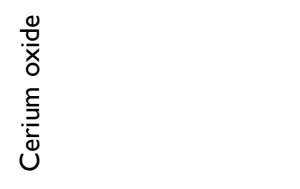 & 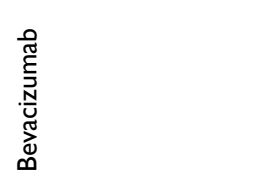 & 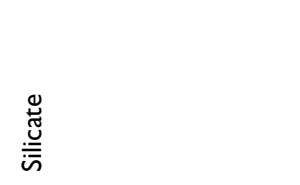 \\
\hline 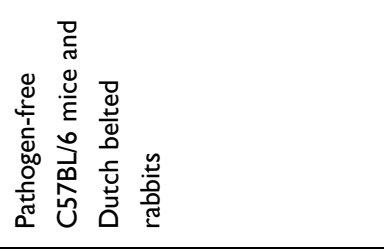 & 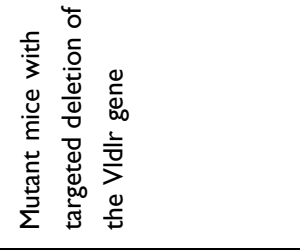 & 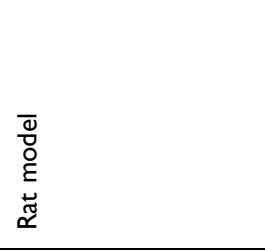 & 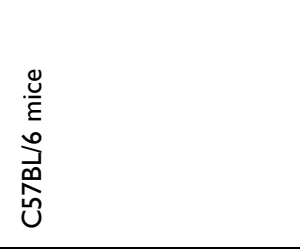 \\
\hline 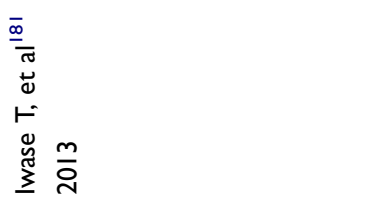 & 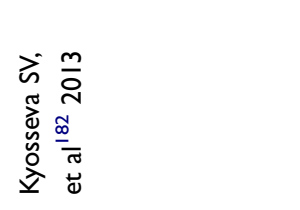 & 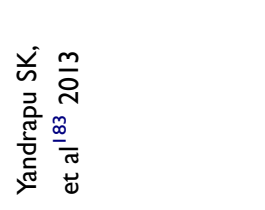 & 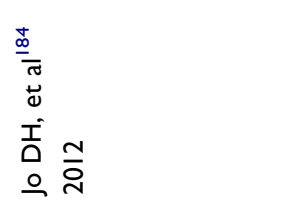 \\
\hline
\end{tabular}




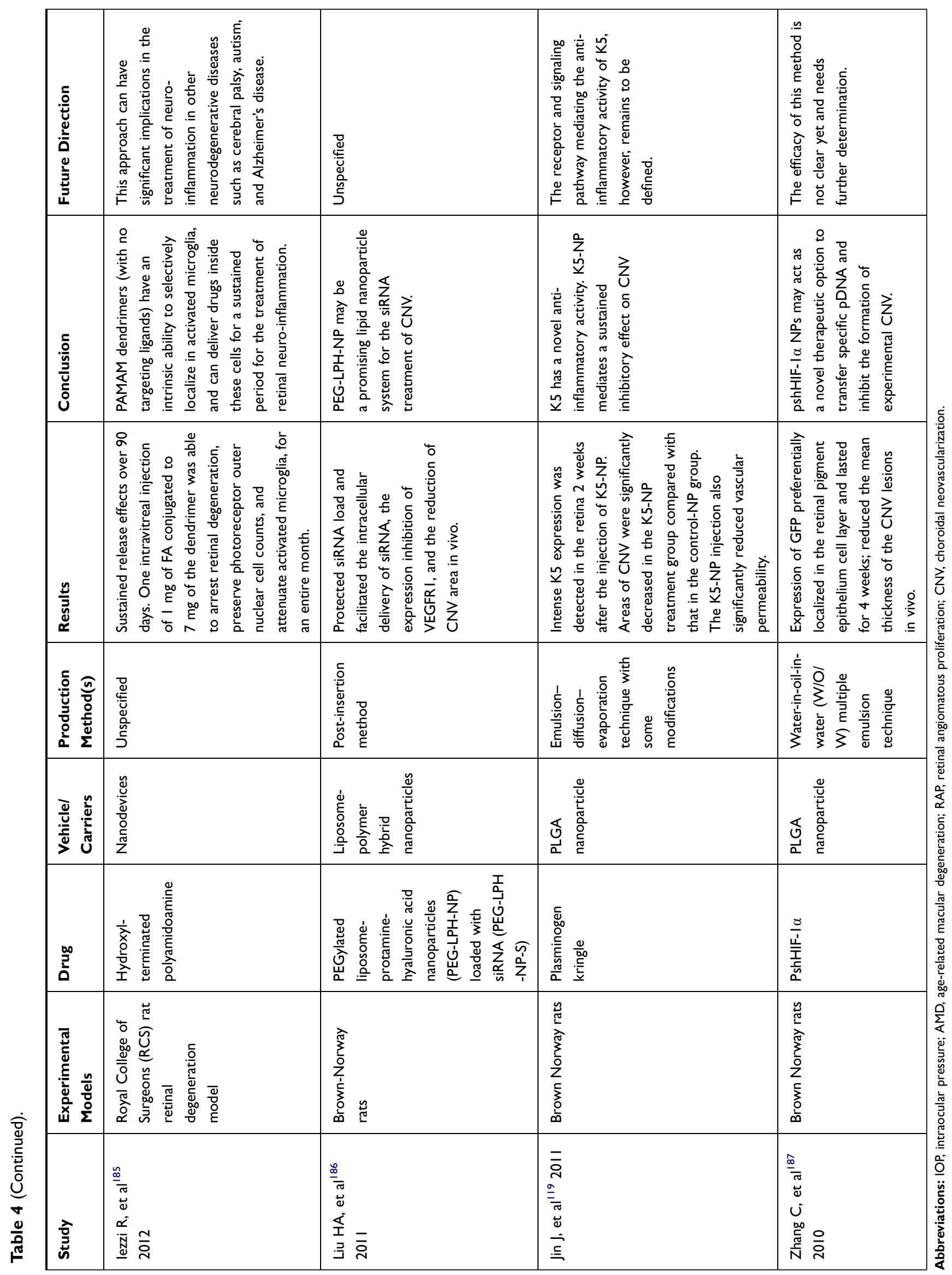


advanced $\mathrm{Rb}$ include the use of chemotherapeutic agents, such as topotecan. Nevertheless, the efficacy of topotecan in the treatment of advanced $\mathrm{Rb}$ is unsatisfactory. ${ }^{122}$ Additionally, the side-effects of long-term anticancer therapy on the health of children cannot be ignored. Consequently, preparing a novel sustained-release formulation of chemotherapeutic agents is of great importance. $\mathrm{Qu}$ et al produced topotecan-loaded mesoporous silica nanoparticles with folic acid conjugated on the surface to achieve superior anticancer efficacy (58\%) in human retinoblastoma cells (Y79). ${ }^{123}$ Further in-vivo experiments by Delrish proved this finding. ${ }^{124}$ In that study, thiolated chitosan nanoparticles were used to encapsulate topotecan and develop an intraocular tumor chemotherapeutic drug carrier with improved biocompatibility, controlled release, targeted delivery, and enhanced physical stability. ${ }^{124}$

\section{Optic Neuropathy}

Optic neuropathy is characterized by the loss of axons in the optic nerve and retina, followed by death of RGCs, resulting in irreversible blindness. ${ }^{125,126}$ RGCs are responsible for signal transmission from the retina to the brain and their death through apoptosis causes visual impairment. The mechanistic target of rapamycin (mTOR) pathway plays a critical role in the health and disease status of the retina and optic nerve. ${ }^{127}$ RGC damage is modulated by rapamycin through the mTOR pathway. ${ }^{128}$ Therefore, combining mTOR pathway stimulating biologics to protect RGCs would provide better control over cell pathway modulator delivery, release, clearance, and residency time. Eriksen et al prepared two liposome formulations using the film hydration method. Liposome aqueous cores were loaded with ciliary neurotrophic factor (CNTF) and insulin-like growth factor-I (IGF), while liposome membranes were loaded with the lipid-conjugated osteopontin peptide (OPP) and either production of anthocyanin pigment 2 (PAP2) or production of anthocyanin pigment 4 (PAP4). Finally, Eriksen et al found that these liposomes promoted neuroprotection by stimulating the mTOR pathway after a single injection in an N-methyl-d-aspartic acid mouse model with extensive retinal damage. Their findings demonstrated significant experimental upregulation of mTOR signaling promoting RGC survival and axon regeneration after an optic nerve crush injury. ${ }^{129}$

\section{Uveitis}

The uvea is composed of the iris, the ciliary body, and the choroid. Inflammation in any part of the uvea can be defined as uveitis. According to the main anatomical sites of ocular inflammation, uveitis can be further divided into anterior, intermediate, posterior, and panuveitis. Anterior uveitis is the main site of inflammation in the anterior segment (iris and ciliary body). Intermediate uveitis is defined as inflammation of the vitreous cavity and serrated margin. Posterior uveitis involves the retina and choroid. Inflammation in panuveitis includes all layers. The main symptoms of uveitis are scleral hyperemia, pain, and visual impairments. Treatments for uveitis include the application of anti-inflammatory and corticosteroids alone or in combination with other immunosuppressive agents. ${ }^{130}$

There is increasing interest in inducing positively charged nanocarriers by coating PLGA nanoparticles, cubosomes/cubosomal gels, or PVCL-PVA-PEG nanomicellar and cationic nanostructured lipid carriers (Table 5). Most recently, the water-insoluble corticosteroid triamcinolone acetonide (TA) was loaded onto cationic, nanostructured lipid carriers to treat anterior uveitis. The outcomes indicated that encapsulation of TA in the cationic lipid nanocarriers increases corneal penetration without increasing toxicity and increases the drug's bioavailability within the eye. ${ }^{131}$ Similar safety and efficiency were found in an evaluation of a topical nanomicellar formulation for the immunosuppressant drug everolimus. In that study, everolimus loaded positively charged Soluplus ${ }^{\circledR}$, a grafted copolymer of polyvinyl caprolactam-polyvinyl alcohol-polyethylene glycol (PVCL-PVA-PEG) of 65.55 $\mathrm{nm}$, was used to improve permeability through ocular epithelia with minimal or no irritation resulting in enhanced ocular bioavailability to treat posterior uveitis. $^{132}$

Cubosomes are lipid-based nanoparticles in which the membranes are entangled into a complex array of pores arranged in a cubic lattice. Compared with liposome analogs, these complex nanoparticles encapsulate a large amount of drug. ${ }^{133}$ The cubosomes were nanosized (100 to $278 \mathrm{~nm})$ with high encapsulation efficiency $(94 \pm 4.7 \%)$ of the lipophilic drug beclomethasone dipropionate. Transcorneal permeation and IOP measurement data suggested significant controlled release, enhanced corneal permeability, and greater relative bioavailability from cubosomes and the Cubo-gel in vitro. Furthermore, superior anti-inflammatory properties were recorded for the Cubo-gel to treat endotoxin-induced posterior uveitis in a rabbit model. ${ }^{134}$ 


\begin{tabular}{|c|c|c|c|c|c|c|c|}
\hline 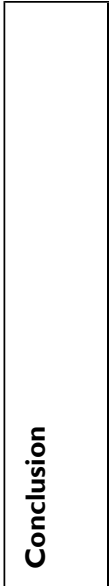 & 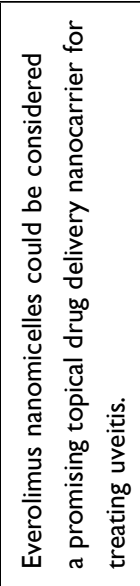 & 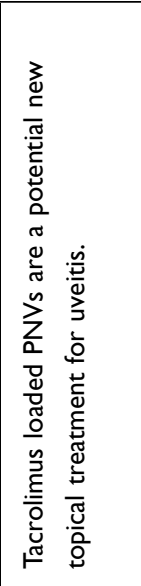 & 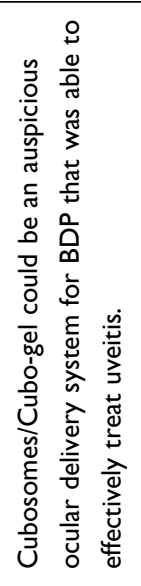 & 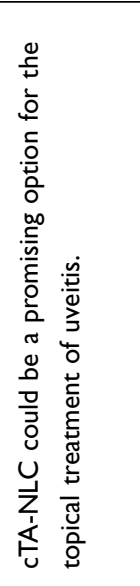 & 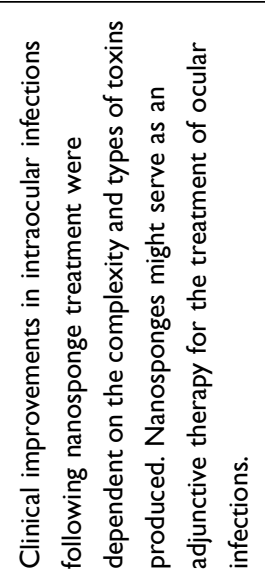 & 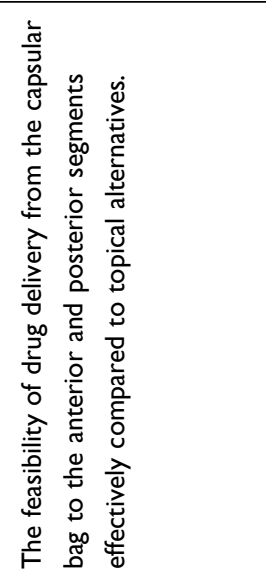 & 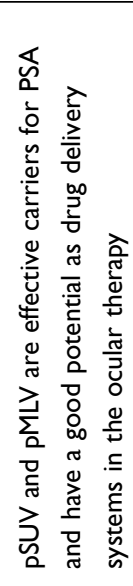 \\
\hline 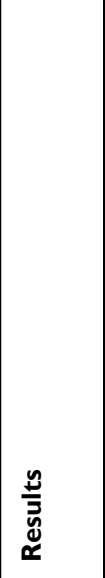 & 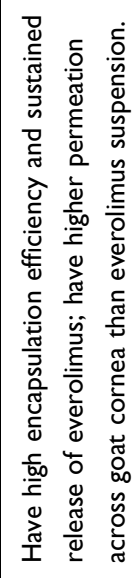 & 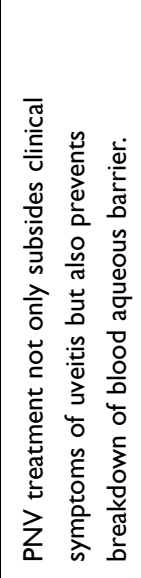 & 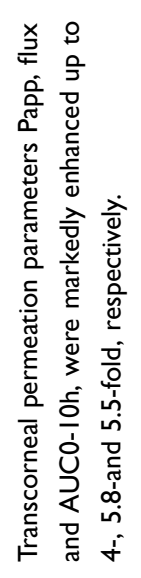 & 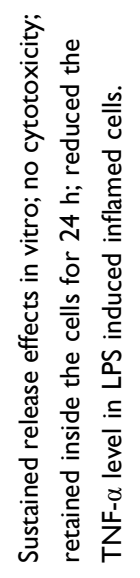 & 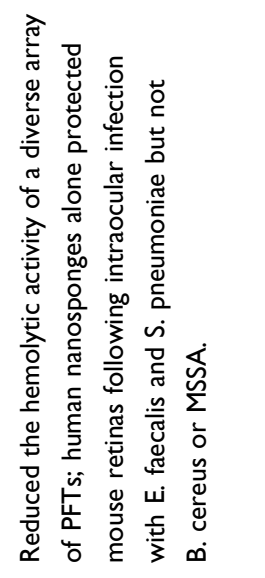 & 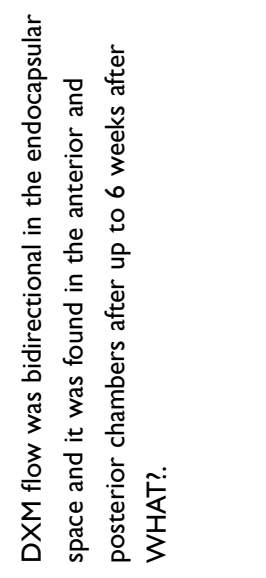 & 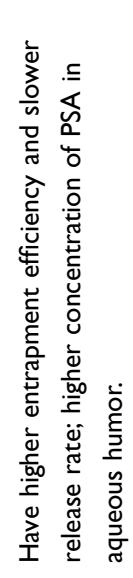 \\
\hline 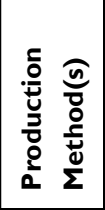 & 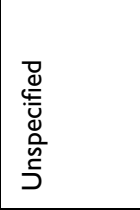 & 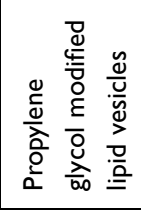 & 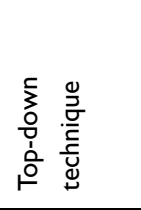 & 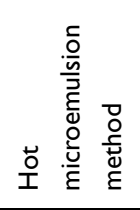 & 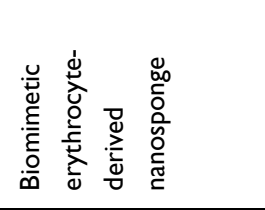 & 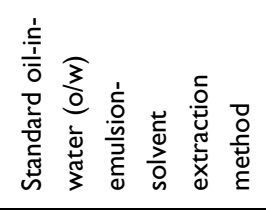 & 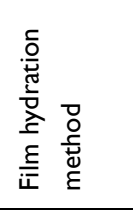 \\
\hline 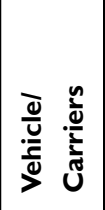 & 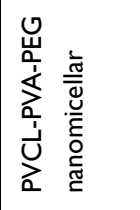 & 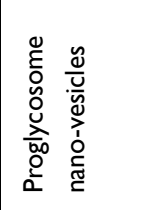 & 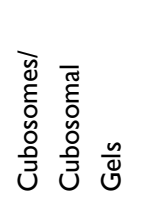 & 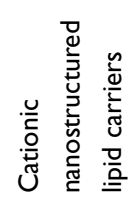 & 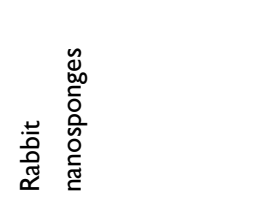 & 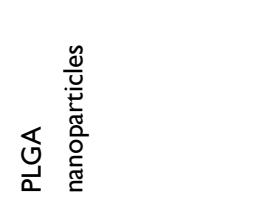 & 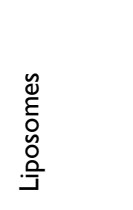 \\
\hline 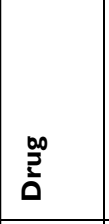 & 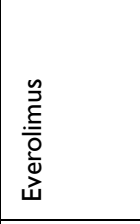 & 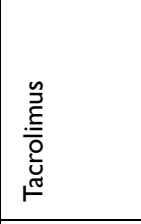 & 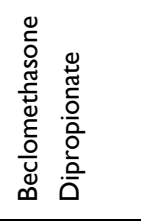 & 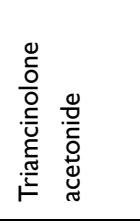 & 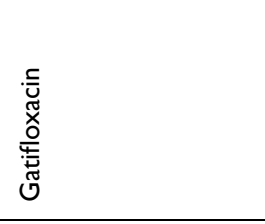 & 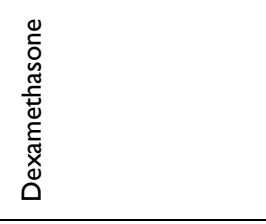 & 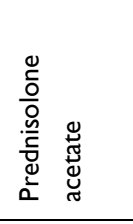 \\
\hline 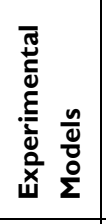 & 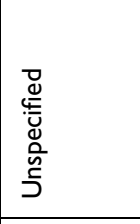 & 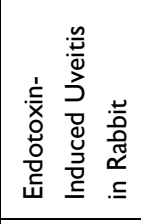 & 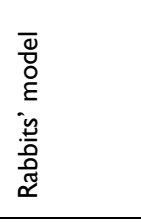 & 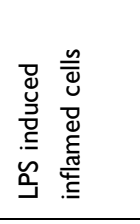 & 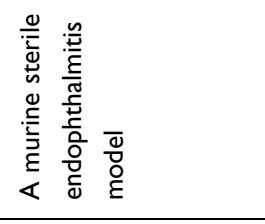 & 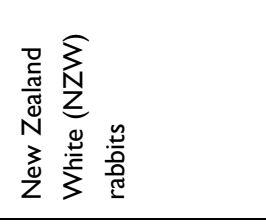 & 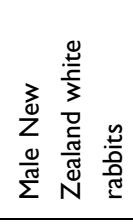 \\
\hline$\stackrel{D}{n}$ & 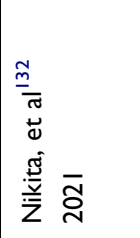 & 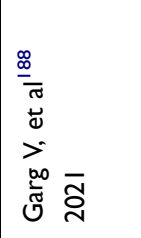 & 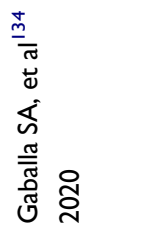 & 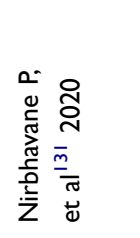 & 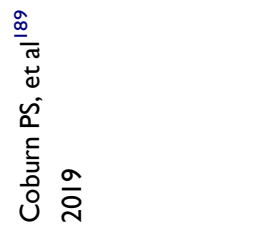 & 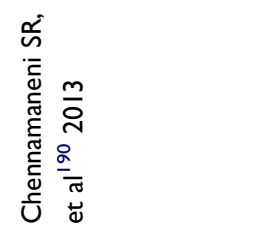 & 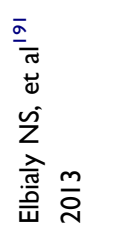 \\
\hline
\end{tabular}




\section{Vitreous Opacities}

Myopia and aging are the main causes of progressive aggregation of vitreous collagen, leading to vitreous opacity and severely affecting vision. The main complaint of vitreous opacity is the visual phenomenon of "floating view". ${ }^{135}$ As nanomedicine-based therapeutic solution can locally ablate "floaters" and highly reduce light energy, compared with traditional YAG laser therapy. Sauvage et al proposed hyaluronic acid (HA)-coated gold nanoparticles to localize them with greatly reduced light energy. In that study, the collagen aggregates were destroyed with approximately 1000 times less light energy after applying nanosecond laser pulses than typically used for YAG laser therapy, indicating that applying the laser to ablate the plasmonic nanoparticles conjugated with the vitreous opacity was a safer, faster, and more reliable treatment for eye diseases. ${ }^{136}$

\section{Anti-VEGF Agents and Novel Strategies Based on Nanotechnology}

Biopharmaceuticals and biotechnological therapeutics for treating angiogenesis in ocular disease are mainly based on intravitreal injection of anti-VEGF agents. ${ }^{137,138}$ The intravitreally injected anti-VEGF drugs improve visual acuity and macular morphology in most patients with pathological ocular angiogenesis, such as $\mathrm{CNV}$, proliferative diabetic retinopathy, ROP, and neovascular glaucoma. ${ }^{139-142}$ The VEGF inhibitors aflibercept, bevacizumab, conbercept, pegaptanib, and ranibizumab are approved treatments for certain eye diseases that occur particularly in the elderly, ${ }^{16}$ and bevacizumab is usually used "off-label" in clinical practice. ${ }^{143}$ Due to the limited residence time of antiVEGF drugs in the vitreous body, monthly intravitreal injections of these agents are recommended with 3-monthly loading dose injections followed by individualized therapy with "pro re nata" (PRN) or "treat and extend" (T\&E) regimens. ${ }^{144,145}$ However, repeated intravitreal injections increase the risk for adverse systemic and ocular effects of the anti-VEGF drugs, including a hypertensive crisis, ischemic stroke, retinal detachment, hemorrhage, cataract, or endophthalmitis. ${ }^{146-148}$ Therefore, strategies to reduce the frequency of intraocular injections of these anti-VEGF agents and extend their residence time in the vitreous body are still needed. The ocular residence time and release time of anti-VEGF medication is related to (1) the molecular size, (2) the formation of molecular conglomerates and (3) the presence of crystallizable fragments. ${ }^{147}$ Several nano- carriers have been used to load anti-VEGF drugs for sustained drug release, thereby minimizing the number of intravitreal injections required. To date, many efforts have been focused on the development of nano-carriers for bevacizumab and ranibizumab, which have demonstrated sustained release effects in vitro and a notably increased antiangiogenic efficacy of pathological ocular angiogenesis in vivo when both formulations are administered via intravitreal injection (Table 6). Furthermore, polymeric nanoparticles enhance permeation after surface modification with a cationic polymer. ${ }^{149,150}$ Recent advances in nanotechnology have offered many promising opportunities as an ocular anti-VEGF delivery system for pathological angiogenetic ocular diseases.

\section{Nanotechnology and Ophthalmic Drug Delivery System: Current Challenges}

Ocular nano-carrier DDSs are particularly versatile, as there has been tremendous progress improving drug stability, solubility, corneal permeability, and retention time, as well as increasing bioavailability and efficacy, but the exact mechanism of action, quality control, and safety evaluation deserve further attention. Notably, the vehicles used for nano-carrier DDSs should be further evaluated. For example, the toxicity of excipients and pollutants has been evaluated in vitro, while the inflammatory reaction has been evaluated in vivo. ${ }^{151}$ Additionally, the size of the mouse lens is quite different from that of humans; thus, drug permeability from the cornea to the target in the retina may be converse. Furthermore, the difficulty is to achieve efficient delivery of drugs to the posterior segment of the eye through non-invasive means. Moreover, the current research trend is to design and synthesize new carrier materials or use two or more methods to prepare composite systems.

\section{Liposomes}

Many problems have developed when applying liposome preparations in ophthalmology, such as low drug loading, leakage of embedded drugs, poor long-term stability, high cost of industrialized large-scale production, difficulty with sterilization, and relatively low formulation targeting. Moreover, the retention time of simple liposomes in the eye is not ideal, so the development of new liposome preparations is necessary. 


\begin{tabular}{|c|c|c|c|c|c|}
\hline 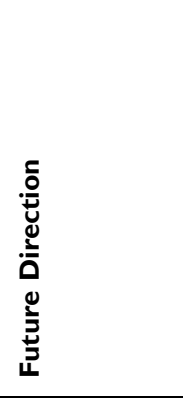 & 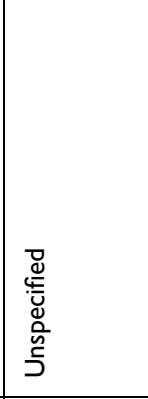 & 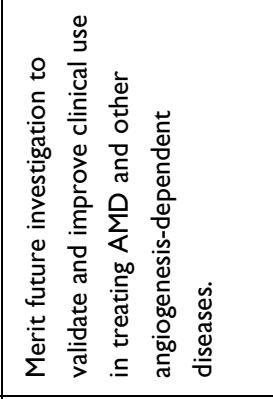 & 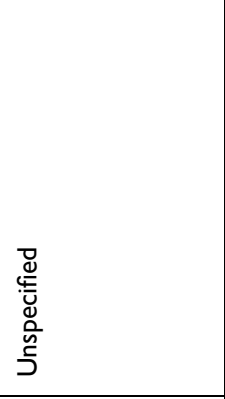 & 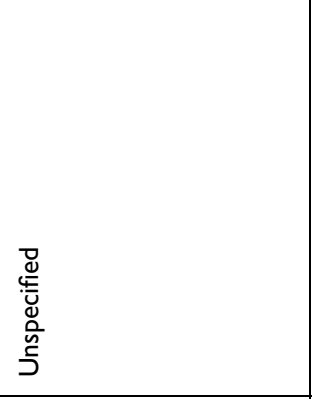 & 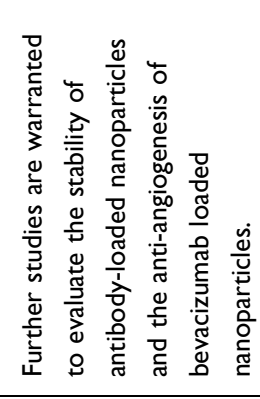 \\
\hline 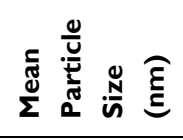 & $\frac{\infty}{\underline{\omega}}$ & 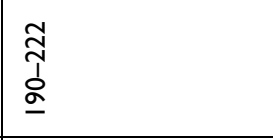 & q & $\begin{array}{l}\text { \& } \\
0 \\
\text { ò } \\
\end{array}$ & $\underline{\infty}$ \\
\hline 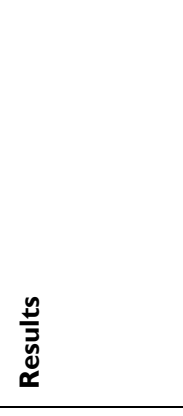 & 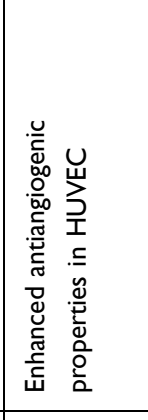 & 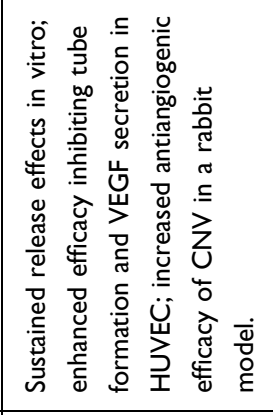 & 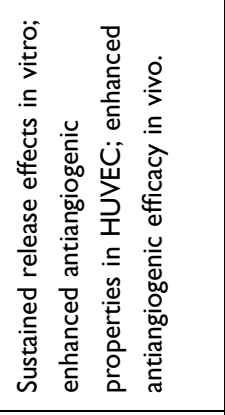 & 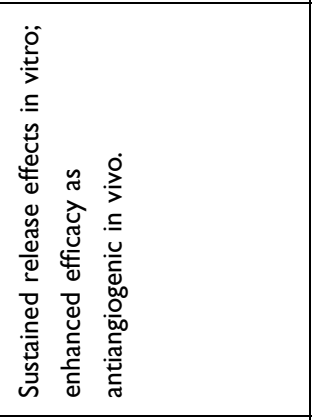 & 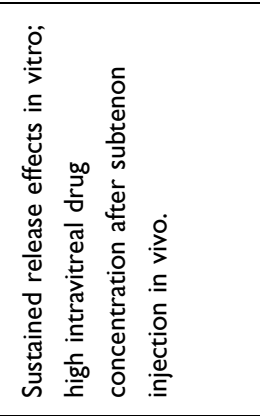 \\
\hline 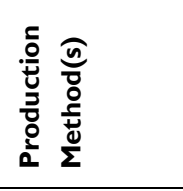 & 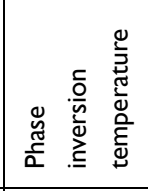 & 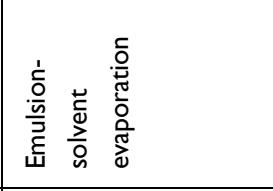 & 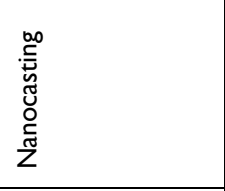 & 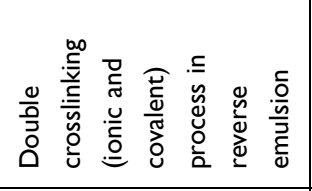 & 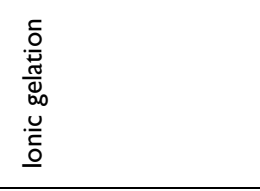 \\
\hline 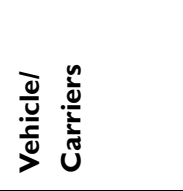 & 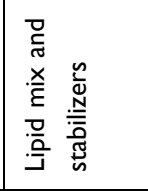 & 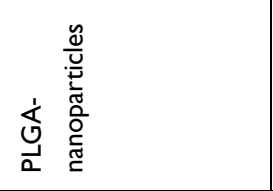 & 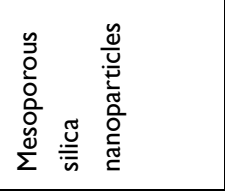 & 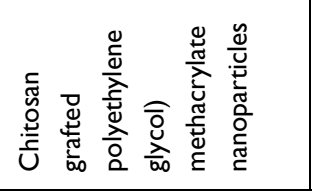 & 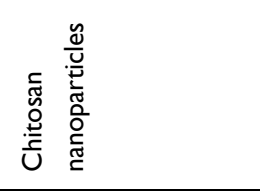 \\
\hline 紫 & 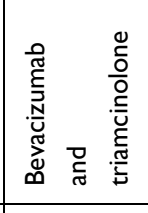 & 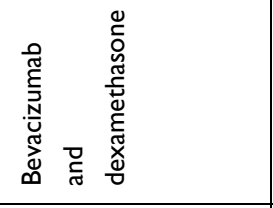 & 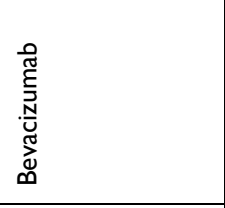 & 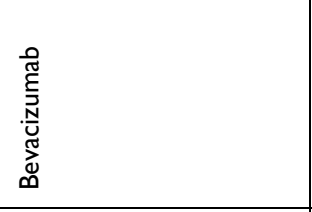 & 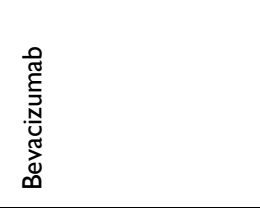 \\
\hline 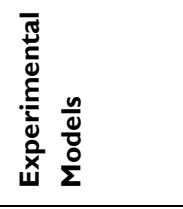 & $\begin{array}{l}u \\
\text { U. } \\
\text { د }\end{array}$ & 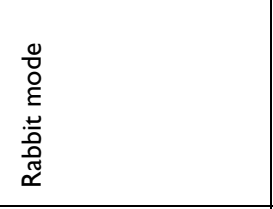 & 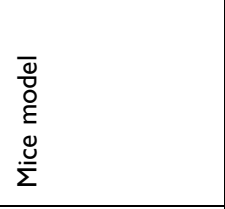 & 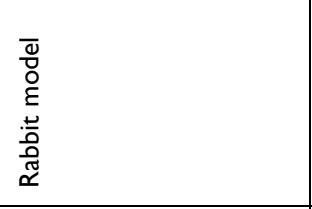 & 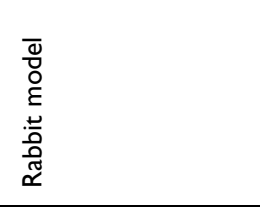 \\
\hline 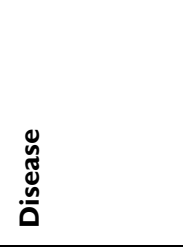 & 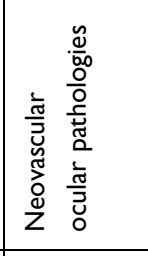 & u & 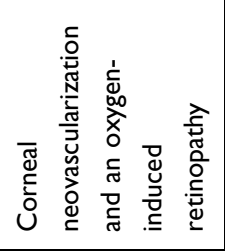 & 吕 & 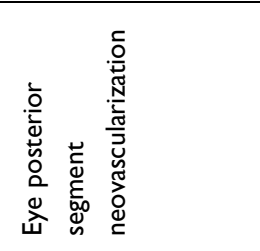 \\
\hline 密 & 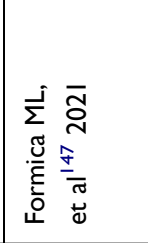 & 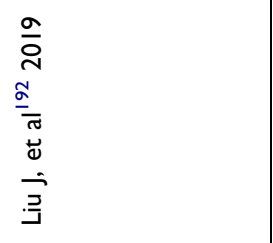 & 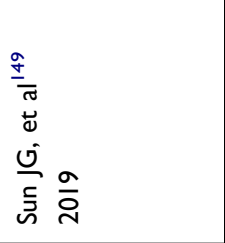 & 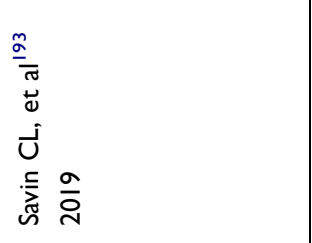 & 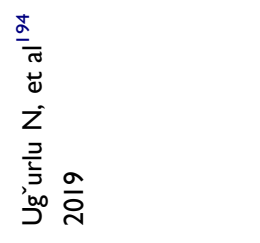 \\
\hline
\end{tabular}




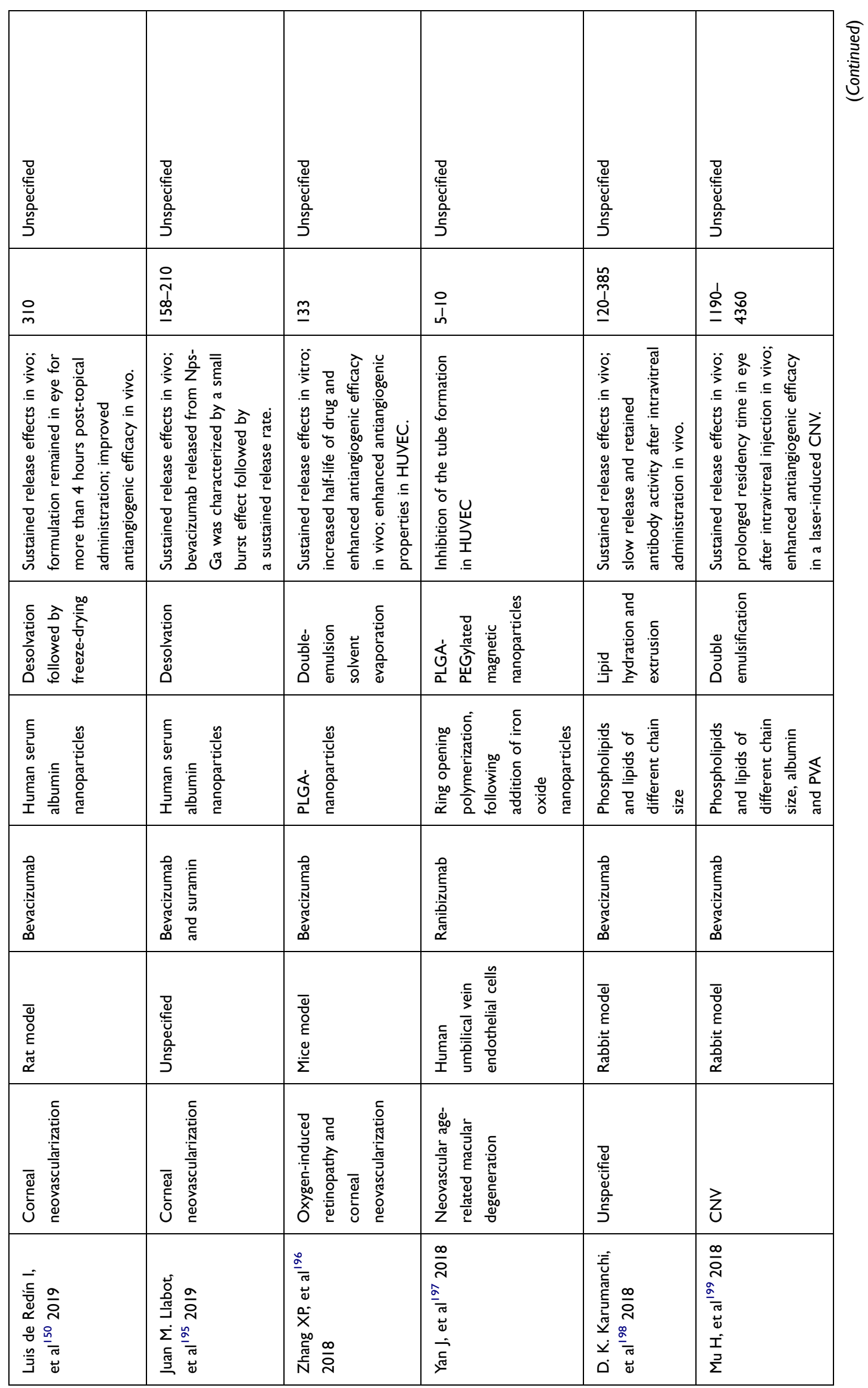




\begin{tabular}{|c|c|c|c|c|c|}
\hline 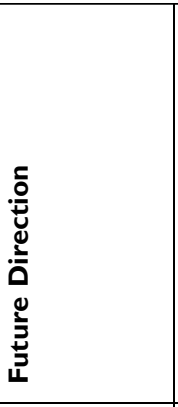 & 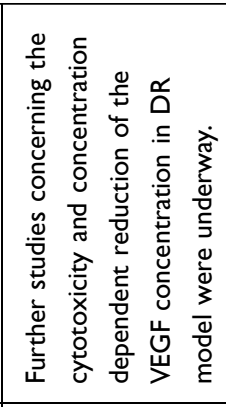 & 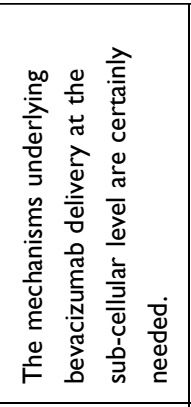 & 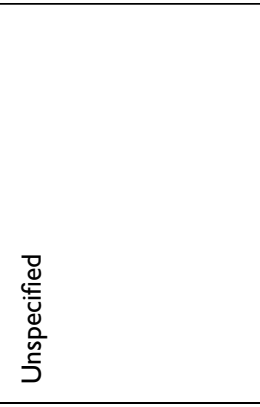 & 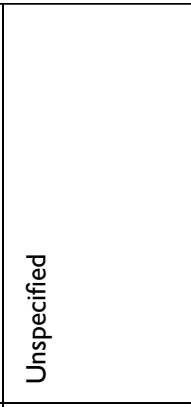 & 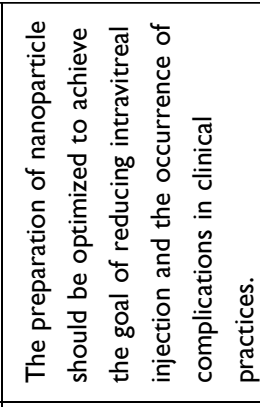 \\
\hline 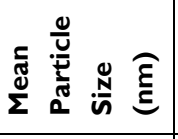 & ป & $\stackrel{\infty}{\stackrel{\infty}{\circ}}$ & $\begin{array}{l}\stackrel{0}{\stackrel{m}{1}} \\
\underline{1}\end{array}$ & $\stackrel{\circ}{\circ}$ & 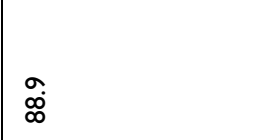 \\
\hline 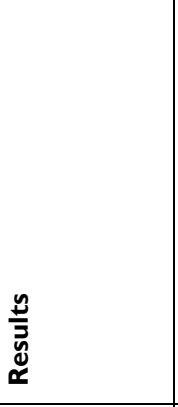 & 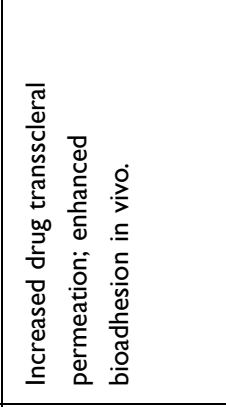 & 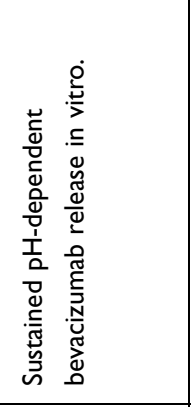 & 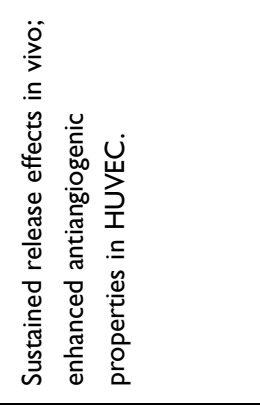 & 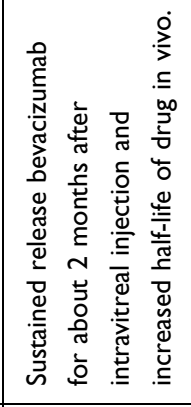 & 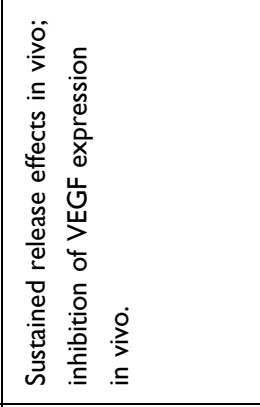 \\
\hline 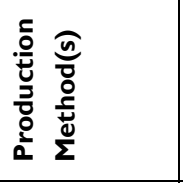 & 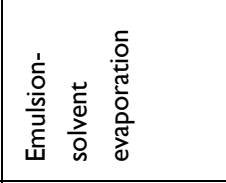 & 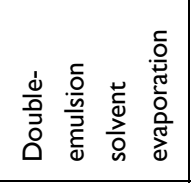 & 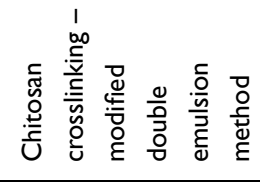 & 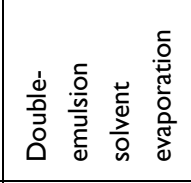 & 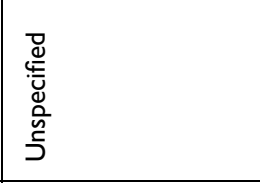 \\
\hline 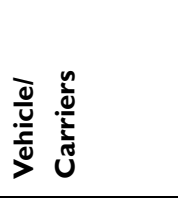 & 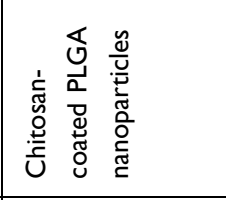 & 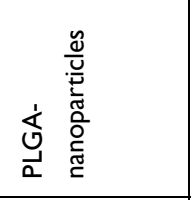 & 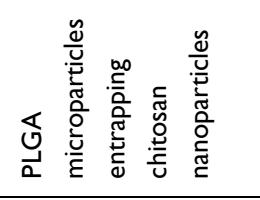 & 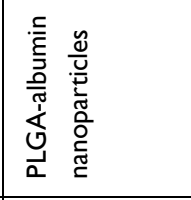 & 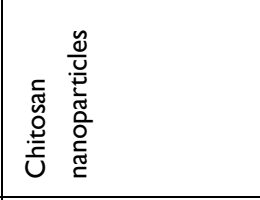 \\
\hline 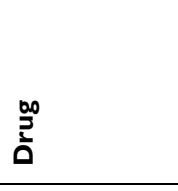 & 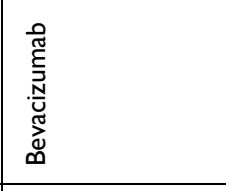 & 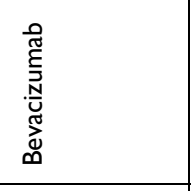 & 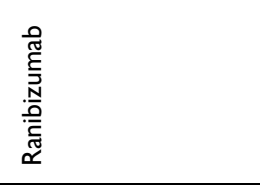 & 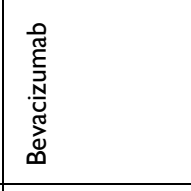 & 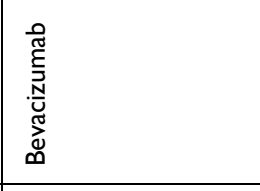 \\
\hline 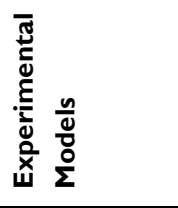 & 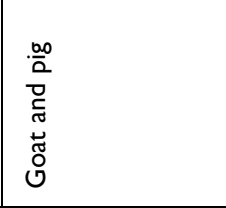 & 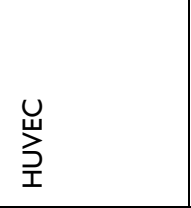 & 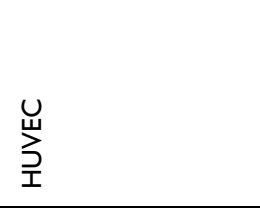 & 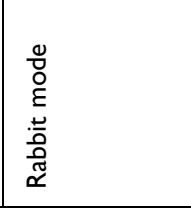 & 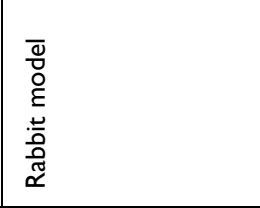 \\
\hline 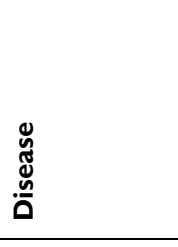 & 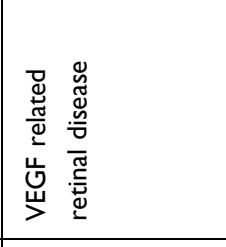 & 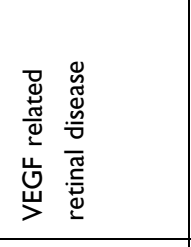 & 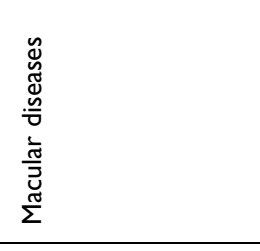 & 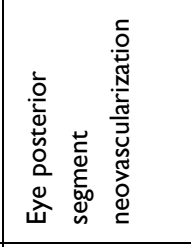 & 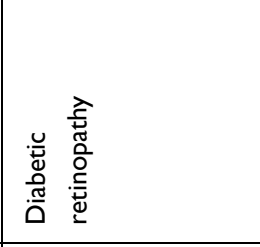 \\
\hline 惫 & 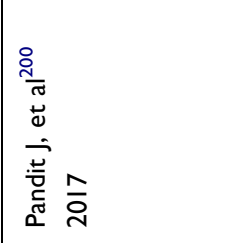 & 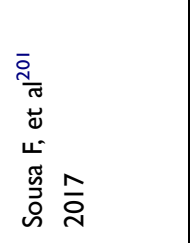 & 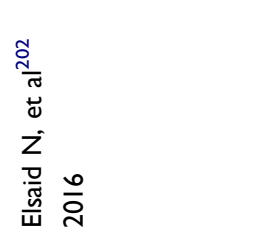 & 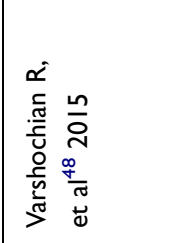 & 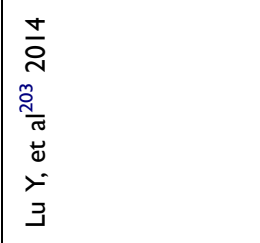 \\
\hline
\end{tabular}




\section{Nano-Suspensions}

Nano-suspensions, particularly cationic suspensions, are suitable for ocular administration of poorly soluble and poorly absorbed drugs. However, most of the suspending agents for nano-suspensions are surfactants, which may be irritating and toxic to the eyes. Therefore, encapsulating the nano-suspension into a suitable gel matrix or bioadhesive matrix, or even preparing an ophthalmic implant, may produce superior sustained release effects. In addition, the stability of a nano-suspension is insufficient compared with other colloidal particle systems, and storage time is shorter under the same conditions.

\section{Microemulsions/Nanoemulsions}

Micro and nanoemulsions also used as ophthalmic preparation carriers, but droplet size, long-term stability, and the toxicity caused by the large number of surfactants and co-surfactants restrict their wide application. Therefore, it is necessary to focus on the irritation caused by nanoemulsions.

\section{Nanomicelles}

PLGA nanomicelles have problems, such as relatively low drug loading, unsuitable release rate control, and difficulty in large-scale production, which have also become an important obstacle to their wide application in sustained drug release. In addition, PLGA nanomicelles contact or enter the eye as a foreign body, and their potential toxicity to eye tissues requires further study.

\section{Polymeric and Lipid Nanoparticles}

Polymeric and lipid nanoparticles have a strong carrying capacity for fat-soluble substances, but insufficient carrying capacity for water-soluble substances. To achieve an optimal effect in the case of topical nano-formulations, it is highly desirable to engineer bioadhesive/mucoadhesive nano-systems to enhance the reactivity and bioavailability of nano-systems in the ocular cul-de-sac. ${ }^{152}$

\section{Anti-VEGF Agents}

The main challenges for an anti-VEGF agent delivery system based on nanotechnology focus on loading molecules that maintain their biological activity after being released from the nanoparticle system, and studying formulation stability, pharmacokinetics, and efficacy in in vivo and in vitro models. ${ }^{153}$

\section{Future Prospects}

Nanotechnology-based therapeutics have revolutionized the prevention of ocular disorders. Although there is a distinct advantage over commonly used ocular administration routes (intravitreal, topical, systemic, and periocular), all approaches are still limited to pre-clinical studies with several challenges need to be overcome, eg, largescale manufacturing, and late phase clinical trials to enable scholars to achieve robust findings and evidence. Furthermore, future development of an ideal nanoscale clinical drug delivery vehicle should focus on the heterogeneous manifestations of the disease, such as the etiology and pathogenesis. The effects of particle size, surface charge, and composition and aggregation on the pharmacokinetic and pharmaco-toxic profiles need to be determined.

Using active targeting ligands to modify nanoformulations or incorporating penetration enhancers into composite systems may be an effective method for ocular nano-carrier DDSs to deliver drugs to the posterior segment of the eye, but studies concerning the uptake of targeted nano-carriers in the treatment of posterior-segment ocular diseases are scarce. Studies are needed to fill these gaps and overcome the problems associated with nano-carriers functionalized with multiple ligands of cells and tissues of the posterior eye as vehicles.

Many excellent nano-carrier DDS therapeutics require innovation to treat ocular disorders. For example, myopia also known as short-sightedness or nearsightedness, has become a serious public health problem worldwide. The number of individuals with myopia has reached nearly 2 billion worldwide, which includes 277 million individuals with high myopia. ${ }^{154}$ Pharmacological strategies to control myopia include the non-specific anti-muscarinic agent atropine ${ }^{155}$ and the M1 receptor-specific antagonist pirenzepine. ${ }^{156}$ Atropine is the most widely studied agent for this indication, and once-daily topical low-concentration atropine eye drops effectively control the development of myopia. ${ }^{157,158}$ However, there is little evidence on the ocular bioavailability of low-concentration eye drops. Due to the limited retention time of the drug in the conjunctival sac and low bioavailability, a nano-carrier DDS should be developed to load topical lowconcentration atropine. The drug may achieve sustained release and improve the curative effect, which has potential value for the control of myopia. 


\section{Conclusion}

The penetration and delivery of drugs is particularly difficult under the complex and multiple physiological ocular barriers. Traditional drug preparations, such as eye drops, have a good therapeutic effect for anterior eye diseases, but there are some shortcomings, such as low bioavailability, frequent drug use, poor permeability. Intravitreal injection of drugs overcomes the ocular barrier for posterior eye diseases and achieves a therapeutic effect, but it has a high risk of various complications and adverse reactions which have brought great challenges to the treatment of diseases. Therefore, research and development of new DDSs are needed to better deliver drugs to the eyes and prolong the duration of drugs in the eyes.

Scientists have actively studied a variety of nanocarrier DDSs, such as liposomes, nanoemulsions, nanoparticles, nano-suspensions and nanomicelles, which show excellent delivery potential in in vitro and in vivo animal models, and prolong the retention time in the eye, suggesting that nano-carrier DDSs are a good application prospect in ocular drug therapy approaches and have potential value for further clinical development.

\section{Abbreviations}

5-FU, fluorouracil; AMD, Age-related macular degeneration; AUC, area under the curve; $\mathrm{BAB}$, blood-aqueous barrier; BRB, blood retinal barrier; $\mathrm{CeCl} 3 @ \mathrm{mSiO} 2$, prepared cerium (III) chloride ( $\mathrm{CeCl} 3)$-loaded mesoporous silica; $\mathrm{CeO} 2-\mathrm{NPs}$, synthesized cerium oxide nanoparticles; CH-MEs, chitosan-coated cationic microemulsions; $\mathrm{CNTF}$, ciliary neurotrophic factor; CNV, choroidal neovascularization; CNV, corneal neovascularization; CsA, cyclosporine; CT, Nano-computed tomography; DDSs, drug delivery systems; DED, Dry eye disease; DM, diabetes mellitus; DR, Diabetic retinopathy; DSP, dexamethasone sodium phosphate; DSP-Zn-NP, dexamethasone sodium phosphate using zinc ion bridging; EAU, experimental autoimmune uveoretinitis; ERK1/2, extracellular signal-regulated kinase; HA, hyaluronic acid; IC50, the $50 \%$ inhibitory concentration; ICAM-1, intercellular adhesion molecule-1; IGF, insulinlike growth factor-I; IOL, intra ocular lens; IOP, intraocular pressure; K5, Kringle 5; K5-NP, K5-carrying PLGA nanoparticles; LECs, lens epithelial cells; LPD, liposome-protamine-DNA complex; MEs, microemulsions; mPEG-PCL, glycol-block-polycaprolactone; mTOR, mechanistic target of rapamycin; NEs, nanoemulsion; NSAIDs, non-steroidal anti-inflammatory drugs; OPP, osteopontin peptide; PAP2, production of anthocyanin pigment 2; PAP4, production of anthocyanin pigment 4; PCNPs, synthesized cerium oxide nanoparticles $(\mathrm{CeO} 2-$ NPs) coated with PEG-PLGA; PEG, poly (ethylene glycol); PLGA, poly lactic co-glycolic acid; PRN, "pro re nata"; PVCL-PVA-PEG, polyvinyl caprolactampolyvinyl alcohol-polyethylene glycol; $\mathrm{Rb}$, Retinoblastoma; RGC, retinal ganglion cell; ROP, Retinopathy of prematurity; ROS, reactive oxygen species; siRNA, small interfering RNA; STZ, streptozotocin; $\mathrm{T} \& \mathrm{E}$, "treat and extend"; TA, triamcinolone acetonide; TNF- $\alpha$, tumor necrosis factor- $\alpha$.

\section{Acknowledgments}

The authors would like to acknowledge financial support from the National Natural Science Foundation of China (No. 81300783; 82003882), China Postdoctoral Science Foundation (No. 2019TQ0358; 2019M661162), LiaoNing Revitalization Talents Program (No. XLYC1807082), Shenyang Young and Middle-aged Science and Technology Innovation Talent Support Program (grant number RC190146).

\section{Disclosure}

The authors declare no conflicts of interest in this work.

\section{References}

1. Ensign LM, Cone R, Hanes J. Nanoparticle-based drug delivery to the vagina: a review. $J$ Controlled Release. 2014;190:500-514. doi:10. 1016/j.jconrel.2014.04.033

2. Adelli GR, Bhagav P, Taskar P, et al. Development of a $\Delta 9$-tetrahydrocannabinol amino acid-dicarboxylate prodrug with improved ocular bioavailability. Invest Ophthalmol Vis Sci. 2017; 58:2167-2179. doi:10.1167/iovs.16-20757

3. Weinreb RN, Robinson MR, Dibas M, Stamer WD. Matrix metalloproteinases and glaucoma treatment. $J$ Ocul Pharmacol Ther. 2020;36:208-228. doi:10.1089/jop.2019.0146

4. DeSantis L. Preclinical Overview of Brinzolamide. Surv Ophthalmol. 2000;44:S119-S29. doi:10.1016/S0039-6257(99)00108-3

5. Mehta M, Deeksha SN, Vyas M, et al. Interactions with the macrophages: an emerging targeted approach using novel drug delivery systems in respiratory diseases. Chem Biol Interact. 2019;304:10-19. doi:10.1016/j.cbi.2019.02.021

6. Drescher S, van Hoogevest P. The phospholipid research center: current research in phospholipids and their use in drug delivery. Pharmaceutics. 2020;1:12.

7. Zheng B, McClements DJ. Formulation of more efficacious curcumin delivery systems using colloid science: enhanced solubility, stability, and bioavailability. Molecules. 2020;1:25.

8. Yavuz B, Pehlivan SB, Unlü N. Dendrimeric systems and their applications in ocular drug delivery. ScientificWorldJournal. 2013;2013:732340. doi:10.1155/2013/732340 
9. Bozzuto G, Molinari A. Liposomes as nanomedical devices. Int J Nanomedicine. 2015;975-999. doi:10.2147/IJN.S68861

10. Baujat B, Krastinova D, Bach CA, Coquille F, Chabolle F. Orbital morphology in exophthalmos and exorbitism. Plast Reconstr Surg. 2006;117:542. doi:10.1097/01.prs.0000200773.00268.56

11. Gupta A, Kafetzis KN, Tagalakis AD, Yu-Wai-Man C. RNA therapeutics in ophthalmology - translation to clinical trials. Exp Eye Res. 2021;205:108482. doi:10.1016/j.exer.2021.108482

12. Fischer N, Narayanan R, Loewenstein A, Kuppermann BD. Drug Delivery to the posterior segment of the eye. Eur J Ophthalmol. 2010;21:20-26. doi:10.5301/EJO.2010.6051

13. Braakhuis AJ, Donaldson CI, Lim JC, Donaldson PJ. Nutritional Strategies to Prevent Lens Cataract: current Status and Future Strategies. Nutrients. 2019;1:11.

14. Xu X, Al-Ghabeish M, Rahman Z, et al. Formulation and process factors influencing product quality and in vitro performance of ophthalmic ointments. Int J Pharm. 2015;493:412-425. doi:10. 1016/j.ijpharm.2015.07.066

15. Shi $\mathrm{XH}$, Wei WB. [Research progress of treatment strategies for choroidal neovascularization secondary to pathological myopia] Zhonghua Yan Ke Za Zhi. 2019;55:791-795. Chinese.

16. Stewart MW. Extended duration vascular endothelial growth factor inhibition in the eye: failures, successes, and future possibilities. Pharmaceutics. 2018;10.

17. Kiser PD, Zhang J, Badiee M, et al. Rational tuning of visual cycle modulator pharmacodynamics. J Pharmacol Exp Ther. 2017;362:131-145. doi:10.1124/jpet.117.240721

18. Kesav NP, Young CEC, Ertel MK, Seibold LK, Kahook MY. Sustained-release drug delivery systems for the treatment of glaucoma. Int J Ophthalmol. 2021;14:148-159. doi:10.18240/ ijo.2021.01.21

19. Sharaf MG, Cetinel S, Heckler L, Damji K, Unsworth L, Montemagno C. Nanotechnology-Based approaches for ophthalmology applications: therapeutic and diagnostic strategies. Asia Pac J Ophthalmol. 2014;3:172-180. doi:10.1097/APO.000000 0000000059

20. Yetisgin AA, Cetinel S, Zuvin M, Kosar A, Kutlu O. Therapeutic Nanoparticles and Their Targeted Delivery Applications. Molecules. 2020;25.

21. Vaishya RD, Khurana V, Patel S, Mitra AK. Controlled ocular drug delivery with nanomicelles. Wiley Interdiscip Rev Nanomed Nanobiotechnol. 2014;6:422-437. doi:10.1002/wnan.1272

22. Honda M, Asai T, Oku N, Araki Y, Tanaka M, Ebihara N. Liposomes and nanotechnology in drug development: focus on ocular targets. Int J Nanomedicine. 2013;8:495-503. doi:10.2147/ IJN.S30725

23. Yasukawa T, Ogura Y, Tabata Y, Kimura H, Wiedemann P, Honda Y. Drug delivery systems for vitreoretinal diseases. Prog Retin Eye Res. 2004;23:253-281. doi:10.1016/j.preteyeres.20 04.02 .003

24. Liu YC, Lin MT, Ng AHC, Wong TT, Mehta JS. Nanotechnology for the Treatment of Allergic Conjunctival Diseases. Pharmaceuticals. 2020;2:13.

25. Li Y, Dong H, Tao Q, et al. Enhancing the magnetic relaxivity of MRI contrast agents via the localized superacid microenvironment of graphene quantum dots. Biomaterials. 2020;250:120056. doi:10.1016/j.biomaterials.2020.120056

26. Srinivasarao DA, Lohiya G, Katti DS. Fundamentals, challenges, and nanomedicine-based solutions for ocular diseases. Wiley Interdiscip Rev Nanomed Nanobiotechnol. 2019;11:e1548. doi:10.1002/wnan. 1548

27. Liu B, Kang C, Fang F. Biometric Measurement of Anterior Segment: a Review. Sensors. 2020;20.

28. Khiev D, Mohamed ZA, Vichare R, et al. Emerging nano-formulations and nanomedicines applications for ocular drug delivery. Nanomaterials. 2021;11.
29. Man D, Słota R, Kawecka A, Engel G, Dyrda G. Liposomes modified by mono- and bis-phthalocyanines: a comprehensive EPR study. Eur Phys J E Soft Matter. 2017;40:63. doi:10.1140/ epje/i2017-11550-4

30. Almeida B, Nag OK, Rogers KE, Delehanty JB. Recent progress in bioconjugation strategies for liposome-mediated drug delivery. Molecules. 2020;25.

31. Man D, Słota R, Broda MA, Mele G, Li J. Metalloporphyrin intercalation in liposome membranes: ESR study. $J$ Biol Inorg Chem. 2011;16:173-181. doi:10.1007/s00775-010-0715-1

32. Almeida B, Nag OK, Rogers KE, Delehanty JB. Recent Progress in Bioconjugation Strategies for Liposome-Mediated Drug Delivery. Molecules. 2020;25(23):5672. doi:10.3390/molecules 25235672

33. Jensen GM, Hodgson DF. Opportunities and challenges in commercial pharmaceutical liposome applications. Adv Drug Deliv Rev. 2020;154:2-12. doi:10.1016/j.addr.2020.07.016

34. Lajunen T, Nurmi R, Kontturi L, et al. Light activated liposomes: functionality and prospects in ocular drug delivery. $J$ Control Release. 2016;244:157-166. doi:10.1016/j.jconrel.2016.08.024

35. Ebrahim S, Peyman GA, Lee PJ. Applications of liposomes in ophthalmology. Surv Ophthalmol. 2005;50:167-182. doi:10.1016/ j.survophthal.2004.12.006

36. Smolin G, Okumoto M, Feiler S, Condon D. Idoxuridineliposome therapy for herpes simplex keratitis. Am J Ophthalmol. 1981;91:220-225. doi:10.1016/0002-9394(81)90177-X

37. Magin RL, Hunter JM, Niesman MR, Bark GA. Effect of vesicle size on the clearance, distribution, and tumor uptake of temperature-sensitive liposomes. Cancer Drug Deliv. 1986; 3:223-237. doi:10.1089/cdd.1986.3.223

38. Barza M, Stuart M, Szoka F. Effect of size and lipid composition on the pharmacokinetics of intravitreal liposomes. Invest Ophthalmol Vis Sci. 1987;28:893-900.

39. Arroyo CM, Quinteros D, Cózar-Bernal MJ, Palma SD, Rabasco AM, González-Rodríguez ML. Ophthalmic administration of a 10-fold-lower dose of conventional nanoliposome formulations caused levels of intraocular pressure similar to those induced by marketed eye drops. Eur J Pharmacentical Sci. 2018;111:186-194. doi:10.1016/j.ejps.2017.09.024

40. Lai S, Wei Y, Wu Q, et al. Liposomes for effective drug delivery to the ocular posterior chamber. $J$ Nanobiotechnology. 2019;17:64. doi:10.1186/s12951-019-0498-7

41. Zhang R, Qian J, Li X, Yuan Y. Treatment of experimental autoimmune uveoretinitis with intravitreal injection of infliximab encapsulated in liposomes. $B r J$ Ophthalmol. 2017;101:17 31-1738. doi:10.1136/bjophthalmol-2016-310044

42. Tan G, Yu S, Pan H, et al. Bioadhesive chitosan-loaded liposomes: a more efficient and higher permeable ocular delivery platform for timolol maleate. Int J Biol Macromol. 2017; 94:355-363. doi:10.1016/j.ijbiomac.2016.10.035

43. Pontillo ARN, Detsi A. Nanoparticles for ocular drug delivery: modified and non-modified chitosan as a promising biocompatible carrier. Nanomedicine. 2019;14:1889-1909. doi:10.2217/nnm2019-0040

44. Wang Y, Rajala A, Rajala RVS. Nanoparticles as Delivery Vehicles for the Treatment of Retinal Degenerative Diseases. Adv Exp Med Biol. 2018;1074:117-123.

45. Wang X, Wang S, Zhang Y. Advance of the application of nano-controlled release system in ophthalmic drug delivery. Drug Deliv. 2016;23:2897-2901. doi:10.3109/10717544.2015.11 16025

46. Xu J, Zheng S, Hu X, et al. Advances in the Research of Bioinks Based on Natural Collagen, Polysaccharide and Their Derivatives for Skin 3D Bioprinting. Polymers. 2020;12(6):1237. doi:10.33 90/polym12061237 
47. Xu J, Zheng S, Hu X, et al. Advances in the research of bioinks based on natural collagen, polysaccharide and their derivatives for skin 3d bioprinting. Polymers. 2020;12.

48. Varshochian R, Riazi-Esfahani M, Jeddi-Tehrani M, et al. Albuminated PLGA nanoparticles containing bevacizumab intended for ocular neovascularization treatment. $J$ Biomed Mater Res A. 2015;103:3148-3156. doi:10.1002/jbm.a.35446

49. Mahaling B, Srinivasarao DA, Raghu G, Kasam RK, Bhanuprakash Reddy G, Katti DS. A non-invasive nanoparticle mediated delivery of triamcinolone acetonide ameliorates diabetic retinopathy in rats. Nanoscale. 2018;10:16485-16498. doi:10.10 39/C8NR00058A

50. Wang B, Tang Y, Oh Y, et al. Controlled release of dexamethasone sodium phosphate with biodegradable nanoparticles for preventing experimental corneal neovascularization. Nanomed. 2019;17:119-123. doi:10.1016/j.nano.2019.01.001

51. Luschmann C, Herrmann W, Strauss O, Luschmann K, Goepferich A. Ocular delivery systems for poorly soluble drugs: an in-vivo evaluation. Int J Pharm. 2013;455:331-337. doi:10. 1016/j.ijpharm.2013.07.002

52. Ali HSM, York P, Ali AMA, Blagden N. Hydrocortisone nanosuspensions for ophthalmic delivery: a comparative study between microfluidic nanoprecipitation and wet milling. J Control Release. 2011;149:175-181. doi:10.1016/j.jconrel.2010.10.007

53. Abrego G, Alvarado HL, Egea MA, Gonzalez-Mira E, Calpena AC, Garcia ML. Design of nanosuspensions and freeze-dried PLGA nanoparticles as a novel approach for ophthalmic delivery of pranoprofen. J Pharm Sci. 2014;103:3153-3164. doi:10.1002/jps.24101

54. García-Millán E, Quintáns-Carballo M, Otero-Espinar FJ. Improved release of triamcinolone acetonide from medicated soft contact lenses loaded with drug nanosuspensions. Int $J$ Pharm. 2017;525:226-236. doi:10.1016/j.ijpharm.2017.03.082

55. Mudgil M, Pawar PK. Preparation and in vitro/ex vivo evaluation of moxifloxacin-loaded plga nanosuspensions for ophthalmic application. Sci Pharm. 2013;81:591-606. doi:10.3797/scipharm.1204-16

56. Kamaleddin MA. Nano-ophthalmology: applications and considerations. Nanomedicine. 2017;13:1459-1472. doi:10.1016/ j.nano.2017.02.007

57. Li X, Zhang Z, Li J, Sun S, Weng Y, Chen H. Diclofenac/ biodegradable polymer micelles for ocular applications. Nanoscale. 2012;4:4667-4673. doi:10.1039/c2nr30924f

58. Grimaudo MA, Pescina S, Padula C, et al. Poloxamer 407/TPGS Mixed micelles as promising carriers for cyclosporine ocular delivery. Mol Pharm. 2018;15:571-584. doi:10.1021/acs. molpharmaceut.7b00939

59. Wu W, He Z, Zhang Z, Yu X, Song Z, Li X. Intravitreal injection of rapamycin-loaded polymeric micelles for inhibition of ocular inflammation in rat model. Int J Pharm. 2016;513:238-246. doi:10.1016/j.ijpharm.2016.09.013

60. Cholkar K, Gilger BC, Mitra AK. Topical, aqueous, clear cyclosporine formulation design for anterior and posterior ocular delivery. Transl Vis Sci Technol. 2015;4:1. doi:10.1167/tvst.4.3.1

61. Stefanek A, Leczycka-Wilk K, Czarnocka-Sniadala S, et al. Fluorosurfactants for medical nanoemulsions, their surface-active and biological properties. Colloids Surf $B$ Biointerfaces. 2021;200:111603. doi:10.1016/j.colsurfb.2021.111603

62. Spaglova M, Cuchorova M, Cierna M, Ponist S, Bauerova K. Microemulsions as solubilizers and penetration enhancers for minoxidil release from gels. Gels. 2021;7.

63. Araújo J, Gonzalez E, Egea MA, Garcia ML, Souto EB. Nanomedicines for ocular NSAIDs: safety on drug delivery. Nanomed. 2009;5:394-401. doi:10.1016/j.nano.2009.02.003
64. Sahoo SK, Dilnawaz F, Krishnakumar S. Nanotechnology in ocular drug delivery. Drug Discov Today. 2008;13:144-151. doi:10.1016/j.drudis.2007.10.021

65. Damiani G, Eggenhöffner R, Pigatto PDM, Bragazzi NL. Nanotechnology meets atopic dermatitis: current solutions, challenges and future prospects. Insights and implications from a systematic review of the literature. Bioact Mater. 2019;4:380-386. doi:10.1016/j.bioactmat.2019.11.003

66. Kalam MA, Alshamsan A, Aljuffali IA, Mishra AK, Sultana Y. Delivery of gatifloxacin using microemulsion as vehicle: formulation, evaluation, transcorneal permeation and aqueous humor drug determination. Drug Deliv. 2016;23:896-907. doi:10.3109/ 10717544.2014.920432

67. Kesavan K, Kant S, Singh PN, Pandit JK. Mucoadhesive chitosan-coated cationic microemulsion of dexamethasone for ocular delivery: in vitro and in vivo evaluation. Curr Eye Res. 2013;38:342-352. doi:10.3109/02713683.2012.745879

68. Vigani B, Rossi S, Sandri G, Bonferoni MC, Caramella CM, Ferrari F. Recent advances in the development of in situ gelling drug delivery systems for non-parenteral administration routes. Pharmaceutics. 2020;12.

69. Al-Kinani AA, Zidan G, Elsaid N, Seyfoddin A, Alani AWG, Alany RG. Ophthalmic gels: past, present and future. Adv Drug Deliv Rev. 2018;126:113-126. doi:10.1016/j.addr.2017.12.017

70. Lin S, Ge C, Wang D, et al. Overcoming the anatomical and physiological barriers in topical eye surface medication using a peptide-decorated polymeric micelle. ACS Appl Mater Interfaces. 2019;11:39603-39612. doi:10.1021/acsami.9b13851

71. Ammar HO, Salama HA, Ghorab M, Mahmoud AA. Development of dorzolamide hydrochloride in situ gel nanoemulsion for ocular delivery. Drug Dev Ind Pharm. 2010;36: 1330-1339. doi:10.3109/03639041003801885

72. Göttel B. Electrospun nanofibers - A promising solid in-situ gelling alternative for ocular drug delivery. Eur J Pharm Biopharm. 2020;146:125-132. doi:10.1016/j.ejpb.20 19.11 .012

73. Li H, Xin HL, Muller DA, Estroff LA. Visualizing the 3D internal structure of calcite single crystals grown in agarose hydrogels. Science. 2009;326:1244-1247. doi:10.1126/science.1178583

74. Gottel B, de Souza ESJM. Electrospun nanofibers - A promising solid in-situ gelling alternative for ocular drug delivery. Eur J Pharm Biopharm. 2020;146:125-132.

75. Ryder EC, Benson S. Conjunctivitis. Treasure Island (FL): StatPearls; 2021.

76. Ryder EC, Benson S. Conjunctivitis. Treasure Island (FL): StatPearls Publishing; 2020.

77. Yasin MN, Hussain S, Malik F, et al. Preparation and characterization of chloramphenicol niosomes and comparison with chloramphenicol eye drops $(0.5 \% \mathrm{w} / \mathrm{v})$ in experimental conjunctivitis in albino rabbits. Pak J Pharm Sci. 2012;25:117-121.

78. Skevaki CL, Galani IE, Pararas MV, Giannopoulou KP, Tsakris A. Treatment of viral conjunctivitis with antiviral drugs. Drugs. 2011;71:331-347. doi:10.2165/11585330-00000 0000-00000

79. Bourcier T, Sauer A, Dory A, Denis J, Sabou M. Fungal keratitis. J Fr Ophtalmol. 2017;40:e307-e13. doi:10.1016/j.jfo.2017.08.001

80. Fan P-S, Sun M-J, Qin D, Yuan C-S, Chen X-G, Liu Y. Nanosystems as curative platforms for allergic disorder management. J Mater Chem B. 2021;9(7):1729-1744. doi:10. 1039/D0TB02590A

81. Chhonker YS, Prasad YD, Chandasana H, et al. Amphotericin-B entrapped lecithin/chitosan nanoparticles for prolonged ocular application. Int J Biol Macromol. 2015;72:1451-1458. doi:10. 1016/j.ijbiomac.2014.10.014 
82. Chen H, Pan H, Li P, et al. The potential use of novel chitosan-coated deformable liposomes in an ocular drug delivery system. Colloids Surf B Biointerfaces. 2016;143:455-462. doi:10.1016/j.colsurfb.2016.03.061

83. Sánchez-López E, Esteruelas G, Ortiz A, et al. Dexibuprofen Biodegradable nanoparticles: one step closer towards a better ocular interaction study. Nanomaterials. 2020;10.

84. Xu Y, Zhang C, Zhu X, et al. Chloramphenicol/sulfobutyl ether- $\beta$ cyclodextrin complexes in an ophthalmic delivery system: prolonged residence time and enhanced bioavailability in the conjunctival sac. Expert Opin Drug Deliv. 2019;16:657-666. doi:10.1080/17425247.2019.1609447

85. Garg V, Suri R, Jain GK, Kohli K. Proglycosomes: a novel nano-vesicle for ocular delivery of tacrolimus. Colloids Surf B Biointerfaces. 2017;157:40-47. doi:10.1016/j.colsurfb.2017.05.049

86. Singh P, Gupta A, Tripathy K. Keratitis. Treasure Island (FL): StatPearls Publishing; 2020.

87. Zorzi GK, Schuh RS, Maschio VJ, Brazil NT, Rott MB, Teixeira HF. Box Behnken design of siRNA-loaded liposomes for the treatment of a murine model of ocular keratitis caused by Acanthamoeba. Colloids Surf B Biointerfaces. 2019;17 3:725-732. doi:10.1016/j.colsurfb.2018.10.044

88. Agarwal P, Craig JP, Rupenthal ID. Formulation Considerations for the management of dry eye disease. Pharmaceutics. 2021;13.

89. Chu LL, Cui K, Pope JE. Meta-Analysis of Treatment for Primary Sjögren's Syndrome. Arthritis Care Res. 2020;72:1011-1021. doi:10.1002/acr.23917

90. Grimaudo MA, Pescina S, Padula C, et al. Topical application of polymeric nanomicelles in ophthalmology: a review on research efforts for the noninvasive delivery of ocular therapeutics. Expert Opin Drug Deliv. 2019;16:397-413. doi:10.1080/17425247.20 19.1597848

91. Kang H, Cha KH, Cho W, et al. Cyclosporine Amicellar delivery system for dry eyes. Int J Nanomedicine. 2016;11:2921-2933.

92. Li Y-J, Luo L-J, Harroun SG, et al. Synergistically dual-functional nano eye-drops for simultaneous anti-inflammatory and anti-oxidative treatment of dry eye disease. Nanoscale. 2019;11:5580-5594. doi:10.1039/C9NR00 376B

93. Nagai N, Ishii M, Seiriki R, et al. Novel sustained-release drug delivery system for dry eye therapy by rebamipide nanoparticles. Pharmaceutics. 2020;12.

94. Tham Y-C, Li X, Wong TY, Quigley HA, Aung T, Cheng C-Y. Global prevalence of glaucoma and projections of glaucoma burden through 2040: a systematic review and meta-analysis Ophthalmology. 2014;121:2081-2090. doi:10.1016/j.ophtha.20 14.05.013

95. Diekmann H, Fischer D. Glaucoma and optic nerve repair. Cell Tissue Res. 2013;353:327-337. doi:10.1007/s00441-013-1596-8

96. Munemasa Y, Kitaoka Y. Molecular mechanisms of retinal ganglion cell degeneration in glaucoma and future prospects for cell body and axonal protection. Front Cell Neurosci. 2012;6:60.

97. Wong TT, Novack GD, Natarajan JV, Ho CL, Htoon HM, Venkatraman SS. Nanomedicine for glaucoma: sustained release latanoprost offers a new therapeutic option with substantial benefits over eyedrops. Drug Deliv Transl Res. 2014;4:303-309. doi:10.1007/s13346-014-0196-9

98. Rodriguez-Aller M, Guinchard S, Guillarme D, et al. New prostaglandin analog formulation for glaucoma treatment containing cyclodextrins for improved stability, solubility and ocular tolerance. Eur J Pharm Biopharm. 2015;95:203-214. doi:10. 1016/j.ejpb.2015.04.032

99. Bravo-Osuna I, Vicario-de-la-torre M, Andrés-Guerrero V, et al. Novel water-soluble mucoadhesive carbosilane dendrimers for ocular administration. Mol Pharm. 2016;13:2966-2976. doi:10. 1021/acs.molpharmaceut.6b00182
100. Davis BM, Crawley L, Pahlitzsch M, Javaid F, Cordeiro MF. Glaucoma: the retina and beyond. Acta Neuropathol. 2016;132:807-826. doi:10.1007/s00401-016-1609-2

101. Cordeiro MF, Migdal C, Bloom P, Fitzke FW, Moss SE. Imaging apoptosis in the eye. Eye. 2011;25:545-553. doi:10.1038/ eye. 2011.64

102. Sánchez-López E, Egea MA, Davis BM, et al. Memantine-loaded pegylated biodegradable nanoparticles for the treatment of glaucoma. Small. 2018;14.

103. Seo Y, Kim S, Lee HS, et al. Femtosecond laser induced nano-textured micropatterning to regulate cell functions on implanted biomaterials. Acta Biomater. 2020;116:138-148. doi:10.1016/j.actbio.2020.08.044

104. Wu K-Y, Lai Y-H, Yang Y-C, Wu W-C, Hong S-J. 5-FluorouracilInduced Apoptosis Changes in Cultured Corneal Epithelial Cells J Ocul Pharmacol Ther. 2016;32:155-162. doi:10.1089/jop.20 15.0109

105. Pandey SK, Cochener B, Apple DJ, et al. Intracapsular ring sustained 5-fluorouracil delivery system for the prevention of posterior capsule opacification in rabbits: a histological study. $J$ Cataract Refract Surg. 2002;28:139-148. doi:10.1016/S08863350(01)01069-0

106. Nibourg LM, Gelens E, Kuijer R, Hooymans JM, van Kooten TG, Koopmans SA. Prevention of posterior capsular opacification. Exp Eye Res. 2015;136:100-115. doi:10.1016/j.exer.2015.03.011

107. Drinkwater JJ, Davis WA, Davis TME. A systematic review of risk factors for cataract in type 2 diabetes. Diabetes Metab Res Rev. 2019;35:e3073. doi:10.1002/dmrr.3073

108. Kato S, Oshika T, Numaga J, Kawashima H, Kitano S, Kaiya T. Influence of rapid glycemic control on lens opacity in patients with diabetes mellitus. Am J Ophthalmol. 2000;130:354-355. doi:10.1016/S0002-9394(00)00546-8

109. Zhang J, Yan H, Lou MF. Does oxidative stress play any role in diabetic cataract formation? -Re-evaluation using a thioltransferase gene knockout mouse model. Exp Eye Res. 2017;161:36-42. doi:10.1016/j.exer.2017.05.014

110. Yang J, Gong X, Fang L, et al. Potential of CeC13@mSiO2 nanoparticles in alleviating diabetic cataract development and progression. Nanomed. 2017;13:1147-1155. doi:10.1016/j.nano. 2016.12.021

111. Zhou Y, Li L, Li S, et al. Autoregenerative redox nanoparticles as an antioxidant and glycation inhibitor for palliation of diabetic cataracts. Nanoscale. 2019;11:13126-13138. doi:10.1039/C9NR02350J

112. Hammer SS, Busik JV. The role of dyslipidemia in diabetic retinopathy. Vision Res. 2017;139:228-236. doi:10.1016/j.visres. 2017.04.010

113. Shi G-J, Li Y, Cao Q-H, et al. In vitro and in vivo evidence that quercetin protects against diabetes and its complications: a systematic review of the literature. Biomed Pharmacother. 2019;109:1085-1099. doi:10.1016/j.biopha.2018.10.130

114. Sun S, Wang Y, Wu A, Ding Z, Liu X. Influence Factors of the pharmacokinetics of herbal resourced compounds in clinical practice. Evid Based Complement Alternat Med. 2019;20 19:1983780. doi:10.1155/2019/1983780

115. Wang S, Du S, Wang W, Zhang F. Therapeutic investigation of quercetin nanomedicine in a zebrafish model of diabetic retinopathy. Biomed Pharmacother. 2020;130:110573. doi:10.10 16/j.biopha.2020.110573

116. Wang Y, Rajala A, Cao B, et al. Cell-specific promoters enable lipid-based nanoparticles to deliver genes to specific cells of the retina in vivo. Theranostics. 2016;6:1514-1527. doi:10.7150/ thno. 15230

117. Skaf AR, Mahmoud T. Surgical treatment of age-related macular degeneration. Semin Ophthalmol. 2011;26:181-191. doi:10.3109/ 08820538.2011 .577133 
118. Li M, Xu Z, Zhang L, et al. Targeted Noninvasive treatment of choroidal neovascularization by hybrid cell-membrane-cloaked biomimetic nanoparticles. ACS Nano. 2021;15:9808-9819. doi:10.1021/acsnano.1c00680

119. Jin J, Zhou KK, Park K, et al. Anti-inflammatory and antiangiogenic effects of nanoparticle-mediated delivery of a natural angiogenic inhibitor. Invest Ophthalmol Vis Sci. 2011;52:6230-6237. doi:10.1167/iovs.10-6229

120. Brown AC, Nwanyanwu K. Retinopathy of Prematurity. Treasure Island (FL): StatPearls Publishing; 2020.

121. Kim JH, Kim MH, Jo DH, Yu YS, Lee TG, Kim JH. The inhibition of retinal neovascularization by gold nanoparticles via suppression of VEGFR-2 activation. Biomaterials. 2011;32:1865-1871.

122. Committee for the National Registry of R. The National Registry of Retinoblastoma in Japan (1983-2014). Jpn J Ophthalmol. 2018;62:409-423. doi:10.1007/s10384-018-0597-2

123. Qu W, Meng B, Yu Y, Wang S. Folic acid-conjugated mesoporous silica nanoparticles for enhanced therapeutic efficacy of topotecan in retina cancers. Int $J$ Nanomedicine. 2018;13:4379-4389. doi:10.2147/IJN.S142668

124. Delrish E, Jabbarvand M, Ghassemi F, et al. Efficacy of topotecan nanoparticles for intravitreal chemotherapy of retinoblastoma. Exp Eye Res. 2021;204:108423. doi:10.1016/j.exer.2020.108423

125. You Y, Gupta VK, Li JC, Klistorner A, Graham SL. Optic neuropathies: characteristic features and mechanisms of retinal ganglion cell loss. Rev Neurosci. 2013;24:301-321.

126. Quigley HA. Neuronal death in glaucoma. Prog Retin Eye Res. 1999;18:39-57. doi:10.1016/S1350-9462(98)00014-7

127. Yao A, van Wijngaarden P. Metabolic pathways in context: mTOR signalling in the retina and optic nerve - A review. Clin Exp Ophthalmol. 2020;48:1072-1084. doi:10.1111/ceo.13819

128. Li N, Wang F, Zhang Q, et al. Rapamycin mediates mTOR signaling in reactive astrocytes and reduces retinal ganglion cell loss. Exp Eye Res. 2018;176:10-19. doi:10.1016/j.exer.2018. 06.014

129. Eriksen AZ, Eliasen R, Oswald J, et al. Multifarious biologic loaded liposomes that stimulate the mammalian target of rapamycin signaling pathway show retina neuroprotection after retina damage. ACS Nano. 2018;12:7497-7508. doi:10.1021/acsnano.8b 00596

130. Burkholder BM, Jabs DA. Uveitis for the non-ophthalmologist. BMJ. 2021;372:m4979. doi:10.1136/bmj.m4979

131. Nirbhavane P, Sharma G, Singh B, et al. Triamcinolone acetonide loaded-cationic nano-lipoidal formulation for uveitis: evidences of improved biopharmaceutical performance and anti-inflammatory activity. Colloids Surf B Biointerfaces. 2020;190:110902. doi:10.1016/j.colsurfb.2020.110902

132. Mehra N, Aqil M, Sultana Y. A grafted copolymer-based nanomicelles for topical ocular delivery of everolimus: formulation, characterization, ex-vivo permeation, in-vitro ocular toxicity, and stability study. Eur J Pharm Sci. 2021;159:105735. doi:10.1016/j. ejps.2021.105735

133. Kim H, Sung J, Chang Y, Alfeche A, Leal C. Microfluidics Synthesis of Gene Silencing Cubosomes. ACS Nano. 2018;12:9196-9205. doi:10.1021/acsnano.8b03770

134. Gaballa SA, El Garhy $\mathrm{OH}$, Moharram H, Abdelkader H. Preparation and evaluation of cubosomes/cubosomal gels for ocular delivery of beclomethasone dipropionate for management of uveitis. Pharm Res. 2020;37:198. doi:10.1007/s11095-02002857-1

135. Ryan EH. Current treatment strategies for symptomatic vitreous opacities. Curr Opin Ophthalmol. 2021;32:198-202. doi:10.1097/ ICU.0000000000000752

136. Sauvage F, Fraire JC, Remaut K, et al. Photoablation of Human vitreous opacities by light-induced vapor nanobubbles. ACS Nano. 2019;13:8401-8416. doi:10.1021/acsnano.9b04050
137. Fogli S, Del Re M, Rofi E, Posarelli C, Figus M, Danesi R. Clinical pharmacology of intravitreal anti-VEGF drugs. Eye. 2018;32:1010-1020. doi:10.1038/s41433-018-0021-7

138. Androudi S, Dastiridou A, Pharmakakis N, et al. Guidelines for the management of wet age-related macular degeneration: recommendations from a panel of Greek experts. Adv Ther. 2016;33:715-726. doi:10.1007/s12325-016-0332-7

139. Ng DSC, Fung NSK, Yip FLT, Lai TYY. Ranibizumab for myopic choroidal neovascularization. Expert Opin Biol Ther. 2020;20:1385-1393. doi:10.1080/14712598.2021.1830969

140. Villegas VM, Schwartz SG. Current and future pharmacologic therapies for diabetic retinopathy. Curr Pharm Des. 2018;24:4903-4910. doi:10.2174/1381612825666190130140717

141. Enriquez AB, Avery RL, Baumal CR. Update on Anti-Vascular Endothelial Growth Factor Safety for Retinopathy of Prematurity. Asia Pac J Ophthalmol. 2020;9:358-368. doi:10.1097/APO.00 00000000000302

142. Andres-Guerrero V, Perucho-Gonzalez L, Garcia-Feijoo J, et al. Current Perspectives on the use of anti-VEGF Drugs as adjuvant therapy in glaucoma. Adv Ther. 2017;34:378-395. doi:10.1007/ s12325-016-0461-z

143. Kovach JL, Schwartz SG, Flynn HW, Scott IU. Anti-VEGF treatment strategies for wet AMD. $J$ Ophthalmol. 2012;2012:786870. doi:10.1155/2012/786870

144. Danyliv A, Glanville J, McCool R, Ferreira A, Skelly A, Jacob RP. The Clinical effectiveness of ranibizumab treat and extend regimen in nAMD: systematic review and network meta-analysis. Adv Ther. 2017;34:611-619. doi:10.1007/s12325017-0484-0

145. Alexandru MR, Alexandra NM. Wet age related macular degeneration management and follow-up. Rom $J$ Ophthalmol. 2016;60:9-13.

146. Bazvand F, Khalili Pour E, Gharehbaghi G, et al. Hypertension and ischemic stroke after aflibercept for retinopathy of prematurity. Int Med Case Rep J. 2020;13:243-247. doi:10. 2147/IMCRJ.S258881

147. Formica ML, Legeay S, Bejaud J, et al. Novel hybrid lipid nanocapsules loaded with a therapeutic monoclonal antibody Bevacizumab - and Triamcinolone acetonide for combined therapy in neovascular ocular pathologies. Mater Sci Eng C Mater Biol Appl. 2021;119:111398. doi:10.1016/j. msec.2020.111398

148. Zarbin MA. Anti-VEGF agents and the risk of arteriothrombotic events. Asia Pac J Ophthalmol. 2018;7:63-67.

149. Sun JG, Jiang Q, Zhang XP, et al. Mesoporous silica nanoparticles as a delivery system for improving antiangiogenic therapy. Int J Nanomedicine. 2019;14:1489-1501. doi:10.2147/IJN.S19 5504

150. Luis de Redin I, Boiero C, Recalde S, et al. In vivo effect of bevacizumab-loaded albumin nanoparticles in the treatment of corneal neovascularization. Exp Eye Res. 2019;185:107697. doi:10.1016/j.exer.2019.107697

151. Mennillo E, Krokje A, Pretti C, Meucci V, Arukwe A. Biotransformation and oxidative stress responses in rat hepatic cell-line (H4IIE) exposed to racemic ketoprofen (RS-KP) and its enantiomer, dexketoprofen $(\mathrm{S}(+)-\mathrm{KP})$. Environ Toxicol Pharmacol. 2018;59:199-207. doi:10.1016/j.etap.2018.03.018

152. Barar J, Aghanejad A, Fathi M, Omidi Y. Advanced drug delivery and targeting technologies for the ocular diseases. Bioimpacts. 2016;6:49-67. doi:10.15171/bi.2016.07

153. Formica ML, Awde Alfonso HG, Palma SD. Biological drug therapy for ocular angiogenesis: anti-VEGF agents and novel strategies based on nanotechnology. Pharmacol Res Perspect. 2021;9:e00723. doi:10.1002/prp2.723

154. Baird PN, Saw S-M, Lanca C, et al. Myopia. Nat Rev Dis Primers. 2020;99. 
155. Pineles SL, Kraker RT, VanderVeen DK, et al. Atropine for the prevention of myopia progression in children: a report by the American Academy of Ophthalmology. Ophthalmology. 2017;124:1857-1866. doi:10.1016/j.ophtha.2017.05.032

156. Walline JJ. Myopia Control: a Review. Eye Contact Lens. 2016;42:3-8. doi:10.1097/ICL.0000000000000207

157. Walline JJ, Lindsley KB, Vedula SS, et al. Interventions to slow progression of myopia in children. Cochrane Database Syst Rev. 2020;CD004916.

158. Huang J, Wen D, Wang Q, et al. Efficacy comparison of 16 interventions for myopia control in children: a network meta-analysis. Ophthalmology. 2016;123:697-708. doi:10.1016/ j.ophtha.2015.11.010

159. Sanchez-Lopez E, Esteruelas G, Ortiz A, et al. Dexibuprofen Biodegradable Nanoparticles: one Step Closer towards a Better Ocular Interaction Study. Nanomaterials. 2020;10.

160. Gai X, Cheng L, Li T, et al. In vitro and in vivo studies on a novel bioadhesive colloidal system: cationic liposomes of ibuprofen. AAPS PharmSciTech. 2018;19:700-709. doi:10.1208/s12249017-0872-4

161. Yu F, Zheng M, Zhang AY, Han Z. A cerium oxide loaded glycol chitosan nano-system for the treatment of dry eye disease. $J$ Control Release. 2019;315:40-54. doi:10.1016/j.jconrel.2019.10.039

162. Huang HY, Wang MC, Chen ZY, et al. Gelatin-epigallocatechin gallate nanoparticles with hyaluronic acid decoration as eye drops can treat rabbit dry-eye syndrome effectively via inflammatory relief. Int J Nanomedicine. 2018;13:7251-7273. doi:10.2147/IJN.S173198

163. Di Tommaso C, Torriglia A, Furrer P, Behar-Cohen F, Gurny R, Moller M. Ocular biocompatibility of novel Cyclosporin A formulations based on methoxy poly(ethylene glycol)-hexylsubstituted poly(lactide) micelle carriers. Int J Pharm. 2011;416:515-524. doi:10.1016/j.ijpharm.2011.01.004

164. Schnichels S, Hurst J, de Vries JW, et al. Self-assembled DNA nanoparticles loaded with travoprost for glaucoma-treatment. Nanomedicine. 2020;29:102260. doi:10.1016/j.nano.2020.102260

165. Orasugh JT, Sarkar G, Saha NR, et al. Effect of cellulose nanocrystals on the performance of drug loaded in situ gelling thermo-responsive ophthalmic formulations. Int J Biol Macromol. 2019;124:235-245. doi:10.1016/j.ijbiomac.2018.11.217

166. Fahmy HM, Saad E, Sabra NM, El-Gohary AA, Mohamed FF, Gaber MH. Treatment merits of Latanoprost/Thymoquinone Encapsulated liposome for glaucomatus rabbits. Int J Pharm. 2018;548:597-608. doi:10.1016/j.ijpharm.2018.07.012

167. Wang F, Bao X, Fang A, et al. Nanoliposome-encapsulated brinzolamide-hydropropyl-beta-cyclodextrin inclusion complex: a potential therapeutic ocular drug-delivery system. Front Pharmacol. 2018;9:91. doi:10.3389/fphar.2018.00091

168. Rathod LV, Kapadia R, Sawant KK. A novel nanoparticles impregnated ocular insert for enhanced bioavailability to posterior segment of eye: in vitro, in vivo and stability studies. Mater Sci Eng C Mater Biol Appl. 2017;71:529-540. doi:10.1016/j. msec.2016.10.017

169. Ikuta Y, Aoyagi S, Tanaka Y, et al. Creation of nano eye-drops and effective drug delivery to the interior of the eye. Sci Rep. 2017;7:44229. doi:10.1038/srep44229

170. Kouchak M, Bahmandar R, Bavarsad N, Farrahi F. Ocular dorzolamide nanoliposomes for prolonged IOP reduction: in-vitro and in-vivo evaluation in rabbits. Iran J Pharm Res. 2016;15:205-212.

171. Yu S, Wang QM, Wang X, et al. Liposome incorporated ion sensitive in situ gels for opthalmic delivery of timolol maleate. Int $J$ Pharm. 2015;480:128-136. doi:10.1016/j.ijpharm.2015.01.032

172. Singh J, Chhabra G, Pathak K. Development of acetazolamide-loaded, pH-triggered polymeric nanoparticulate in situ gel for sustained ocular delivery: in vitro. ex vivo evaluation and pharmacodynamic study. Drug Dev Ind Pharm. 2014;40:1223-1232. doi:10.3109/03639045.2013.814061
173. Tuomela A, Liu P, Puranen J, et al. Brinzolamide nanocrystal formulations for ophthalmic delivery: reduction of elevated intraocular pressure in vivo. Int $J$ Pharm. 2014;467:34-41. doi:10.1016/j.ijpharm.2014.03.048

174. Mishra V, Jain NK. Acetazolamide encapsulated dendritic nano-architectures for effective glaucoma management in rabbits. Int J Pharm. 2014;461:380-390. doi:10.1016/j.ijpharm. 2013.11.043

175. Jung HJ, Abou-Jaoude M, Carbia BE, Plummer C, Chauhan A. Glaucoma therapy by extended release of timolol from nanoparticle loaded silicone-hydrogel contact lenses. J Control Release. 2013;165:82-89. doi:10.1016/j.jconrel.2012.10.010

176. Wu W, Li J, Wu L, et al. Ophthalmic delivery of brinzolamide by liquid crystalline nanoparticles: in vitro and in vivo evaluation. AAPS PharmSciTech. 2013;14:1063-1071. doi:10.1208/s12249013-9997-2

177. Natarajan JV, Ang M, Darwitan A, Chattopadhyay S, Wong TT, Venkatraman SS. Nanomedicine for glaucoma: liposomes provide sustained release of latanoprost in the eye. Int J Nanomedicine. 2012;7:123-131

178. Tang M, Ji X, Xu H, et al. Photostable and biocompatible fluorescent silicon nanoparticles-based theranostic probes for simultaneous imaging and treatment of ocular neovascularization. Anal Chem. 2018;90:8188-8195. doi:10.1021/acs.analchem.8b01580

179. Huu VA, Luo J, Zhu J, et al. Light-responsive nanoparticle depot to control release of a small molecule angiogenesis inhibitor in the posterior segment of the eye. $J$ Control Release. 2015;200:71-77. doi:10.1016/j.jconrel.2015.01.001

180. Luo L, Zhang X, Hirano Y, et al. Targeted intraceptor nanoparticle therapy reduces angiogenesis and fibrosis in primate and murine macular degeneration. ACS Nano. 2013;7:3264-3275. doi:10.1021/nn305958y

181. Iwase T, Fu J, Yoshida T, et al. Sustained delivery of a HIF-1 antagonist for ocular neovascularization. $J$ Control Release. 2013;172:625-633. doi:10.1016/j.jconrel.2013.10.008

182. Kyosseva SV, Chen L, Seal S, McGinnis JF. Nanoceria inhibit expression of genes associated with inflammation and angiogenesis in the retina of Vldlr null mice. Exp Eye Res. 2013;116:63-74. doi:10.1016/j.exer.2013.08.003

183. Yandrapu SK, Upadhyay AK, Petrash JM, Kompella UB. Nanoparticles in porous microparticles prepared by supercritical infusion and pressure quench technology for sustained delivery of bevacizumab. Mol Pharm. 2013;10:4676-4686. doi:10.1021/ mp400487f

184. Jo DH, Kim JH, Yu YS, Lee TG, Kim JH. Antiangiogenic effect of silicate nanoparticle on retinal neovascularization induced by vascular endothelial growth factor. Nanomedicine. 2012;8:78 4-791. doi:10.1016/j.nano.2011.09.003

185. Iezzi R, Guru BR, Glybina IV, Mishra MK, Kennedy A, Kannan RM. Dendrimer-based targeted intravitreal therapy for sustained attenuation of neuroinflammation in retinal degeneration. Biomaterials. 2012;33:979-988. doi:10.1016/j.biomaterials.2011.10.010

186. Liu HA, Liu YL, Ma ZZ, Wang JC, Zhang Q. A lipid nanoparticle system improves siRNA efficacy in RPE cells and a laser-induced murine CNV model. Invest Ophthalmol Vis Sci. 2011;52: 4789-4794. doi:10.1167/iovs.10-5891

187. Zhang $\mathrm{C}$, Wang $\mathrm{YS}$, Wu $\mathrm{H}$, et al. Inhibitory efficacy of hypoxia-inducible factor 1alpha short hairpin RNA plasmid DNA-loaded poly (D, L-lactide-co-glycolide) nanoparticles on choroidal neovascularization in a laser-induced rat model. Gene Ther. 2010;17:338-351. doi:10.1038/gt.2009.158

188. Garg V, Nirmal J, Riadi Y, Kesharwani P, Kohli K, Jain GK. Amelioration of endotoxin-induced uveitis in rabbit by topical administration of tacrolimus proglycosome nano-vesicles. J Pharm Sci. 2021;110:871-875. doi:10.1016/j.xphs.2020.10.060 
189. Coburn PS, Miller FC, LaGrow AL, et al. Disarming Pore-forming toxins with biomimetic nanosponges in intraocular infections. mSphere. 2019;4.

190. Chennamaneni SR, Mamalis C, Archer B, Oakey Z, Ambati BK. Development of a novel bioerodible dexamethasone implant for uveitis and postoperative cataract inflammation. J Control Release. 2013;167:53-59. doi:10.1016/j.jconrel.2013.01.007

191. Elbialy NS, Abdol-Azim BM, Shafaa MW, El Shazly LH, El Shazly AH, Khalil WA. Enhancement of the ocular therapeutic effect of prednisolone acetate by liposomal entrapment. J Biomed Nanotechnol. 2013;9:2105-2116. doi:10.1166/jbn. 2013.1711

192. Liu J, Zhang X, Li G, et al. Anti-angiogenic activity of bevacizumab-bearing dexamethasone-loaded plga nanoparticles for potential intravitreal applications. Int $J$ Nanomedicine. 2019;14:8819-8834. doi:10.2147/IJN.S217038

193. Savin CL, Popa M, Delaite C, Costuleanu M, Costin D, Peptu CA. Chitosan grafted-poly(ethylene glycol) methacrylate nanoparticles as carrier for controlled release of bevacizumab. Mater Sci Eng C Mater Biol Appl. 2019;98:843-860. doi:10.1016/j.msec.2019.01.036

194. Urlu N, Asik MD, Cakmak HB, Tuncer S, Turk M. Transscleral Delivery of Bevacizumab-Loaded Chitosan Nanoparticles. $J$ Biomed Nanotechnol. 2019;15:830-838. doi:10.1166/jbn.20 19.2716

195. Llabot JM, Luis de Redin I, Agüeros M. In vitro characterization of new stabilizing albumin nanoparticles as a potential topical drug delivery system in the treatment of corneal neovascularization (CNV). J Drug Deliv Sci Technol. 2019;52:379-385. doi:10.1016/j.jddst.2019.04.042

196. Zhang XP, Sun JG, Yao J, et al. Effect of nanoencapsulation using poly (lactide-co-glycolide) (PLGA) on anti-angiogenic activity of bevacizumab for ocular angiogenesis therapy. Biomed Pharmacother. 2018;107:1056-1063. doi:10.1016/j.biopha.2018.08.092
197. Yan J, Peng X, Cai Y, Cong W. Development of facile drug delivery platform of ranibizumab fabricated PLGA-PEGylated magnetic nanoparticles for age-related macular degeneration therapy. J Photochem Photobiol B. 2018;183:133-136. doi:10. 1016/j.jphotobiol.2018.04.033

198. Karumanchi DK, Skrypai Y, Thomas A, Gaillard ER. Rational design of liposomes for sustained release drug delivery of bevacizumab to treat ocular angiogenesis. J Drug Deliv Sci Technol. 2018;47:275-282. doi:10.1016/j.jddst.2018.07.003

199. Mu H, Wang Y, Chu Y, et al. Multivesicular liposomes for sustained release of bevacizumab in treating laser-induced choroidal neovascularization. Drug Deliv. 2018;25:1372-1383. doi:10.1080/10717544.2018.1474967

200. Pandit J, Sultana Y, Aqil M. Chitosan-coated PLGA nanoparticles of bevacizumab as novel drug delivery to target retina: optimization, characterization, and in vitro toxicity evaluation. Artif Cells Nanomed Biotechnol. 2017;45:1397-1407. doi:10.1080/2169 1401.2016.1243545

201. Sousa F, Cruz A, Fonte P, Pinto IM, Neves-Petersen MT, Sarmento B. A new paradigm for antiangiogenic therapy through controlled release of bevacizumab from PLGA nanoparticles. Sci Rep. 2017;7:3736. doi:10.1038/s41598-017-03959-4

202. Elsaid N, Jackson TL, Elsaid Z, Alqathama A, Somavarapu S. PLGA microparticles entrapping chitosan-based nanoparticles for the ocular delivery of ranibizumab. Mol Pharm. 2016;13:2923-2940. doi:10.1021/acs.molpharmaceut.6b00335

203. Lu Y, Zhou N, Huang X, et al. Effect of intravitreal injection of bevacizumab-chitosan nanoparticles on retina of diabetic rats. Int J Ophthalmol. 2014;7:1-7.
International Journal of Nanomedicine

\section{Publish your work in this journal}

The International Journal of Nanomedicine is an international, peerreviewed journal focusing on the application of nanotechnology in diagnostics, therapeutics, and drug delivery systems throughout the biomedical field. This journal is indexed on PubMed Central, MedLine, CAS, SciSearch ${ }^{\mathbb{}}$, Current Contents ${ }^{\mathbb{R}} /$ Clinical Medicine, $^{-}$

\section{Dovepress}

Journal Citation Reports/Science Edition, EMBase, Scopus and the Elsevier Bibliographic databases. The manuscript management system is completely online and includes a very quick and fair peer-review system, which is all easy to use. Visit http://www.dovepress.com/ testimonials.php to read real quotes from published authors. 